Claremont Colleges

Scholarship @ Claremont

Spring 2021

\title{
Globalization and Geoblocking: Sustaining Nationally Bound Economic and Political Practices of Media Distribution and Access on the Internet
}

Elaine Venter

Claremont Graduate University

Follow this and additional works at: https://scholarship.claremont.edu/cgu_etd

\section{Recommended Citation}

Venter, Elaine. (2021). Globalization and Geoblocking: Sustaining Nationally Bound Economic and Political Practices of Media Distribution and Access on the Internet. CGU Theses \& Dissertations, 230.

https://scholarship.claremont.edu/cgu_etd/230. doi: 10.5642/cguetd/230

This Open Access Dissertation is brought to you for free and open access by the CGU Student Scholarship at Scholarship @ Claremont. It has been accepted for inclusion in CGU Theses \& Dissertations by an authorized administrator of Scholarship @ Claremont. For more information, please contact scholarship@cuc.claremont.edu. 
Globalization and Geoblocking: Sustaining Nationally Bound Economic and Political Practices of Media Distribution and Access on the Internet

By

Elaine Venter

Claremont Graduate University

2021 
(C) Copyright Elaine Venter, 2021

All rights reserved 


\title{
Approval of the Dissertation Committee
}

This dissertation has been duly read, reviewed, and critiqued by the Committee listed below, which hereby approves the manuscript of Elaine Venter as fulfilling the scope and quality requirements for meriting the degree of Doctor of Philosophy in Cultural Studies with a concentration in Media Studies.

\author{
Dr. Eve Oishi, Chair \\ Claremont Graduate University \\ Associate Professor of Cultural Studies \\ Dr. David Luis-Brown \\ Claremont Graduate University \\ Associate Professor of Cultural Studies and English \\ Dr. Joshua Goode \\ Claremont Graduate University \\ Associate Professor of Cultural Studies and History
}




\begin{abstract}
Globalization and Geoblocking: Sustaining Nationally Bound Economic and Political Practices of Media Distribution and Access on the Internet

By

Elaine Venter

Claremont Graduate University: 2021
\end{abstract}

Where we access the internet dictates what we see or, more importantly, do not see online. Access to online media content and information on the internet is controlled worldwide by a process called geoblocking. The term geoblocking refers to the process whereby a website blocks a user's access to digital media content or other information based on their geographic location. While it is possible that openness can exist on the internet, this dissertation asserts that the internet is not a completely free and open space as it continues to be shaped and bordered by media corporations, governments, and audiences. This dissertation further argues that geoblocking media content is an economic, political, and social reaction against the perceived danger of digital permeability of national borders through the internet. This dissertation examines how traditional, older models of media distribution and exhibition based on national borders, persist when the internet allows for global media access. Because of globalization, media corporations, governments, and the audience are in a connected loop where each are negotiating the real and virtual positive and negative effects of economic, political, cultural, and technological globalization. This dissertation finds that media corporations, governments, and the audience are responsible for using geoblocking to serve their varying motivations for maintaining control over accessibility of content and information. Examining geoblocking from the perspectives of media corporations and governments and the audience gives us further insight into the larger whole of the digital and real infrastructure of the internet - where it is located, 
who has power over it, and who has access or not and why. By analyzing the relationships between media corporations, and motivations this study shows an uneven power distribution exists with media corporations and governments maintaining most of the control with the ability to dictate audience behaviors online to match their expectations and offline model. It is determined that what is at stake when geoblocking borders off the world by censoring content on the internet is: balance or power, access, and freedom. 
Dedication

For my parents and sister. 


\section{Acknowledgements}

Thank you to my dissertation committee for the support and guidance in completing this doctorate. Thank you to my chair, Dr. Eve Oishi, who pushed me to think critically in ways I never thought I was capable of before I started at Claremont Graduate University. I am especially grateful for Eve's immense patience and remarkable ability to help me work through a myriad of different thoughts to better focus my dissertation during revisions. I am so thankful for Dr. David Luis-Brown's probing questions in revision that helped guide me to better answer my own research questions. David has been a positive force since the first day I met him in class in 2012, which has been a great source of motivation toward completing my degree. Special thanks and gratitude to Dr. Joshua Goode who generously agreed to join my committee very late into the process. Josh's expertise added another level of acute scrutiny that pushed me to consider the through-lines and analysis more critically in the dissertation. This has helped elevate me as a scholar and the dissertation.

Special thanks to my department head, Dr. Barry Laga, for support and guidance. To my colleague and dear friend, Dr. Tiffany Kinney-Ison, thank you for taking the time even during school breaks for in-person and virtual writing sessions and mental support! To my friend and fellow Mass Communication colleague, Dr. James Perez, thank you for your constant motivation and positive attitude. To fellow CGU colleagues and alumni and friends, Drs. Hillary Kirkham and Julianna Kirchner, my time at CGU was enriched with you both as comrades-in-arms in coursework and during my time working on my dissertation. Thank you both for your continued cheers and support. Hillary, thank you for letting me text you at all odd hours rambling about this and that as I made my way through. Thank you to Dr. Cate Fugazzola for being a friend not only since our MA days, but a virtual accountability writing buddy during my $\mathrm{PhD}$. To my fellow 
media geek and friend and colleague, Dr. Amber L. Hutchins who offered me opportunities to expand my work and nerded out with me over Doctor Who and more, thank you. Also, thank you to my students, some of whom have gone their entire college career hearing me talk about my dissertation - it is done now!

Thank you to friends Web, Ella, Tara, and Ryann for years of support. To my Duo of Doom, Rachel and Mo, thank you and maybe you'll get me to a soccer game now. To my dear friends Alex, Monica, and Cha, thank you for always opening the group chat to dissertation talk and being the ultimate cheerleaders. Special thank you to my friend, Race, who was an unwavering banner of support and constant reminder to FIFI! To Courtney and Amanda, I cannot thank you both enough for how you have not only been there for me, but my entire family. I know we are all blessed to have you in our lives. Of course, I am ever so thankful to my two best friends, Jen "Pluto" Bleasdale" and Christine Joy Muchado. Your constant love and lifting me up to believe in myself on especially hard days is dearly appreciated.

Finally, how does one put into words the immense gratitude you have for family who support you no matter what. I find it truly difficult because there is nothing that I say that can do justice to the endearing and unwavering support my mother, father, and sister - Drs. Catharina, Henry, and Sonja Venter - gave to me over the last eight and a half years of my $\mathrm{PhD}$. They have given so much of themselves in helping me achieve my own goals. To my family, we have been to the brink more than once but through it all, we have stuck together. Thank you for sticking with me when things became extremely difficult. To my mom and dad, thank you for your patience, letting me take over your home over breaks, making sure I was awake early to write, and talk your ears off about my work. To my sister, thank you for all the memes and pictures of cute things and BTS to motivate me. I love you all and this was as much for you as it was for me. 


\section{Table of Contents}

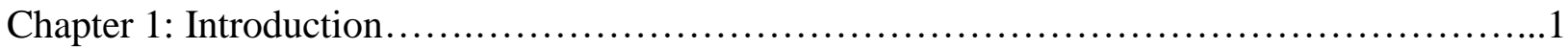

What Is Geoblocking? ..........................................................

Historical Roots of Geoblocking............................................13

Geoblocking and Globalization................................................... 16

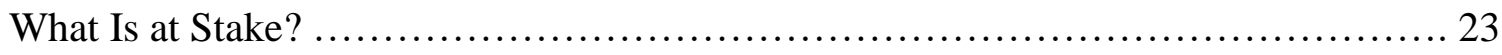

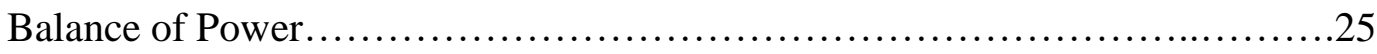

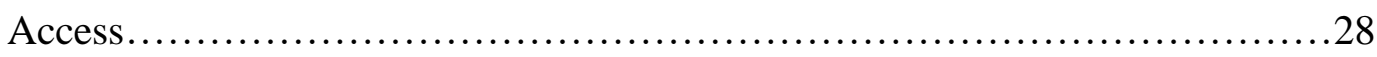

Internet Freedom............................................................... 33

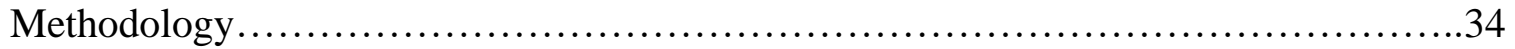

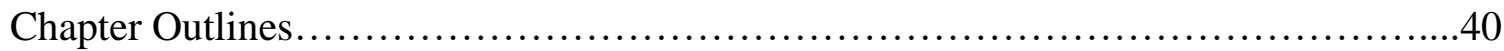

Geoblocking and the Media Corporations..................................41

Geoblocking and Government..........................................42

Geoblocking and the Audience...........................................43

Conclusion................................................................ 45

Chapter 2: Geoblocking and the Media Corporations....................................... 47

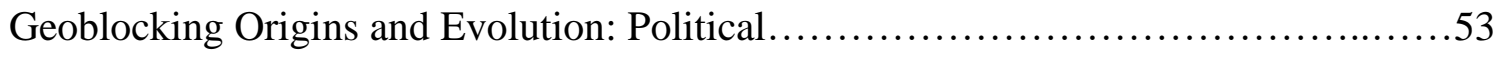

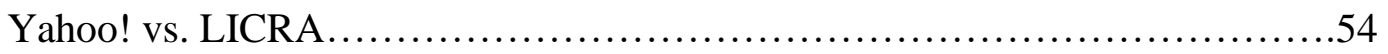

Geoblocking Origins and Evolution: Copyright .................................60

Geoblocking Origins and Evolution: Region Blocking of DVDs....................63

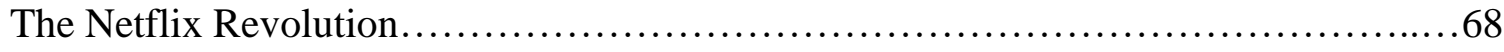

Global Expansion: Netflix vs. Legacy Media .......................................74

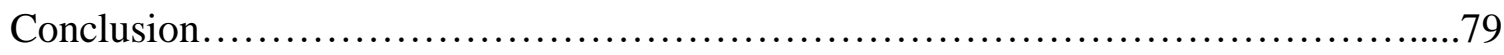

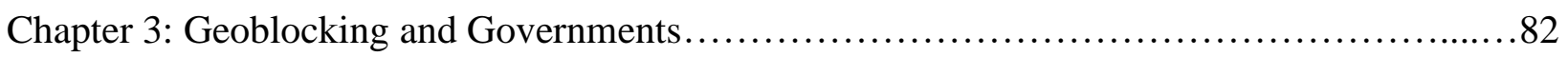

Geoblocking and Media-Cultural Imperialism...................................... 84

The Netflix Imagined-Community and Government.................................89

Sovereignty, Region Codes, and Streaming Media................................93 
Netflix Nation vs. the Republic of China.........................................95

The Great Firewall of China and Blocking Media Content.....................97

Maintaining Cultural and National Identity in a Global, Online

Media Landscape ..................................................... 100

The Price of Doing Business in China.....................................102

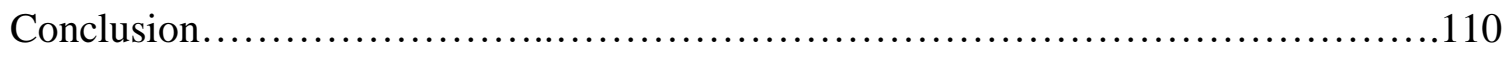

Chapter 4: Geoblocking and the Audience............................................. 114

The Audience, Discrimination, and Geoblocking................................117

Geographic Discrimination: E.U. Audience and Cross-Border Portability.......117

Cultural Discrimination: Language and Cultural Heritage.....................121

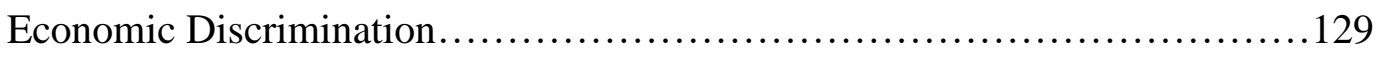

The Audience, Social Media, and Geoblocking....................................135

Social Media and Spoilers...............................................135

The American Audiences........................................................ 140

Conclusion.....................................................................

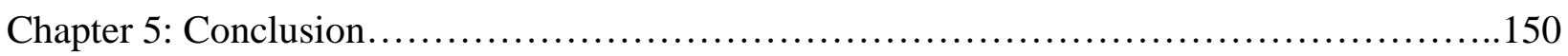

Geoblocking and Media Corporations............................................151

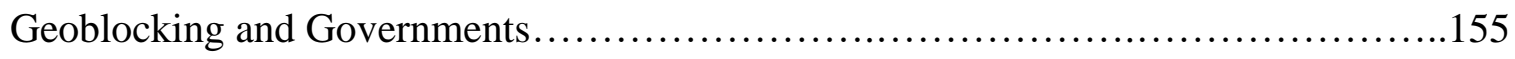

Geoblocking and the Audience....................................................157

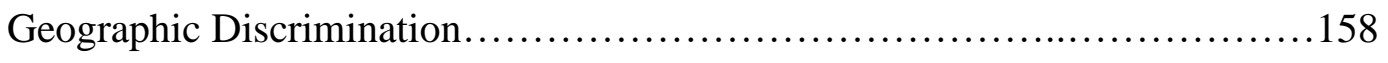

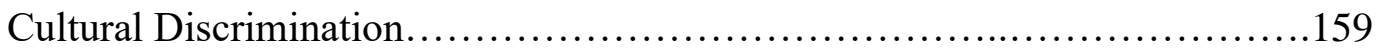

Economic Discrimination................................................. 161

Social Media and Spoilers...............................................162

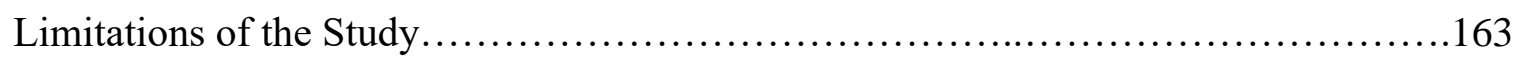

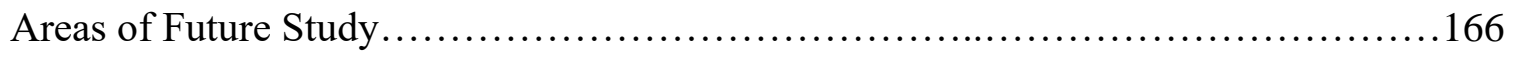

Discussion and Analysis of the Research..........................................167

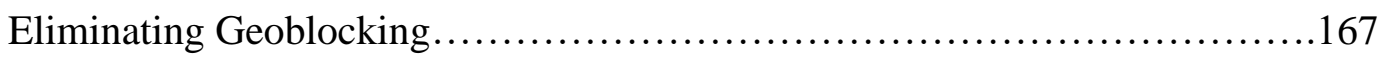




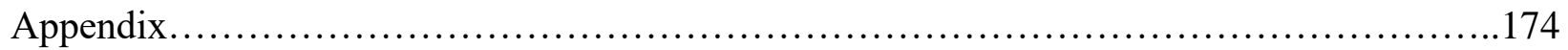

Bibliography.............................................................. 177 


\section{Chapter 1: Introduction}

Where we access the internet dictates what we see or, more importantly, do not see online. This is because the internet is not actually the worldwide, free access entity that the "World Wide Web" depicts. Access to online media content and information on the internet is controlled worldwide by a process called geoblocking. The term geoblocking refers to the process whereby a website blocks a user access to digital media content or other information based on their geographic location. While it is possible that openness can exist on the internet, this dissertation asserts that the internet is not a completely free and open space as it continues to be shaped and bordered by media corporations, governments, and audiences. This dissertation further argues that geoblocking media content is an economic, political, and social reaction against the perceived danger of digital permeability ${ }^{1}$ of national borders through the internet.

Media corporations, governments, and the audience have different motivations for controlling accessibility of content and information on the internet that pre-dates the existence of the internet. As such, these motivations serve to justify each group's application of geoblocking to influence free and open access. Media corporations are essentially motivated by profit, more specifically, profit tied to systems of copyright of Intellectual Property (IP) pre-existing the internet; in addition, media corporations must also abide by laws instituted by governments that dictate the operations of business. Governments in turn are motivated by pre-existing legal systems that corporations and the audience abide by as well as pre-existing ideas of national identity. The audience is generally motivated by the level of convenience of access to relevant media content and information. Geoblocking essentially acts as the digital border control

\footnotetext{
${ }^{1}$ Media corporations and governments have vested interests in maintaining existing national borders, such as protecting profit of their intellectual property and national sovereignty.
} 
mechanism interpolating between all these motivations and the pre-existing economic, political, and social practices around media content distribution and access.

A truly open internet has the power to profoundly influence commerce, politics, and culture. Take television viewing for example, an entity that historically has been tightly controlled to maintain viewership at a premium cost via cable and satellite, but that Amanda D. Lotz (2017) states has evolved drastically over the last 20 years that have had profound implications in the way television is produced, distributed, and accessed. In a 2015 report on home broadband, the Pew Research Center indicated that $15 \%$ of American adults identified as "cord-cutters" - consumers who have canceled paid cable or satellite television services - and attributed the change to the availability of television content on the internet (Netflix, Amazon, Hulu) as a factor (Horrigan \& Duggan, 2015). According to a 2019 report from Nielsen, there is evidence that cord cutting has increased by 48 percent over the past 8 years, totaling 16 million homes. In 2019, there were 39.3 million cord-cutters in the US. Nearly all Americans aged 25-34 access TV content through the internet; $90 \%$ of young people prefer this method. Among the younger segment of viewers, those aged 18-24, the percentage is similar: $87 \%$ opt for internet access. The biggest cable TV provider Comcast has 22.1. million subscribers (Nielsen, 2019). Netflix has 195.15 million users as of November $2020^{2}$ (Watson, 2020b).

Take Netflix as an example of the power of increased access to the internet. In 2007 the company adjusted its operation from a DVD mail-order provider to an online streaming platform at a time when the internet was largely not yet considered commercially viable by larger and older media corporations. In a 2015 CNBC interview by Jim Cramer with Reed Hastings, cofounder and CEO of Netflix, Hastings attributed Netflix's success to the internet, stating "People

\footnotetext{
${ }^{2}$ As of 12/28/2020. U.S. subscribers account for over 73 million total global subscribers (Watson, 2020b).
} 
love the internet, the thing that gives them more options...The internet offers such power"3 (Stevenson, 2015). Netflix is a prime example of how changing practices of media content distribution and access after the internet effects media corporations and audiences. Hastings stated that Netflix is giving the audience the freedom to watch media content outside of a linear scheduled timetable across multiple devices as "People love to have selection and be able to just click and watch, click and watch; it's just a more normal interaction than waiting until six o'clock or 8 o'clock for a particular show"4 (Stevenson, 2015). In the 2015 interview, Hastings gave further insight into the future of TV in the next 10 to 20 years saying:

There's a few people that have cut the cord, but it's very, very small still today, but it's a worry about the long-term, but what's happening now is that sports networks are going on-demand. You'll be able to watch any game, you'll be able to watch it on any device, and, so, think of all the current linear networks, they're going to go on-demand also, just like HBO has... There's this big internet sector story that's transforming our society, not as fast as we thought in the 90s, but, you know, when you look at the big picture now, it's pretty impressive ${ }^{5}$ (Stevenson, 2015).

In 2015, Hastings painted a utopian picture of an open, accessible internet - albeit with a corporate focus - with audiences watching media content anytime and anywhere. Five years later, Hastings's vision is realized in part with legacy media companies such as Disney joining the streaming service bandwagon with Disney Plus, offering an additional subscription to popular cable sports channel ESPN. ${ }^{6}$ Disney Plus managed to gain 54.4 million customers less than 6 months from launching (Bursztynsky, 2020).

So, if the possibility of an open, accessible internet exists, why is digital media content distribution and access determined by one's geographic location? The simple answer: because

\footnotetext{
${ }^{3}$ CNBC Mad Money interview by Jim Cramer. Time stamp 2:49-7:18.

${ }^{4}$ Time stamp 3:36-3:46.

5 Time stamps 5:18-5:38 and 5:56-6:04.

${ }^{6}$ Amazon Prime members can add subscriptions (or channels) to previously cable-only channels such as HBO, Starz, Showtime, Cinemax, and even subscribe to other non-cable TV streaming channels such as CBS ALL ACCESS. Members can also add sports channels, such as MLB.TV, NBA League Pass, and PGA Tour Live.
} 
that is how media consumption was designed prior to the internet- to control access to media to maximize profit. In this regard, this study will show how media corporations and governments work with and against one another in contention over media content with both utilizing geoblocking in the process to reach their goals.

The media corporations serve their own interests with the use of geoblocking to maximize profits through territorial copyright and staggered releases whereby they manipulate pricing across different regions. In the Cramer interview, for example, Cramer asks Hastings why he could not access his Netflix account and watch The Princess Bride with his wife on their honeymoon in Italy (Stevenson, 2015). If he could watch anytime, and on any device, why not in another country as well? Hastings made it clear the reason was because of licensing copyright, which does not come free and is highly competitive: "It's because we have to pay for all the content...We have to win the bidding for the content and that's why we're going country by country"7 (Stevenson, 2015). While Netflix managed to challenge the system of linear scheduled viewing, it still must abide by a very traditional method of obtaining the rights of distribution of media content: a media licensing system designed before the internet that requires bidding for the license to air content in specific geographic regions.

Although it is adapting slowly, generally, a pre-existing system designed for physical, not virtual, national boundaries controls media production, distribution, and exhibition with the intent of maximizing profits for corporations rather than providing free and open access for the general audience. Older media corporations like Disney helped establish this system and procured government support in protecting territorialized copyright even at a global scale (Elkins, 2019). However, governments can also work against media corporations by dictating

\footnotetext{
7 Time stamp 00:31-00:36.
} 
regulations that affect media content access, especially if it concerns national security or protecting national cultural identity. Governments (in conjunction with media corporations) also dictate the policies and laws surrounding media content access for the audience, but the audience through economic and social pressure can exert influence over media content itself and change points of media content distribution and access. When Napster, the peer-to-peer music sharing website, went live in 1999, audiences flocked to the site in the millions from around the globe. Between February and August 2000, the number of Napster users rose from 1.1 million to 6.7 million, making it the fastest-growing software application ever recorded (McCourt \& Burkart, 2000). While audiences expressed an interest in accessing media content online, media corporations in the music industry were slow to adapt due to pre-existing systems of operating that already determined their bottom line before the internet. The Recording Industry Association of America (RIAA), a lobbying and trade group representing the media corporations, pursued legal action against Napster in December 1999, claiming that the free service cut into sales of CDs through media piracy (McCourt \& Burkart, 2003). Previously, buying a physical copy of musical content entitled a consumer to share that content as property. When music became a digital product, media corporations turned to the government to redefine the audiences' consumer rights, so music bought was no longer property but rather leased intellectual property. In February 2001, Napster began filtering its system to block copyrighted material. Napster declared bankruptcy and ceased operations in 2002. Rather than working to adapt to a system audiences are drawn to, media corporations enlisted the government to maintain the status quo (McCourt \& Burkart, 2003). There is a disconnect between evolving audience practices and the static technological systems that enable or limit those practices. 
Geoblocking is used by media corporations and governments alike as a means by which to prevent users from viewing websites or downloading software or media content based on geographical location. Audiences do not use geoblocking but can influence the other two agents to either remove or add geoblocking. But how did media corporations and governments come to use it? Researching the origins of geoblocking reveals that it was not born spontaneously, but it was born of specific, human coding to make physical sense of the virtual; it was allegedly created out of audience demands, but also the necessity to comply with pre-existing infrastructures of business policies and of law; it was created as a bridge between the real and virtual world - not to advance models of practice, but to ensure the smooth continuation of existing models of practice. While the above alludes to some of the motivations that justify media corporate, government, and audience application of geoblocking, the larger issue that geoblocking addresses for each group is managing the effects of globalization. It helps control the flow of changes - whether positive or negative - from the globalization process. Geoblocking was developed as a reaction to the porousness of national borders caused by globalization. It now exists to sustain old economic, political, and social practices around media that are tied to antiquated ideas about national identity and media consumption from before the advent of the internet.

This dissertation explores the friction between two disparate realities that media corporations, governments, and the audience are negotiating: the older media distribution and access model that assumes fixed national borders and a newer globalized model in which both corporations and audiences cross those existing national borders albeit for different reasons. These realities are balanced by the process of geoblocking. As copyright scholar and lawyer Tim Wu (2011) states in The Master Switch: The Rise and Fall of Information Empires, "Nearly 
every program we use is a type of thinking aid - whether the task is to remember things (an address book), to organize prose (a word processor), or to keep track of friends (social networking software)" (p. 172). Geoblocking is a digital tool that serves to transform digital borders into real borders. However, conflict arises when rather than revising the old system to fit the new, the new system is forced to adhere to the parameters of the old. The internet is a virtual space being forced to operate like a real space by existing ways of business, regulations, and laws based on a region's economic, political, and even cultural infrastructure being forced upon it.

According to Ira Wagman and Peter Urquhart (2014), the internet's perceived openness versus the restrictions that close it off "reveals one of the internet's central tensions" (p. 124). This tension is maintained by media corporate entities and governments who have instilled a funnel system on the internet that Cameran Ashraf and Luis Felipe Alvarez León (2016) describe as a system of "blockages and flows" - controlled systems of virtual gateways and checkpoints that either allow or prevent access to content - to maintain pre-existing models of operations. Geoblocking is one form of digital geolocation technology used to block access to or allow the flow of information on the internet.

Online streaming audiences are prohibited access to a great deal of digital media content because of where in the world they are accessing content from and what is made available to them. As Wagman and Urquhart (2014) put it, “where you access the internet says a lot about what kind of internet you experience" (p. 126). In a 2016 Netflix press release titled "Netflix Is Now Available Around the World," Netflix CEO Hastings was quoted as saying "[t]oday you are witnessing the birth of a new global internet TV network" as he announced Netflix's operation in over 190 countries (par. 2, line 1). Hastings further adds, 
With this launch, consumers around the world - from Singapore to St. Petersburg, from San Francisco to Sao Paulo - will be able to enjoy TV shows and movies simultaneously - no more waiting. With the help of the internet, we are putting power in consumers' hands to watch whenever, wherever and on whatever device (Netflix, 2016, par. 2 lines 1-5).

Hastings's intended not only to upend the old model of media by allowing audiences to watch content anytime online, but also, by giving access to a global content library. However, even Hastings's vision of a global content library accessible to everyone is limited by old systems of media copyright and political agendas. While Netflix audiences in both Singapore and St. Petersburg can now access the Netflix Original show, House of Cards (2013-2018), their content libraries will still exhibit differences based on older media copyright, licensing, and geopolitics.

For many growing up with online discussion boards, chatrooms, and current social media platforms, a naïve assumption of the internet took hold as a large, open virtual space, connecting people from all over the world; a vision of the internet as "placeless and instantaneous" (Wagman \& Urquhart, 2014, p. 124). In the words of Lawrence Lessig (2004): “...the internet unleashed an extraordinary possibility for many to participate in the process of building and cultivating a culture that reaches far beyond local boundaries" (p. 9). The reality is an internet with complex virtual borders. While we can access media content from around the world, it is only insomuch as certain laws and regulations permit that access. There is a complex web of motivations by media corporations, governments, and the audience that determines why some content is or is not available online. To maximize profit and revenue, corporations do not make all content, services and products available to all people let alone at the same time, so they would not do so online if it does not benefit their revenue stream.

Examining geoblocking of digital media content allows for a critical understanding of the tensions between old systems of practice in physical space based on economic, political, and 
cultural maps versus new practices afforded by the digital space. While this dissertation focuses primarily on an analysis of these tensions between the old and the new, it aims to reveal uneven relationships between the different contrasting systems of corporations, governments, and audiences. It examines where the practices and interests of these groups converge, but, at times, where they also diverge and conflict with one another. It will answer the pertinent questions including who gets to block content and why and how? Who knows about geoblocking and why or why not? As noted already, media corporations and governments directly implement geoblocking to protect profit and to maintain law and order, however, the audience is not without power in the process. The audience can influence both increased access to content or the blocking of content that they feel may harm societal or cultural norms. However, this is predicated on the audience being aware that content is geoblocked. Media spreads unevenly with some regional audiences serving as primary targets for media content (receiving more), such as American audiences (Elkins, 2019). Geoblocking becomes more of a political and cultural concern for audiences in regions who have historically been importers of American media content, such as European and Australian regions, to name just two (Lobato, 2019). This fact provides a richer layer of insight into conceptions and understanding of not only what power exists in the digital era, but the practice of power as well. Who controls media production and distribution and who controls the internet, and how does who controls the internet determine access to content and access to what kind of content? Power dynamics are determined by answering questions like these. This is the scaffolding to understand the bigger picture. Geoblocking is one piece to a larger puzzle that, when examined, opens further insights and meaning to media globalization - it is about understanding how corporations, governments, and 
audiences balance changes that seem to occur at faster speeds and in more places than ever before.

This dissertation is not about understanding how the internet works. Insightful examination of geoblocking does not help us understand the logic of the internet. Evgeny Morozov (2011) believes that the logic of the internet can never be understood, but what we can understand is the logic around how the internet is worked on and by whom. The most important question answered in this dissertation is why and how have traditional, older models of media distribution and exhibition based on national borders, maintained overall control in an era where the internet allows the opportunity and even expectation of global media access? Essentially, media corporations, governments, and the audience have motivations that pre-date the internet; they all have ways of doing things that have become infrastructural norms that require time to adapt to structured changes, such as those brought on by the processes of globalization, including the internet. As such, geoblocking becomes a necessary tool for corporations and government entities not to stop change but control the time and pace in which change happens in order not to lose power and revenue.

\section{What Is Geoblocking?}

Geoblocking essentially blocks access to digital content based on geographic location, but this would be a somewhat simplistic definition. Defined in more detail, geoblocking is a digital part of geolocation technology, which is a larger umbrella of computing processes consisting of many kinds of technologies that rely on or use geographic location in some way shape or form. For example, when using an application (app) like Google Maps on a smartphone, 
a user may be prompted to give access to his or her location so that the application route guidance system can work through the phone GPS (global positioning system). ${ }^{8}$

Many websites use geo-ID technology, which asks users to identify the region they are accessing the website from by entering an area code for a specific country to gain access to the page (Lessig, 2006; Goldsmith \& Wu, 2008). This is a crude form of geoblocking - an active user-based sign-in block - but it is not really geoblocking if these sites allow you to input another area code from another country to gain access to the localized web page of that site version. The purpose of actively providing your area code is to access a localized site that has relevant information for where you are in relation to the page, but the purpose is not to actively restrict access to another version per se. The user is actively aware and involved in the process of identifying a geographic region rather than the technology itself. However, if a website does not allow you the ability to change the location to view another version of the site because of your location, then that is geoblocking.

Geoblocking is a more sophisticated digital geolocation technology that works actively to create a barrier of entry to a website or specific content on a website, based on an Internet Protocol (IP) number of a specific device. In the case of an actual geoblocked site or content, the user has no immediate control on identifying an area code without having to use active traversing methods. When accessing a website, the IP address is provided to the site, which then makes the decision to block access or not. Every digital device ${ }^{9}$ is given an IP number, which can either be

\footnotetext{
${ }^{8}$ For many smartphones, at startup, location identification may be automatically turned on as soon as it finds a connection as every smartphone is now built with GPS tracking technology that can track the movement of the phone. Even individual apps will use location data and track movement every few minutes, such as the popular restaurant and general business app Yelp, which even sells "location data" and "location intelligence" as part of its metrics services provided to businesses (Yelp, 2018).

${ }^{9}$ Digital devices can be anything from desktop computers, laptops, smartphones, video game consoles, DVD players, printers, and even today's "smart" TVs. Essentially, anything with the ability to connect to another device and/or network will have an IP address allocated.
} 
an IPv4 version (a 32-bit number: $108.253 .128 .9^{10}$ ) or an IPv6 version (a 128-bit number:

2001:0db8:582:ae33::29 ${ }^{11}$ ). Global IP addresses are allocated and managed by the Internet Assigned Numbers Authority (IANA), which is a U.S.-based non-profit arm of the Internet Corporation of Assigned Names and Numbers (ICANN), ${ }^{12}$ which is the voluntary global group tasked with allocating and managing domain names, IP addresses, and other naming and numbers of the internet to ensure stable and secure operations of networks (IANA, 2018a; ICANN, 2018). While IANA is the global manager, IP addresses are allocated through a hierarchy of numbers systems. An IP address is allocated to a computer by an Internet Service Provider (ISP), of which there are several. ISPs, however, obtain these IP number allocations through either a Local Internet Registry (LIR), National Internet Registry (NIR), or a Regional Internet Registry (RIR) (IANA, 2018b). According to IANA, the globe is split into five major RIRs: 1) AFRINIC (Africa Region); 2) APNIC (Asia/Pacific Region); 3) ARIN (Canada, USA, and some Caribbean Islands); 4) LACNIC (Latin America and some Caribbean Islands); and 5) RIPE NCC (Europe, the Middle East, and Central Asia). Each region is a database of IP addresses and are saved as lists, and this data is what helps build the block- versus access-lists. A website will screen the IP address of the device requesting access and confirm the location of the user through a database. If the IP address is associated with a location on the approved list, then access to any media content on the site is granted.

\footnotetext{
${ }^{10}$ This is the current public IP address of my laptop as I sit in a Coffee Bean coffee shop in Venutra, CA, USA. You can do a simple Google search to check your device IP, but programmers will know how to access that IP by simply checking device settings.

${ }^{11}$ My current IPv6 number cannot be identified - not all devices may have one as IPv6 is the newer identification method. This number is the example number provided by the Assigned Numbers Authority (IANA).

${ }^{12}$ ICANN is a multi-stake holder non-profit consisting of people from the public and private sectors. It is a cooperative that is responsible for the Domain Name System (DNS) of the internet. To put it simply, they manage and operate the internet's address book to help ensure users can find one another on the internet and that the internet has a uniform system of address communication to help consistent performance and access of networks.
} 
While a user can access the BBC.co.uk website when trying to access certain video content through the BBC iPlayer, the site reads that user's computer's numerical IP address upon requesting access, which then reveals that the user was viewing from a location outside of the U.K., and, as such, gets barred from viewing that video content. ${ }^{13}$ Geoblocking is not just the blocking of an entire page or a single device only. While an IP address is allocated to a device, that IP address can change depending on where the user is located. If a user were in the U.K., using the same laptop as in the U.S., the IP address would change to note that the device is now in the U.K. As such, were a user attempting to access for instance his or her Netflix accounts while in the U.K., it would be geoblocked since the streaming giant is split into several markets similar to the RIR splits of the globe. ${ }^{14}$ Since the user would be accessing the internet through a U.K.-based ISP, it would be allocated a U.K. IP address, which would come from and be recorded into the RIPE NCC registry database. Geoblocking is a remarkably sophisticated digital code that can fence off either an entire page or specific content on a page to a singular device no matter where it is in the world.

\section{Historical Roots of Geoblocking}

If geoblocking is so profoundly and intricately part of the internet and accessing content, where did it originate? Understanding the actual origin of geoblocking is a complex issue. There does not seem to be much concern with a historical analysis of the origins from any fields of study including a computer programming perspective of its technical functioning, a political analysis of the implications on managing and translating existing law to a digital space, or the

\footnotetext{
${ }^{13}$ The specific why my IP address is blocked is explained further in chapter two.

${ }^{14}$ However, this has been adapted and now, rather than geoblocking Netflix in another region, an account's content library will now adjust to the region it is now accessing from. For more on this, see Chapter 2.
} 
ethical ramifications of blocking content and connections to online piracy (i.e., how to traverse geoblocking). In fact, when searching "geoblocking" in Google, the first page results are all about what geoblocking is as a technical process (a process blocking media content based on geographic region), how to bypass it, and what it means for online shoppers. ${ }^{15}$ Geoblocking seems almost a specter, a ghost in the machine, appearing organically, as if born spontaneously from a set of $1 \mathrm{~s}$ and $0 \mathrm{~s}$; not there one day, then there the next. However, as emphasized earlier, geoblocking was not a spontaneous technological development. It was designed by human ingenuity to serve, primarily and at first, a commercial purpose.

According to Lawrence Lessig (2006), one of the earliest documented cases of online geoblocking ${ }^{16}$ is in January 1995 concerning the regulation of pornography in Germany. The government of Bavaria told the ISP CompuServe to remove pornography from the servers that its citizens could access. Pornography was already heavily regulated offline in Bavaria. The government threatened the executives of CompuServe with punishment if they did not abide with the censorship. At first CompuServe said it would be impossible unless they removed all pornography everywhere. Then, they "devised a technology to filter content on a country-bycountry basis" (Lessig, 2006, p. 39). To do this, however, they had to know who a user was specifically, what they were accessing, and where from. The means of programming was not quite there yet for the more sophisticated form of geoblocking done today but the inception stemmed from this history.

\footnotetext{
${ }^{15}$ At the time of writing this dissertation and this search on January 2, 2019, the European Union (E.U.) has been in major talks regarding geoblocking, especially in regard to online shopping and content access, and the results seem to showcase the growing impact of their talks as two results of the first ten websites on page one results were in connection with geoblocking and the E.U. How to bypass geoblocking is by far the more popular of the search results. This could also involve the algorithm registering my searches on the topic in connection to my area - the concept seemingly being to give the most relevant information first, which is translated sometimes as information that appears most geographically relevant to the user in relation to where they are when they access the internet.

${ }^{16}$ The word itself is not used. Rather, geofiltering software appears often in delving into historical roots.
} 
It was not until 2000 when the League Against Racism and Anti-Semitism (Ligue Internationale Contre le Racisme et l'Antisémitisme, LICRA) sued internet company giant Yahoo! (hereafter "Yahoo") in a French court for violating French law for permitting the sale of Nazi memorabilia on their then-existing auction sites to be accessible for purchase by French citizens, that Cyril Houri came forward to claim he developed advanced geolocation filtering software that could be used specifically as a blocking tool (Goldsmith \& Wu, 2008). While Yahoo claimed on several grounds that they could not block access to content, Houri served as an expert witness showcasing his geofiltering software, which is the process of IP registry database cross-checking, ${ }^{17}$ to prove that Yahoo could in fact block access to their site to users based on geographic location.

The Yahoo case presented an answer to a question both corporations and, especially in this case, governments had: how can something be regulated that does not physically exist? The answer: by making it resemble the physical. A giant leap in doing so was utilizing geoblocking to transpose the lines of plotted maps, the physical border control centers, onto cyberspace. Geoblocking is a veritable parceling of the internet into a map of nations that both corporations and governments can regulate and control. However, even as both parties utilize geoblocking to adhere to economic and political laws and policies, the two do not always have aligned goals. In addition to these two parties, the audience has their own expectations of the internet as well, in their case more focused on increased access than limiting content. The struggle for control is complicated with different ideas of what the internet should be and for whom, with some internet utopianists siding with the philosophy of John Perry Barlow (1996) who wrote in his Declaration of the Independence of Cyberspace:

17 "Method and systems for locating geographical locations of online users" Filed April 13, 2000 https://patents.justia.com/patent/6665715 Retrieved January 2, 2019. 
Cyberspace consists of transactions, relationships, and thought itself, arrayed like a standing wave in the web of our communications. Ours is a world that is both everywhere and nowhere, but it is not where bodies live. We are creating a world that all may enter without privilege or prejudice accorded by race, economic power, military force, or station of birth. We are creating a world where anyone, anywhere may express his or her beliefs, no matter how singular, without fear of being coerced into silence or conformity. Your legal concepts of property, expression, identity, movement, and context do not apply to us. They are all based on matter, and there is no matter here. (par. 6-9)

Essentially, this raises the question of what we think the internet should be, and for what purposes. More than just a tool to create customized markets, for Ramon Lobato (2016), "geoblocking is a 'soft' form of cultural regulation. Its widespread adoption is changing the nature of the open internet by locating users within national cyberspaces and customizing content based on certain ideas about territorial markets" (p. 10). He asks who dictates what cultural stories are worth dissemination, but, especially, which ones are not, and why? For Lobato, geoblocking changes the very expected nature of the open internet, with territorial boundaries creating virtual national borders - feeding into the perception of the territorial identity - to correlate to geographical borders, and it does all this seemingly without military force. The historical advent of geoblocking with the imposition of these virtual national borders can be traced to another element, a process called globalization.

\section{Geoblocking and Globalization}

While corporations can recruit the government to protect their intellectual property (IP), at the same time, governments have their own interest, beyond economics, to use geoblocking. Lessig (2004) states that before the founding of the U.S., people were "geographically based - a nation was a society located in a physical space, with a single sovereign allegiance" (p. 285), which eventually also became the pattern in the U.S. when the area became the United States with individual States and allegiance to an ultimate sovereignty, the Federal government. 
Citizens (who Lessig call the ultimate sovereigns) could vest their sovereignty to these two government entities, State or Federal. Certain rights became attached to citizenry, which means that entitlement to citizenship and the associated rights became attached to geography, "but as mobility has increased, the at-one-time obvious link between geography and citizenship has become less and less obvious" (p. 286). The last thing governments need is confusion or questioning of their authority to regulate the people offline, but especially online. Geoblocking is a control mechanism to help governments maintain a semblance of their established identity and authority - from physical space to the virtual.

Geoblocking is essentially geotechnology used to stem the flows of globalization. In his book Globalization and Media: Global Village of Babel (2015), global media scholar, Jack Lule states that while the word globalization has been used since perhaps the $1970 \mathrm{~s}^{18}$ and entered languages across the globe, "people are still unsure what it means, when it began [exactly], or if it even exists" (p. 21). Lule (2015) believes it is real and has very real, objective, and tangible effects on our lives. However, what is globalization? Is it a process or an outcome? Some believe globalization is an outcome - a result, something completed, and universal. Others believe globalization is a process or even processes - a progression that can be altered, perhaps even reversed. Lule (2015) believes that globalization is not just a process, but a host of processes that include economic, political, and cultural developments. Furthermore, Lule (2015) indicates that globalization processes are not inevitable or linearly continuous - they can start and stop and

\footnotetext{
${ }^{18}$ Lule refers to its seemingly wider acceptance from the 1970s, although he does point out in his research that the etymology of the word could date bake even further to 1940s when Merriam-Webster's dictionary dates the word globalize to 1944. Globalization as a word became popularized in the 1980s with Theodore Levitte using the term in his 1983 Harvard Business Review article, "The Globalization of Markets." However, Lule notes an even earlier use by Mexican educator, Emilia Elias de Ballesteros, in her article La Globalizacion de la Ensenanza (The Globalization of Education) dated 1965.
} 
take different directions, even reverse order. Also, these processes are not necessarily progress and do not necessarily have an end.

If globalization does not have an end, what about its beginning? Lule (2015) states some scholars believe globalization is a modern phenomenon and started around the late 1900s with the advancements in media and transportation technologies connecting the world, however, others believe globalization began with the rise of modernity during the age of Enlightenment in the $17^{\text {th }}$ century or at the time of expansive European exploration as early as the $16^{\text {th }}$ century. Then there are those, like Lule and me, who believe globalization is as old the beginning of humanity. Sociologist and globalization expert, Saskia Sassen (2006), argues that globalization is not a modern concept, and the technological and sociological changes are inherent to a long process of evolution.

Globalization is a process of economic, political, social, and technological transference that connects the entire globe forming an interconnective network. Sassen (2006) notes that while globalization is predominantly used in an economic sense referring to the worldwide integration of trade and other technological systems, there is a specific personal characteristic emerging on a transnational scale through the global exchange of ideas, language, and culture. Lule (2015) states that there would be no globalization without media; globalization and media have "shaped and been shaped by world economics, politics, and culture." (p. 4). Media, says Lule (2015), plays a central role in globalization:

Could global trade have evolved without a flow of information on markets, prices, commodities, and more? Could empires have stretched across the world without communication throughout them? Could religion, music, poetry, film, fiction, cuisine, and fashion have developed as they have without the intermingling of media and culture? Globalization and media have proceeded together through time. (2015, p. 10) 
Within Arjun Appadurai's (1990) theory of "scapes" of global flow, he identifies the mediascape as its own category of global flow, which connects media and globalization and which, while independent, is still interrelated to the four other scapes of global flow ${ }^{19}$. Appadurai (1990) is not concerned with identifying some "single moment - call it the modern moment - that by its appearance creates a dramatic and unprecedented break between past and present" when it comes to globalization (p. 2-3). Appadurai (1990) is arguing for rupture moments happening across different times and spaces focusing on media and migration as two major and interconnected diacritics. Lule's (2015) globalization argument, however, centralizes the role of media in globalization as a globalizing force - media is not just part of the globalization process as its own scape, it makes globalization possible.

Lule (2015) argues that media is one of the most powerful forces. If one agrees with Lule's argument that media makes globalization possible, then it makes even more sense that economic and political spheres of power have a vested interest in controlling the flow of media the flow and access of media, the flow and change from globalization. At the introduction of this dissertation, I stated that geoblocking exists as a reaction to the porous national boundaries caused by globalization. Geoblocking is being used as a tool to control one of the most powerful forces: media. (Lule, 2015) However, unlike Lule (2015), who focuses predominantly on globalization due to media, my dissertation gives insights into globalization through the lens of geoblocking digital media content to gain deeper insight into the economic, political, and social tensions in pre-existing infrastructures based on physical national boundaries and evolving virtual national boundaries. It is not that flows of people, ideas, money, and technology are not

\footnotetext{
${ }^{19}$ Ethnoscapes: the flow of people like tourists, immigrants, refugees, exiles, guest workers, etc. Technoscapes: the flow of technology. Financescapes: the flow of capital and connections between currency markets, nation stock exchanges, and commodity speculations. Ideascapes: flow of ideologies.
} 
sought after, but the amount of change brought by these flows, especially in the age since the internet, is what causes concern for media corporations and governments.

There are many works about globalization, much of which seems split either between the rhetoric of "global village" utopia or dystopian transnational corporation invasion of cultural heritage and values. Early media and globalization scholar, Marshall McLuhan (1962), coined "global village" to explain how media played a role in connecting people across the world (p. 80). The global village concept is a positive conceptualization of globalization where people from all over the globe come together in harmonious community. In Understanding Media: The Extension of Man (2003), McLuhan states that the technology afforded by computers ${ }^{20}$ would connect people to a "universal understanding and unity." (p. 80). In contrast, technology historian and scholar, Lewis Mumford, who originally inspired McLuhan's work on the global village, became more disillusioned over the global connective power of the media as he observed corporations and governments use it for their own benefits (Lule, 2015). Mumford (1974) became more critical of the global village utopia and conceptualized the "megamachine" or what he coined as "the pentagon of power" - consisting of centralized power components of power (as in energy, specifically, atomic energy), political power, productivity, profit (of which productivity is connected directly to), and publicity (or propaganda). Mumford (1974) described how the entire complex of power masquerades under progress for society, humanity, when, in fact, it is only working towards more accumulation of power for itself. Where technological advancements were praised as new ways to connect and come together, Mumford saw that "moral disruptions, antagonisms, and collective massacres have become more flagrant, not in local conflicts alone but on a global scale" (quoted in Lule, 2015, p. 78). Even McLuhan later

\footnotetext{
${ }^{20}$ Including in the ability to translate languages and the universal computer language in coding.
} 
came to admit to the shortcomings of the global village utopia, although, both scholars would agree that on some level there had been some progress and there was always space for actual positive change for humanity (Lule, 2015). Neither conceptualization of globalization is wrong. They are both correct. However, while I do still believe in the possibility of McLuhan's earlier global village utopia, this dissertation grapples with the realities where Lule (2015) describes globalization and media working in partnership to create a "divided village, a village of gated communities and border walls.” (p. 10)

Historically, nation states developed as borders became geographical boundaries that actively separated peoples based on certain shared cultural values and norms (Sassen, 2006; Anderson, 2006). It is generally easy to establish a state of the same held beliefs and ideas in a small community where, typically, the same people reside, communicate, and connect with one another, but what happens when someone new comes along? Or when someone in that community travels to another, and brings back with them the ideas, values, and beliefs from another community? Change occurs. There is a big difference between the rate of change that occurred over a thousand years ago compared to today, however. A thousand years ago the world did not have email, social media, or a digitally intertwined global system of economics. Today, the global exchange of ideas, language, and culture is at such a pace that corporations, governments, and even audiences have a difficult time not only keeping up with it but making sense of it as well.

Lessig (2006) states that at one time the U.S. was "these United States...As the nation became socially and economically more integrated, the plausibility of saying 'I am a Virginian first' declined, and the significance of being a citizen of the nation as a whole increased" ( $p$. 292). I see a reversal on this with the mobility of people not only in real space, but, especially, 
because of cyberspace. It has made our world seem both significantly bigger and smaller, challenging standardizations of borders, nation, even a state or region. "Ordinary citizens are connected internationally and can make international transactions as never before" (Lessig, 2006, p. 292). Lessig (2006) states that as things progress, users online will find it difficult to remain neutral on matters, even those that do not seem of local importance.

Take the case of the Arab Spring, for example. By late 2010, the way people, corporations, but especially governments perceived social media at a global scale had shifted, as the Arab Spring became a global social media event sharing the protests, civil wars, and even the toppling of several regimes in countries of Northern Africa and the Middle East thanks to uprisings among people using Facebook and blogs to organize in those territories (Castells, 2015). While posts were coming in from one region, they were quickly being spread to other geographic regions and within a matter of days, citizens of other nations were not only aware of what was happening in another part of the world, but even getting involved and putting pressure on their own governments to provide aid to protestors (Castells, 2015). "Cyberspace is an international community; there are constitutional questions for it to answer; and we cannot simply stand back from this international space and say that these questions are local issues" (Lessig, 2006, p. 292). At least, not since the internet in the 1990s (Net '95), which Lessig (2006) describes consisting of an infrastructure that:

facilitated extraordinary free speech and extraordinary privacy; that enabled secure communications through a protocol that permitted encryption and that encouraged free communications through a protocol that resisted censorship. That was the speech architecture that the Net gave the world - that we gave the world (p. 292).

Geoblocking is helping to erase Lessig's described Net '95 infrastructure, and, in its place, institute an infrastructure that helps corporations and governments wrest back more control. 
Nations have long had to balance the need for change with what kind of change to exist and stay relevant - regimes rise and fall; it is all about maintaining that balance between rise and fall. This means constantly making the concept of the nation, government, and especially, citizenship relevant to the people.

Corporations and governments are both vying for control of the internet, however, not motivated similarly. Corporations want safety and control of their "exclusive rights" - their intellectual property - and profits. Governments want stability of existing law and order, essentially to maintain their national and cultural sovereignty. Sometimes, their motivations overlap in their executions of control, thereby, requiring cooperation; however, at other times, their motivations may pit them against one another. Other times they deeply rely on one another with corporations relying on governments to help normalize the bordering of cyberspace (create laws that can enforce cyber borders). While corporations are driven primarily by profit, the economic territories they create "are constantly in dialogue, interacting, and sometimes in tension with those of the state" (Ashraf \& Leon, 2016, p. 47). Sometimes, even corporations are pitted against each other as their motivations are in direct competition with one another, leading to an internal jockeying of control in the private sector. Regardless of motivation, regardless of corporations versus governments or one another, they all use many tools not only for control, but for the management of change and in cyber-economy particularly, they utilize geoblocking.

\section{What Is at Stake?}

Examining geoblocking from the perspectives of media corporations and governments and the audience gives us further insight into the larger whole of the digital and real infrastructure of the internet - where it is located, who has power over it, and who has access or 
not and why. While a cooperative network exists between the three groups in shaping the internet, that cooperation is only amicable in so much as their motivations align. As soon as their motivations deviate from one or both other groups in the cooperative, the others exact their own countermeasures of control to ensure their own goals are not negatively affected. Examining geoblocking gives us insight into the effects of globalization and the economic, political, and cultural make-up of digital infrastructure. Because of globalization media corporations, governments, and the audience are in a connected loop where each are negotiating the real and virtual positive and negative effects of economic, political, cultural, and technological globalization. Examining the infrastructures of geoblocking reveals the effects of the internet on the topographical infrastructure of "real" local and global territories - the response from economic, political, and cultural sectors in either adapting their pre-existing offline systems to virtual or vice versa. It allows us to analyze how previously existing non-digital infrastructures have either subsumed the digital space or have evolved to the digital. Especially from the economic and political spheres, geoblocking is a reaction to advanced changes due to globalization, and while both have had to make peace with certain changes, both have proven capable of using globalization to their advantage as well in maintaining older systems of practice. We can more critically examine flows of change - the frequency and pace of change. How we do this is by looking at where geoblocking came from, who controls it, and how. In the grand scheme, it is about making visible the infrastructure at who has a hand in shaping and controlling it:

People commonly envision infrastructure as a system of substrates - railroad lines, pipes and plumbing, electrical power plants, and wires. It is by definition invisible, part of the background for other kinds of work. It is ready-to-hand. This image holds up well enough for many purposes - turn on the faucet for a drink of water and you use a vast infrastructure of plumbing and water regulation without usually thinking much about it (Star, 1999, p. 380). 
What is really at work in geoblocking beyond what is visible? It is about making visible and attempting to make sense of the incredibly intricate network of blockages and flows.

Geoblocking deserves more thorough and critical examination because it helps us better understand not only what infrastructure is, but globalization's effects on infrastructural changes and how economic, political, and audience parties exercise their powers either together or against one another in reaction; a critical analysis of geoblocking and these parties and digital media uncovers how geoblocking is used to reinforce existing concepts of corporation, nation, and audience as an extension of the offline world to the online that helps extend pre-existing offline systems of doing business, managing government and defining the national identity, and providing and accessing media and information to the online - geoblocking not only reinforces existing concepts, but gives media corporations, governments, and audiences time to weigh the positive and negative effects of adapting to new possible ways of doing business, identifying national identity, accessing media content and information online. Geoblocking is at the heart of what is at stake, particularly in three areas vital to corporations, government, and the audience: balance of powers; internet access; and internet freedom.

\section{Balance of Powers}

For some digital theorists such as Barlow (1996) and Howard Rheingold (2000), cyberspace, the Net, online communication means transcending race, gender, age, class, etc. The internet allows for a blurring of the lines that separate people, corporations, and even governments. Rheingold praises "the Net" for its capability to connect and allow people to organize in new ways. It is more than just about playing online video games together, more than just streaming episodes of a British show in America or watching Princess Bride while 
vacationing in Italy; it is about creating cultural and even political organizing. However, the age of the net utopianist has long since passed. Rather than utopianists, there are positivists, who, although believing in the general empowerment cyberspace can offer us, recognize there are pitfalls and concerns. Rheingold (2000) has been active online, and with some of the oldest social media networks, since 1985, and even as Rheingold would describe himself as utopian about the revolutionary capabilities allowed by the Net, he is not without misgivings and warnings, citing examples of corruption by governments and corporations, conflicts among community members, people lying about their identity, and even obsessive behavior. Net positivists such as Clay Shirky (2009), Henry Jenkins (2013), Manuel Castells (2013, 2015), and Elizabeth Coleman (2011) speak to the revolutionary advancements in thinking about identity, community organization, government structures, but in all their works, they each identify issues voiced by more critical perspectives. Digital scholars such as Jodie Dean (2010), Mark Andrejevic (2013), and Nicolas Carr (2011) indicate the complications in collective action through online communication with many people voicing concerns with their likes and shares, but never actually following through with concrete action, and the continued restrictions of action managed through invasive internet control and surveillance by both corporations and governments. Media scholars exist on both sides on the revolutionary power of new content platforms and providers and whether Netflix is as disruptive of traditional systems, or just another Disney Corporation. ${ }^{21}$

${ }^{21}$ In The Age of Netflix: Critical Essays on Streaming Media, Digital Delivery and Instant Access (2017), Cory Barker and Myc Wiatrowski edit a series of critical essays that both support claims of Netflix's revolutionary power, but are also critical of it as a streaming platform and the content it purports to have revolutionized as well. in her article "Doing Time: Queer Temporalities and Orange is the New Black", Maria San Filippo discusses the queering of temporal shifts in contexts of the TV timetable and queer representation through Netflix's "Orange is the New Black." In Amanda D. Lotz's (2017) Portals: A Treatise on Internet-Distributed Television, she states that while Netflix certainly influenced industry and audiences, it was not as revolutionary in destroying old media as some reported would occur with even cable and satellite still very much existing. 
Gaining a better understanding of geoblocking and globalization gives us insight into not only how a local balance of power is negotiated, but power at a global level as well. Castells (2013) notes that "that power is not an attribute but a relationship" (p. 11). Power is not something inherent or natural to one specific group or people; it is not something owned, or a given. Power is practiced. Power is practiced. Some are only better at it than others allowing for dominant control, or seemingly dominant control. Corporations and governments attempt to practice power as much as audiences do. Sometimes corporations and audiences use government to practice their power, sometimes governments use corporations and the audience, and sometimes each rely on themselves. Castells (2013) argues that ours is a society of power and counter-power. It is too simple to separate between those who are empowered and those who are not as everyone can exercise power. The concern is over how much power one can practice and in what setting and against whom. If it were a matter of simply those who have power versus those who do not, then there would never be social movements because a social movement must conceptualize themselves as having some sort of power against another force instigating power against them. Already, I have focused more on corporations and governments in discussing control through geoblocking, suggesting an unevenness in the scales of power where the everyday person - the audience - has no say in such control.

However, looking at the issue of freedom of speech online, the audience - the people, the user, the citizen - have even called upon the government and corporations to control virtual spaces indirectly. When Tablet magazine senior writer Yair Rosenberg reported someone opening a Twitter account under the handle @ rosenberg_yair and posting a photo of a baby with a swastika on its forehead as the profile photo, people reported the account as "abusive behavior" 
after Rosenberg tweeted that his initial report had been denied (Warzel, 2019). Rosenberg is an avid writer against Neo-Nazis and often receives threatening posts from users - typically, through fake accounts that give little idea of the person's identity. Twitter's policy is to allow anonymous users. Anonymity online can help individuals to question and even criticize their governments, which Western society typically accepts when it is against a seemingly totalitarian government. However, anonymity online has come under fire with increasing threatening and abusive posts directed at people. But how can a government use legal infrastructure designed offline to enforce laws to online, especially when a user might not even be a citizen of the physical territory the alleged victim resides in? This is a complex issue with many governments still unsure how to navigate local, national, and international law in connection with crimes committed on the internet. So, what does an examination of geoblocking reveal to us about the balance of power over the internet? Who gets to govern and why and how? These questions are answered in the dissertation through an examination of all the entities involved - corporations, governments, and audiences - and how they work either with or against one another in balancing their power, and if there is an unevenness in the balance, what does it look like and how does one tip the scale, and in whose direction?

\section{Access}

Access relates to balance of power, because whoever has dominant control of the processes of production and distribution of information has potential control in dictating a dominant body of knowledge, helping to further ingrain a certain set of acceptable norms and behaviors. Global media scholar Evan Elkins (2019) states that the concentration of power over 
media is maintained through a regional code system ${ }^{22}$ in terms of a stand in for representation of cultural capital power of both corporations and countries - effectively, the two work together to maintain much of the control over media content and access, however, audiences, some more so than others ${ }^{23}$, have the power to influence their control. Access is not just access to information, but, especially in the digital age, also the timing of such access. In this dissertation, I include access to production and distribution, as well of information into the larger issue of "access" on the internet.

In connection with access is examining what the internet was designed for initially and its evolution to its purpose of use today. Rheingold (2000) states that the Net is an amalgamation of people who piggybacked off technologies that were meant for another purpose. According to Rheingold, they were visionaries that looked beyond motive of profit. They were not even all "experts" of a particular field professionally. The idea of "acceptable use" of the Net has been widened with every passing age with the pressure of the audience wanting access, but access to what? Not just the internet itself, but the information - the content - available on the internet. While the idea of the Net may have originated with military purposes, scientists expanded it with ease of communication of information between themselves, and from there it expanded into the commercial industry before it reached the everyday user (Rheingold, 2000). This is now a typical pattern of diffusion, with each new advancement pressured into new terms of acceptable use and access. However, this diffusion does not mean same level of access as the others in the pattern. As the internet has seemingly been expanding, it contains more information as well. Several questions relate first to what gets digitized or not and who makes those decisions,

\footnotetext{
${ }^{22}$ A system that although implemented on DVDs was informally in place before the digital era, but enforced after and expanded to the internet.

${ }^{23}$ Discussed more in Chapters 3: Geoblocking and Government and Chapter 4: Geoblocking and the Audience.
} 
especially in concern with national libraries. Furthermore, who has the rights to access that information, and what does it mean for one territory's audience to access information the managing government may not find is in the best interest of the people, whether that is defined as military or cultural concerns insofar as both are dependent on the territory? Essentially, whoever the government approves can access officially, but for all content considered unacceptable, audiences have to turn to illicit pathways of geoblocking circumvention to illegally download content or access blocked websites.

The question of access is important when we examine media as important artifacts that matter and have meaning. What the meaning is, however, depends on various factors. Meanings change from time and space. Nothing exists until meaning is ascribed. Ideology tasks itself with this function. Ideology makes sense of things by placing meaning on images, symbols, etc. Any media artifact produced is produced with a meaning already inscribed, but that does not guarantee that that meaning will be accepted by everyone - people inscribe their own meanings on already created items as well (Hall, 1985).

According to Hall (1985), Althusser states that "knowledge has to be produced as the consequence of a particular practice. Knowledge, whether ideological or scientific, is the production of a practice" (p. 97-98). We learn by doing. Hall reminds us that we must look at the semantic field within which any ideological chain signifies. It is where we come from (our culture, our heritage, etc.) that influences who we are and how we act, how we see certain things. If only a set of approved content is available for access, it does set up a certain dominant ideological view of that time and place. For Hall (1985), ideological power is the power to signify events in a particular way, so when an event occurs, and all the people get is access to the signification of that event through only particular media outlets or productions, that could 
possibly limit the way that that event is then ascribed meaning for the viewer. One event may not be covered in the same way in one place as another. This presents us with the issue then of "which kinds of meaning get systematically and regularly constructed around particular events" (Hall, 1982, p. 67). Geoblocking can be used as a systematic tool to help regulate the access to certain meanings as more and more information - different perspectives - are uploaded to the digital sphere.

This leads to answering the bigger question: to what extent does access equal more democracy? If everyone around the world gets to watch the Netflix original British show, The Great British Baking Show (GBBS) ${ }^{24}$, at the same time, are we suddenly going to automatically develop world peace? While I would fantasize that we can all come together around a nice piece of cake while watching bakers bake on $\mathrm{TV}$, it is unrealistic to imagine that equal and simultaneous access to all digital content, would change all major issues facing mankind. The issue is far more complex than that. Open and equal access itself does not automatically mean better relationships between people, corporations, and governments; in fact, the opposite is often the case. It does not mean that there will be a rise in democratic freedoms, because people do not all use the same technology for the same reasons, in the same way, or even have the same definition or experience of democracy (Balsamo, 2011). However, access is a required first step to open the possibility for changes that might otherwise take us to conceptualizations of ourselves, capital, and government that could very well be for the betterment of all societies in some fashion.

For example, communication researchers Dana Mastro and Riva Tukachinsky (2011) state that media effects research supports the conclusion that exposure to unfavorable

\footnotetext{
${ }^{24}$ The Americanized name of the British title The Great British Bake Off (GBBO) since Pillsbury has the trademark to the words "bake off."
} 
racial/ethnic stereotypes in media can contribute to negative perceptions about minorities in society, which is then used as a basis by which to make race-based evaluations and decisions that can affect public policy. They conducted a media study in which they measured the attitudes and judgements of White audience members exposed to positive Latinx exemplars (representation of well-known individuals) and prototypes (representations of generalizations). Their findings supported the conclusion that continued inclusion of positive and diverse representation in media is beneficial. However, Mastro and Tukachinsky (2011) do qualify that to influence predisposed judgments, representation should not merely be favorable, but rely on archetypal representations that can be relatable to the audience - relying on more representation of positive stereotypes versus negative. I am not suggesting that content alone will change things or people. There will always be people who do not agree to change, let alone even accessing media of opposing values at all. Mastro and Tukachinsky (2011) state that prejudiced individuals will selectively avoid exposure to counter opinions, values, etc. in entertainment programming. Although I agree with their conclusion, this should not prevent people from demanding not only more of our media content from our corporations, governments, and ourselves, but also of our access to media offline, but, especially, online. Media content is important, but what does any of that matter if that content cannot be accessed by the wider audience? Access is necessary to exposure, which could lead to rethinking things and even becoming involved in discussion, which can further lead to positive progress in society, such as decreased racial evaluation in policy making, for example. 


\section{Internet Freedom}

Whether we should, or even can, have a free internet connects back to the internet utopian arguments that believe in the main premise that geoblocking by corporations and governments puts to question the issue of what the internet should be, which, for them, should be a free and open system of access (Lobato, 2016). When internet freedom is discussed it seems to mean an internet that is not regulated by any force, corporate or government. However, this brings up questions about freedom of expression, freedom of association, and even the free flow of information. For example, what is considered appropriate freedom of expression online then? What kind of information? What if you associate with a hate group? The earlier noted case of Rosenberg on Twitter illustrates the complications inherent in all these questions. Many people were vehemently against the person opening the account in Rosenberg's son's name with the picture of the baby with the swastika on its forehead and condemned it as "abusive behavior". Where, however, is the line? When do we cross a line or not? In the U.S., my illegally downloading GBBO is not crossing a political line, for example, whereas in China it is, because the law building the online infrastructure there is written in such a way to identify any illegal crossing (digital and/or otherwise) as a political act against the state. Expressing my opinion on matters on social media may not even be crossing political lines in the U.S. depending on how the law is phrased, but the law on the topic may be different in another country. It is easy to regulate and enforce that offline, but how to regulate that online? As long as regulation exists offline, it will be expanded to online. While there is disagreement over who should regulate that - the government, corporations, or the audience - there will always be lines to delineate space and place, geography, to enforce the rules. Investigating geoblocking allows us to examine the 
question of what the internet should look like and for whom at both a macro and micro level of control and regulation.

\section{Methodology}

This study primarily focuses on geoblocking from a technological viewpoint (examining what it is and how it works), especially on the development and use of the technology as a reaction to globalization. This means examining geoblocking from not just one perspective, but from multiple angles, looking at the relationship between geoblocking technology and different spheres of influence in society - the economic, the political, and the audience. Content can be blocked by corporations and governments. The audience can pressure both corporations and governments to enforce geoblocking, but, by and large, the audience has no other option but to traverse blocks to access certain content. At the core of this study is the examination of the complex levels of practice of power and resistance in respect to geoblocking in managing the pace of adaptation from existing rules and regulations in a physical world to a digital world, and vice versa. This involves gaining a deeper understanding of what geoblocking is, why and how it functions, how its function is affected by globalization and how it affects society, as well as how society affects geoblocking. This study's focus on connecting geoblocking and society is influenced by Lessig's (2006) note on four things that regulate people - law, norms, market, and architecture - and, therefore, the analysis is conducted along the lines of three agents and their motivations: geoblocking and media corporations (the economic); geoblocking and governments (the political); and geoblocking and the audience (the sociocultural). Infrastructure is not an agent in and of itself, but a common element throughout and this dissertation will show how geoblocking connects in these spheres of influence to work on and through infrastructure which 
ensures that the modern internet infrastructure is not open and never will be, because of the physical and technological infrastructure already in place.

This study on geoblocking posed several challenges. First, the research focuses on a very technical element in the field of computer science and information technology. Therefore, an understanding of the technical aspects of geoblocking is a prerequisite for developing a clearer picture of the relationship between geoblocking, globalization, the internet and access to content. There are complex processes involved in geoblocking necessitating extensive research and understanding of the work of scholars who are considered both new media and information technology experts, such as Lessig (2006) - whose work as a copyright and information lawyer led him to complete extensive research on computer code - and Tim Wu (Goldsmith \& Wu, 2008; Wu, 2011), a law professor who is known for his work on Net Neutrality and who researches and writes about private (corporate) power and copyright, especially in a growing digital environment.

The second challenge was researching a subject in an American context where the key word, geoblocking, is not generally used in much of the American-based research and where not much research exists on geoblocking and its effect specifically. Even when authors are describing geoblocking, the word does not seem to be used in much of the research on internet studies. Even Lessig (2004; 2006) and Wu (2011), who describe geolocation technologies in detail, never use the term "geoblocking" specifically. While they refer to geolocation technology and how it can be used for blocking access to content, the term geoblocking - or the other widely used spelling "geo-blocking" - does not appear. There is a reason for this: American consumers typically do not struggle to gain access to media content because a large share of it is created by U.S.-based production companies primarily for the American market region first. 
However, with new publications from Television and New Media scholars focusing on the increased prevalence and popularity of online streaming services, such as Amazon Prime, Hulu, and Netflix with their media spreadability through online streaming, the term "geoblocking" has appeared more often, even though still limitedly. For example, in the book The Age of Netflix: Critical Essays on Streaming Media, Digital Delivery and Instant Access (edited by Barker \& Wiatrowski, 2017), "geoblocking” appears four times in the text: twice as a reference to two essays (both essays reference the same article) and twice in one article on geoblocking and the spreadability of the documentary The Square as potential activism. ${ }^{25}$ In the book's introduction by Cory Barker and Myc Wiatrowski and the essay about The Square by James Gilmore, both reference Evan Elkins' (2016) article “The United States of America: Geoblocking in a Privileged Market" in Geoblocking and the Global Video Cultures (Lobato \& Meese, 2016), which was one of the first and very few scholarly publications I found focusing primarily on geoblocking ${ }^{26}$ while completing what became the first step of this work during qualifying exams. The book is edited by Ramon Lobato and James Meese through the Institute of Networked Cultures in Amsterdam. That there was an American perspective added was intriguing and shows an increased awareness of the topic, even as it is not yet as readily discussed in everyday conversation, let alone in policy, as it is in countries such as Australia or in the European Union (E.U.) region.

As such, research on geoblocking is rather abundant when examining Europe, Australia, China, and several Middle Eastern countries. Especially with the E.U.'s recent referendum on copyright law, geoblocking has become a key political issue for E.U. citizens for online shopping

\footnotetext{
${ }^{25}$ Gilmore, James N. "Circulating The Square: Digital Distribution as (Potential) Activism". The Age of Netflix: Critical Essays on Streaming Media, Digital Delivery and Instant Access. Edited by Cory Barker and Myc Wiatrowski. McFarland \& Company, Inc., Publishers. 2017.

${ }^{26}$ And one of few available in English.
} 
and accessing online content from their E.U.-member country regardless of where they are within the E.U. (Stamatoudi, 2016). This points to a key difference between the U.S. and other countries, and an element that has complicated the efforts of this study to place geoblocking into a larger U.S. context. While the E.U. and Australian audiences equate geoblocking as a political and cultural concern even when focused on economics, geoblocking is not necessarily a political issue in the U.S., but strictly an economic one. When geoblocking is connected to U.S. politics, it revolves around economic concerns, specifically in protecting copyright or intellectual property rights - in being able to enforce the existing laws from physical to virtual (Lessig, 2006). The question of freedom of access to information and the internet is a widely more political issue in other areas of the world compared to the U.S. ${ }^{27}$ While this is a challenge, it also presents an opportunity. As the global media market seems to be becoming smaller and the more accessible social media is exposing media content from many countries to audiences not from that country, the research involved in this study can serve as a bridge for U.S. audiences and scholars to become more aware of the larger existence of geoblocking and, further, give insight into the intricate relationships of concentration of corporate and government power in the U.S. and the world through the media's ability or inability to spread.

The findings of this study can also serve as a possible bridge between several different fields of study that look at geoblocking through their own lenses to bring the issue into a much larger, and even more complex, context. Scholarship on Television, New Media, and Media

\footnotetext{
${ }^{27}$ Although the issue of Net Neutrality was widespread for a time in the U.S., net neutrality is not about blocking content in or outside the U.S., but about the concentration of media ownership, especially when companies are both media producers and ISPs, such as Comcast who can control the speed at which a site is managed on the net. Netflix claimed ISP services, such as Comcast, were throttling internet speeds to slow down website loading speeds, frustrating their users, trying to push them away from those platforms (Clover, 2019). Net neutrality is about the speed at which someone can access the web, not about blocking a particular page or content based on geolocation. However, it is no less important an issue to investigate as well in overlapping corporate goals from both geoblocking and throttling internet speeds.
} 
Infrastructure Studies focused on online streaming platforms and media distribution, such as Holt and Sanson's (2014) Connected Viewing, Barker and Wiatrowski's (2017) The Age of Netflix, and Kevin McDonald and Daniel Smith-Rowsey's (2018) The Netflix Effect: Technology and Entertainment in the $21^{\text {st }}$ Century are recent sources focusing on this topic with a wide multidisciplinary approach from globalization, law, policy to computer science to approaches on issues from the humanities. As such, although the study draws heavily from a humanities perspective, the nature of this research is multidisciplinary, with a distinct focus on textual analysis of varied documents, analyzed from a wide range of different perspectives (as the ranging theoretical orientations should indicate). Fields of study that influenced this research include globalization studies, media studies, new media studies, fandom studies, infrastructure studies, digital humanities, law, political science, computer science, information technology, economics, sociology, and communication.

A third challenge is that with multidisciplinary research such as this study, focusing on examining the topic from one identifiable perspective also poses a distinct challenge. How a source was interpreted for this study depended on where that source connected in relation to the three agents and their motivations as previously delineated, and thus places a constraint on the study. One source requires multiple perspectives providing many avenues of reading and interpreting the material, while other sources did not require such extensive application. Some of the legal documentation, for example, was read for historical perspective in helping to create a working timeline of development and movement of geoblocking from physical products to digital, while other legal documents only provided a purely legal perspective in examining the relationship between ownership and copyright and how that connects to geoblocking as a legal tool. Some documents contained connections to all the agents and their motivations requiring 
several rounds of analysis through the different perspectival lenses. Taking the stance of a political legal scholar can help provide investigations into the political aspect in relation to aspects of geoblocking as censorship or control by government entities, while a media marketing and business law perspective can help give insights into the issues of licensing agreements and the capital issues surrounding piracy in examining economics, which is then also further analyzed from an audience perspective around "share culture" and piracy. Throughout the dissertation, I identify and explain principles from different fields and through what lens an element is being examined.

In terms of the objects of study, I am examining geoblocking through a textual analysis of primary and secondary research, sifting through several documents to develop a map of connections across different perspectives and conclusions on geoblocking. Documents can take many forms, including: legal write-ups covering international law and local legal codes, whether legal frameworks established officially by government institutions or legal contractual agreements used amongst corporations covering copyright, licensing, or rights (specific examples would include the Digital Single Act referendums documents passed by the E.U. and the Digital Millennium Copyright Act passed in the U.S. in connection with corporate Digital Rights Management practices); website information from official sources, such as the FAQ and press releases from Netflix; newspaper articles from international and local news sources; blog pages, including official news sources, but also other sources that may not appear in larger news streams, such as blogs by working professionals like lawyers or even media producers or distributors who may focus on copyright or even geoblocking directly, or blogs by everyday users who express their experiences with geoblocking; social media postings by individuals or through larger entities, such as corporations (official social media profiles of media brands) or 
governments - social media include anything from Tumblr posts, tweets on Twitter, Facebook posts (and pages), Instagram posts, etc.; and scholarly works by authors from various disciplines who provide further analytical investigation and insight on the topic.

\section{Chapter Outlines}

Previous research and scholarly work on geoblocking typically focus on one of three topic areas: corporations, governments, or the audience. These are the three parties representing the main spheres of influence affecting the internet and affected by the internet as they manage rates of change. This study does not deviate from this trend; however, it expands on the effects of and on each. While each chapter is designed to examine the relationship between globalization, access to online media content, and geoblocking, it also expands the analysis by examining the intersections between the different parties in each section. Corporations rely on governments to institute geoblocking as law to help control their power structure within the economic market; governments utilize corporate advancements in geoblocking to maintain their own power; corporations provide convenience to the audience for shopping and accessing media content online; and government responds to audience demands for law and order. These are all motivations that align but the study also examines where they diverge and the reasons why. Essentially, the chapters examine why and how geoblocking is used by these parties leading to more critical contextual understanding of the infrastructure of blockages and flows that makes up the internet today. Ultimately, a more critical perspective of the complex pathways of cause and effect between these realms in relation to geoblocking can help us think more critically about the effects of globalization and existing economic, political, and social infrastructures of practice. The dissertation chapters work as a larger examination of the relationship between the 
infrastructure of the internet - how it is organized, controlled, and regulated - and the balance of power of access.

The organization of the dissertation is inspired by Lobato's (2019) Netflix Nations: The Geography of Digital Distribution in that every chapter examines geoblocking through a case study or case studies that connects to Netflix. Lobato provides key reasoning for why Netflix provides for an excellent case study when he explains that "Netflix's story tells us a lot about what happens when a digital service enters national markets, coming in over the top of existing institutions and regulations" (pp. 11-12). However, while Lobato's book is an examination of access to global television through Netflix, it should be clarified that this dissertation is not about Netflix, but rather it serves as a relevant case study of the utilization of geoblocking as a reaction to globalization by corporations, governments, and even the audience. Each chapter focuses on and advances examinations of geoblocking from the perspective of one of the three different entities involved: media corporations, government, and the audience.

\section{Geoblocking and the Media Corporations}

This chapter focuses on corporate reactions to the globalization of media content and technology and its effects on the traditional models of distribution, copyright, and intellectual property earnings. It provides a timeline of geoblocking's development and application as it pertains to corporations. It further examines the development of copyright in relation to economic concerns leading to digital enforcement, but also describes the issues of production and distribution, which connects to issues of moving from local markets to global and vice versa in a digital era - media spreadability - where a pre-existing system of production and distribution exists and is still maintained to some extent. It lays out the issues surrounding 
copyright and licensing as universally the same across the globe, even as the rules and regulations on copyright and licensing are not, complicating globalized media distribution for multinational SVODs like Netflix. Part of the issue is the market regions into which the world is segmented, which is not always necessarily a political issue, making geoblocking in this context not an issue of censorship, but of corporate responsibility and control.

This chapter also focuses on the development and evolution of Netflix as a case study in examining how Netflix reacted to globalization from a corporate perspective versus legacy media producers and providers such as the Disney corporation. This includes examining Netflix's growth as an American company to an eventual global giant with the influx of localized global or globalized local content and the role geoblocking plays in this process.

\section{Geoblocking and Government}

Geoblocking and government is a complex chapter that focuses on two elements: the law and politics. Politics is not always an issue of what is legal or not, but the law can be an issue of political concern. As such, this chapter parcels out the relationships between the law and governments and how the two work together or against one another, especially when put into economic context - the added relationship with corporations. The subject of geoblocking and the law focuses first on how geoblocking shifted from an informal process to a legally sanctioned tool - especially as one to protect corporate interests, which then advanced as a tool to protect against perceived media-cultural imperialistic forces. One question that must be asked is not so much whether the application of geoblocking is illegal, but is the content that is being blocked illegal, and why? Who decides what is sanctioned content or not? In addition to copyright or licensing laws, some countries have rules about the nature of the media content permitted, and 
this can affect how geoblocking is then applied to ensure local laws are followed (Rugg \& Burroughs, 2016). This is further illustrated when examining the relationship between Netflix and China, one of the few countries Netflix is not able to operate in due to the intricate control of the media system in that country both offline and online. It is a matter of local law and cultural power. An issue, however, is that international law is not always neatly categorized or even agreed upon in relation to local law complicating relationships between transnational corporations and governments, which has only been exacerbated by the internet and online transnational corporations.

This chapter examines how geoblocking is used as a compliance tool to ensure that in the age of "boundless" internet, certain laws and judgments could still be enforced territorially. It will show how countries use it as a tool to ensure legal compliance and maintain the concept of "territorial rights." This chapter unpacks the political intricacies of national borders and the difficulty of translating those borders to the digital realm; as stated by Llamas-Rodriquez (2016),

"The internet is now a site for struggles over sovereignty, surveillance, and control, concerns that were once the domain of the offline world (or at least imagined as such)" (p. 32).

\section{Geoblocking and the Audience}

What is meant by audience in the context of geoblocking? In this dissertation, consumers, citizens, users are all essentially used to mean the audience. They all allude to the everyday person: that is, people who neither practice corporate control nor are in government. This chapter examines different reasons that motivate audiences to push, typically, for dissolution of geoblocking. The chapter does this by examining several case studies, such as the E.U. referendum on copyright since early 2014 for the purpose of updating policies for a world 
connected by the internet, which was influenced by E.U. audience dissatisfaction with crossborder portability of online media content among other reasons (Stamatoudi, 2016). This case examines geoblocking as geographic and cultural discrimination especially against minority language groups in the E.U. For Europeans, and people in other countries, such as Australia, geoblocking is familiar enough to be a cultural and political issue. In Australia, however, the audience is motivated mostly by economic reasons as a country that sees some of the highest inflation rates of media content (offline or online) in the world where it is cheaper for them to access online portals of media content, such as HBO Now, than pay for it through their very few local broadcasting options. This led to an issue when a local Australian cable company sued HBO leading to transnational corporations tightening restrictions on geoblocking circumvention, including virtual private networks (VPNs).

In comparison, American audiences seemingly are not preoccupied with geoblocking, however, social media is connecting even American audiences to foreign media in ways not possible before. While Netflix does air GBBO on Netflix U.S., many fans follow the only existing corporate social media accounts for the show, which focused, at first, on their U.K. audiences first, posting results as they happened. However, Netflix still airs GBBO at a three-day delay leaving American audiences who followed the accounts spoiled at the ending.

These cases are significant each because of the variety of complex reasons people are access media content from within and outside of their territories, but, also, noting the conditions for which geoblocking needs to be brought into the political arena and policies amended. The E.U. and Australian cases show that geoblocking became more significant, the more of an issue it became for more audiences, who eventually push for change from either the media corporations, governments, or both. As such, for any kind of change to geoblocking policies to 
take place, it would mean the audience has to have knowledge about. They must know they are being geoblocked from content, which leads them to question the nature of the geographic media environment and how media corporations and governments are working together to gain the best advantages for them. While questions of whether change of the media corporate system of geoblocking can be removed - due to issues surrounding copyright - are taking place, they are happening at a regional level. For a large-scale global change, I assert in this chapter it would require audiences, such as the Americans, especially, to become aware of geoblocking and start pressuring media corporations and governments.

\section{Conclusion}

There will never be a world without geoblocking. The already existing territorial models of media ownership and distribution coupled with government regulation of law and order are too intricately intertwined into the fabric of the way the world works, even though globalization threatens to tear many of the threads. Corporations and governments, especially, are utilizing new tools and technologies to stem changes from globalization that could threaten their systems of practice. However, change is inevitable, and corporations and governments can only work to stem the rate of change. I remain positive about the progressively positive open spaces that could exist on the internet, but they will exist with concessions are negotiated between media corporations, governments, and audiences. I express some of this positive outlook in the conclusion to theorize what a world without geoblocking might look like and consider what circumstances would need to exist for it to be dissolved even as I do not believe it can truly ever be achieved. However, just because something does not seem possible, does not mean we should not entertain the notion as a critical practice to understanding the intricate patterns of power at 
play in shaping the internet. The conclusion also ends with a reflection on the future of geoblocking as a field of study. 


\section{Chapter 2: Geoblocking and the Media Corporations}

This dissertation examines the relationship between geoblocking digital media content and media corporations, governments, and audiences. As introduced in chapter one, geoblocking developed as a technological reaction to increasing digital permeability of national borders online. Geoblocking serves to sustain economic, political, and social infrastructure and practices around media that are tied to ideas about national identity and media distribution and consumption pre-dating the internet. While there is no way to stop changes brought on by the internet, media corporations are finding ways to stop-gap the flow of changes and ensure that profits generated by their already-developed systems are at least not negatively affected and, at best, maximized. Systems that started open, such as the internet, quickly become closed off as corporations gained more authority and ensured control over their intellectual property, especially across several medium types (music, books, films, etc.) by putting structures in place like geoblocking (Wu, 2011). Corporations are not closed off to change, however, but they want to ensure that change is controlled and managed appropriately and does not negatively affect their control over their property and, as such, profits, which is their continued motivation for control mechanisms like geoblocking.

This chapter examines the motivations that leads media corporations (referred to as corporations from here on) to justify their use of geoblocking. It entails an examination of the corporate application of geoblocking by focusing on the frictions between old media versus new media corporate systems of development and operation. This chapter further illustrates that territorial economic infrastructure works as a tool to help corporations control the internet. This chapter argues that geoblocking is a digital tool evolving from previously existing non-digital industry market principles that are actively used in the enterprise of corporate control of media 
properties. Using specific case studies, this chapter examines what that control looks like, where and how it has been challenged, and what that means in better understanding how, by whom, where, and when the internet is controlled.

More specifically, this chapter is about examining the evolution of geoblocking as a reactionary and inevitable tool used by media corporations to control changes brought on by globalization - balancing positive versus negative consequences between different corporate and even political parties and the audience. This study focuses particularly on old and new media in an evolutionary sense as it is connected to globalization - examining the movement of people and technology that led to the adoption and spread of media platforms and content and the development and global integration of online geoblocking, especially in the entertainment media industry. For example, Reed Hastings, CEO, and co-founder of Netflix, has been public about the internet's role in the success of the company, but also laments the geographically based copyright licensing that prevents even Netflix originals to be offered when Netflix opens in new

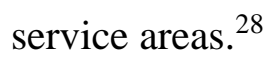

Netflix makes for an interesting case study in connection with globalization of media content and geoblocking in the media market because it showcases the tensions that exist between pre-existing models of media distribution through a geographically-based copyright system and the internet - the DVD distribution system that Netflix relied on to help first make its name is the very thing that restricts their growth into a truly global new media empire. While there are over 300 online streaming services available in the U.S., including Amazon Prime, Hulu, HBO Max, Disney Plus, CBS All Access, and NBC Peacock to name but a few, Netflix is

\footnotetext{
${ }^{28}$ Netflix makes licensing deals with pay-for TV and cable channels to distribute Netflix shows in geographic markets in which Netflix was not otherwise permitted to legally operate. Many of those deals now prevent those very shows from appearing on Netflix when it does go live until the contracts expire.
} 
still considered a leader in the online streaming market (Hersko, 2019; Sing, 2019). In addition, streaming services like HBO Max, and CBS All Access are only available in the U.S. and Canada, Hulu is available in both the U.S. and Japan, and Disney Plus is now available in 30 countries since its launch in November 2019 (Trenholm, 2020). While Amazon Prime is reportedly available in over 200 countries and territories compared to Netflix's 190 regions, Netflix still leads in content production and the highest number of subscribers globally at 195.15 million as of November 2020 (Watson, 2020b). Comparatively, Amazon Prime has 150 million subscribers globally while Disney Plus has 74 million global subscribers (Katz, 2020; Watson, 2020a). While the focus here is on Netflix in detail, as the primary case study, some of the other above mentioned OTT streaming platforms are also discussed, especially since some of these services were online before Netflix, like $\mathrm{HBO}$, and are considered legacy media corporations with histories of development pre-dating the internet. Compared to these other services, Netflix has one of the more unique origins and perspectives on global to local media content access - not necessarily supporting geoblocking to maintain control of their media properties, but still very much creating their own global digital market blocked only by a paid subscription exclusively the user's location.

It is somewhat complex to define Netflix as a company. In fact, Netflix has described itself in several different ways. In a report on its 2002 quarterly earnings (Netflix, 2003), Netflix described itself as "the world's largest online subscriptions-based DVD rental service"; in a report on 2007 earnings (Netflix, 2008) it "is the world's largest online movie rental service" including not only DVDs, but a "growing library" of titles "that can be watched instantly" on a subscriber's PC; in a report on 2009 earnings (Netflix, 2010) "it is the world's largest subscription service streaming movies and TV episodes over the internet and sending DVDs by 
mail”; and in reports since 2011 (Netflix, 2012), “a global internet TV network of unparalleled reach and consumer delight" becoming not only a content distributor, but a content programmer as well. Netflix has been described both by corporate insiders and academics as "disruptive" and "revolutionary" for its evolution of media services online and content production and distribution (Barker \& Wiatrowski, 2017; ${ }^{29}$ McDonald \& Smith-Rowsey, 2018; $;{ }^{30}$ Newman, $2018^{31}$ ). Netflix is described as "new media" as opposed to "old media."

Considering the above, it then begs the question, how "new" is Netflix really in the grand scheme of the global media corporate system? What distinguishes old from new media in production, distribution, and access - what is the evolutionary history? While Netflix is a streaming video on-demand (SVOD) system providing quality streaming of media content and even producing its own content, is it not, essentially, still providing television series and movies like what "old media" corporations are providing? Television media forms of storytelling have not necessarily changed ${ }^{32}$, but the platform has. Netflix describes itself as a global internet TV network. So, is what makes it new that it is online? And if Netflix is so new, disruptive, radical, revolutionary, why then does it geoblock or georestrict its service or content by the very same national boundaries that "old" media does? What exactly is "new media"? The popular definition of new media identifies it with the use of a computer for distribution and exhibition rather than

\footnotetext{
${ }^{29}$ Cory Barker and Myc Wiatrowski edited a collection of essays in The Age of Netflix that examines Netflix's disruption in the entertainment industry and cultural dominance.

${ }^{30}$ Kevin McDonald and Daniel Smith-Rowsey edit a collection of essays in The Netflix Effect: Technology and Entertainment in the $21^{\text {st }}$ Century that, while writing the disruptive and radical aspects of Netflix from industry perspective, the authors tend to be more critical of Netflix as a disruptor compared to its industry counterparts. ${ }^{31}$ Forbes contributor and principal analyst of Futurum Research and CEO of Broadsuite Media Group, Daniel Newman puts Netflix on a list of radical innovators who initiated disruptive innovation in the media industry since 1997.

${ }^{32}$ Although Netflix has recently started producing "interactive" media content, such as "Black Mirror: Bandersnatch" airing in 2018, which is a film based on the TV program "Black Mirror" where audiences are given choices at key points to progress the story into different directions. However, these are considered Netflix specials and since the first release in 2017, Netflix has produced 11 interactive titles (Netflix Help, 2020)
} 
production. It usually includes the idea of new media objects such as websites, computer multimedia, computer games, CDs and DVDs, and virtual reality. Old media encompasses media platforms like print, radio, and even television (broadcast). However, In Language of New Media, Lev Manovich (2002) asks: What about television shot on digital film and edited on computers? What about 3-D animated films? What about other images and text-compositions made on a computer but then printed on paper? Manovich feels the distinction of products of new media as objects created by the computer and anything in a book or on paper is too limiting. Manovich states that "the computer media revolution affects all stages of communication, including acquisition, manipulation, storage, and distribution; it also affects all types of mediatexts, still images, moving images, sound, and spatial constructions" (2002, p. 19). New media is a convergence of two separate historical trajectories: computing and media technologies.

Old media suggests platforms that may be considered outdated (analog technologies) while new media refers to digital technologies, more specifically, the internet and platforms that connect to the internet, such as computers, video game consoles, and even TV sets. In this chapter, I take inspiration from Ramon Lobato's (2019) analysis of old versus new media using television studies, new media history, internet studies, and platform studies to develop an understanding of old media and new media more critically and how geoblocking works to navigate the distinctions between the two and the historical contexts and systems they are linked to. However, this chapter is not focused on the nuanced debate of old versus new media as much as my focus here might suggest. I will not complete a full historical or contextual analysis of what distinguishes old media from new. New media scholars Lisa Gitelman (2008), David Bolter and Richard Grusin (2000), and Manovich (2002) all provide excellent in-depth critical historical 
analysis of old and new media in broader terms that focuses on several more nuanced debates around the subject and language on the topic.

I, on the other hand, examine old versus new media from a business operations angle, examining media corporate operations that correlate to either old or new media or both, especially surrounding media production, distribution, and exhibition. So, in this chapter, "old media" (I will also use the term "legacy media") denotes older models of business or media corporations that operated for years before the internet (The Walt Disney Corporation, for example, HBO; CBS, etc.). This model assumes fixed national borders, while new media connects to corporations that originate from "Information Age" advancements and function through a newer, more globalized model in which both corporations and audiences cross national borders both physically and, especially, digitally over the internet.

Netflix presents itself as an interesting case study to gain deeper insight into geoblocking its purpose and application - in the economic sphere because of its historical development from a physical medium provider online to an online streaming platform. As such, Netflix holds an interesting liminal space that complicates its new media status even from its origins within old and new medium technologies relying on online subscriptions and ordering of physical DVDs but utilizing the mail service as distribution before evolving to its focus as a premium SVOD service. Examining Netflix's origin as an internet-powered company of content gives an interesting point of analysis, then, on its perspective on the internet and globalization versus legacy media companies like Disney who have had to evolve from traditional old media models to one that makes integral use of the internet. Investigating the issue of geoblocking through an analysis of Netflix in this chapter provides a unique perspective on examining the differences and similarities from the evolution (or appearance of evolution) from physical national, territorial 
geoblocking to modern-day, digital, yet still territorially and nationally bordered, geoblocking of media content; it gives a unique understanding of how media corporations are changing because of and on the internet as legacy media corporations respond to the years of Netflix's fast growth and domination of the streaming market, and how they are managing to now exploit the changes afforded by the internet in new models of entertainment distribution by relying on territorial systems of media distribution that they can enforce using geoblocking.

In this chapter, I examine how geoblocking works as a balancing mechanism between an older, nationally bound system of media corporate operation versus a more globalized model by first examining where geoblocking originated from - a recorded history of development and rationale for implementation at a local, and then global, scale. Second, the chapter will examine the relationship between copyright and old and new media corporations as the primary controlling factor that restricts legacy media but is also used to control new media corporations like Netflix, forcing the application of geoblocking. Third, the chapter examines the rise of Netflix in comparison to legacy media (Disney) and other new media competitors (HBO and Hulu) by examining their business models and how geoblocking is used within their business practices. The conclusion summarizes the key concepts, but also considers evolving geolocation technology affecting content access applied by Netflix, georestriction.

\section{Geoblocking Origins and Evolution: Political}

Geoblocking finds its origins in the corporate sector, evolving from analog tools of property, market, and profit control to a digital tool as the business of doing business shifted more into digital space along with property, markets, and the audience. It originated to help corporations target a specific audience that is now spread out across the globe via the internet in 
the same manner used to control audiences offline through mapped geographic market regions. However, while corporations may claim this is based on providing convenience for the consumer - being able to offer them relevancy with localization through geographical mapping - a closer examination of the development of geoblocking in the corporate sector shows that geoblocking actually helps corporations sustain infrastructures of media production and exhibition with the goal of exerting checks and balances against change that could affect their overall business operations, especially their profit margins. It allows corporations to capitalize on the ability to close of those aspects of distribution on the internet that jeopardizes their profit margins by fragmenting the world into separate closed off media markets that already exist and serve them offline.

\section{Yahoo! vs. LICRA}

As mentioned in chapter one, Lessig (2006) documents one of the earliest cases of online geoblocking ${ }^{33}$ from January 1995 when the Bavarian government attempted to enforce preexisting pornography regulations to the internet in its case against ISP provider CompuServe. However, Compuserve stated it needed to know the exact locations of users to block pornography pages on the internet, a capability they claimed they did not have. As such, under continued threat from Bavarian prosecutors, Compuserve decided to block worldwide access to over 200 discussion groups online based on a list provided by the Bavarian government who determined they could fall under Bavaria's definition of pornographic material (Nash, 1996). At that stage, the programming means was not quite there yet for the more sophisticated form of geoblocking in use today. It was not until 2000 when the International League Against Racism

\footnotetext{
33 The word itself was not used at the time. Rather, geofiltering software appears often in delving into historical roots.
} 
and Anti-Semitism (Ligue Internationale Contre le Racisme et l'Antisémitisme; LICRA) sued internet-company giant Yahoo! Inc. (Yahoo) in French court for violating French law for permitting the sale of Nazi memorabilia on online auction sites that online geoblocking became more apparent. It is not that geoblocking did not exist prior to 2000, but that this specific court case brought it to the forefront as legalized technological bordering tool and where it displayed both its economic implications as well as opportunities for political use. Before the case went to court, restrictions on websites selling Nazi memorabilia were actually already in place on French Yahoo (fr.yahoo.com) (Goldsmith \& Wu, 2008). The case was brought forward by LICRA who accused Yahoo of violating French law that forbids the selling or displaying of items that could incite racism since French citizens could still access auctioned Nazi items through the www.yahoo.com portal, technically U.S. Yahoo, even though they could not do so through French Yahoo. A summons was sent to Yahoo, who rejected it, claiming that the internet was a global space and France was over-reaching their jurisdiction of control in a place it did not belong (Goldsmith \& Wu, 2008). The plaintiff argued that if the U.S. based Ford Motor Company (Ford) must obey safety and environment laws in all other countries where they sell their cars, Yahoo should be held responsible for following local laws and restrictions of internet sales of other countries even if citizens access auction sites from outside the country. Yahoo reasoned it was meeting the law by providing an already existing French Yahoo with the www.yahoo.fr address adhering to French legal restriction, while it also maintained a U.S. portal. The French court argued that the main issue was that although French citizens had access to French Yahoo meeting and adhering to French government standards, Yahoo was not doing enough to prevent their citizens from accessing the U.S. portal where they could purchase and ship merchandise to France that is actually prohibited for sale in France. Yahoo's defense stated 
that unlike Ford Motor Company, who could at least suspend sales in a country where they found they did not meet standards without affecting their other markets globally, Yahoo could not accomplish this with their internet services. According to Yahoo reasoning at that time, to shut down one area would mean shutting down their whole system. So, while they could create and implement changes on French Yahoo, to do so on the U.S. Yahoo portal would have overarching effects on all their business, and not just on the French market. According to Goldsmith and Wu (2008):

Yahoo's 'impossibility' argument reflected turn-of-century assumptions about the architecture of the internet. The Net was not built with physical geography in mind. Neither internet Protocol Addresses (each computer's internet ID), nor internet domain names (such as McDonald's.com or CNN.com) nor e-mail addresses, were designed to dependably indicate the geographical location of computers on the Net (p. 6).

However, Yahoo's defense and case were demolished with the help of Cyril Houri, the founder of technology company Infosplit. Houri contacted the plaintiff's legal team and told them he had developed technology that could screen and identify internet content based on geographical source that could be used as a blocking tool (the location of access) (Goldsmith \& Wu, 2008).

While Yahoo claimed they could not block content on several grounds, Houri served as an expert witness showcasing his geofilter software as proof that Yahoo could, in fact, block certain content, and were already filtering users based on location - they just were not blocking them from accessing other location portals. Houri is considered a veteran in geolocation technologies and has founded two geolocation companies (Navizon, 2015). ${ }^{34}$ He holds several geolocation patents, including the one presented in this case, the process of IP registry database cross-checking, ${ }^{35}$ to prove that Yahoo could, in fact, block access to their site based on

\footnotetext{
${ }^{34} \mathrm{https}$ ///www.navizon.com/navizon-company.

35 "Method and systems for locating geographical locations of online users" Filed April 13, 2000 https://patents.justia.com/patent/6665715 Accessed January 2, 2019).
} 
geographic location. As an international businessman, Houri often traveled across the globe, and it was on a return trip from New York to his home in Paris that Houri observed an advertisement for 1-800-FLOWERS while he was browsing the internet. However, the number was only usable in the U.S. - "In that moment, Houri realized that the logic of the internet did not point inexorably toward the flattening of frontiers. He saw that, on the contrary, a borderless flowerdelivery service made no sense at all" (Goldsmith \& Wu, 2008, p. 59). If one traveled to New York from Paris, what is the point from receiving advertisements from businesses in Paris? Houris did not believe there was much point. Houri believed in a localization technology that could help a website determine where users were and then provide content local to that area. Localization of content, at that time, was not unfamiliar in analog and digital production of film before the internet. Fragmenting the world into different market regions gave corporations time to localize media content to a region's audience, such as dubbing and creating subtitles for films and TV shows, printing translated books, etc. Goldsmith and Wu (2008) state that when it comes to the internet, "geographical borders first emerged on the internet, not as a result of fiats by national governments, but rather organically, from below, because internet users around the globe demanded different internet experiences that correspond to geography" (pg. 49). According to Goldsmith and $\mathrm{Wu}$ (2008), corporations were particularly pressured by their consumers to provide them with a relevant experience, in physical locations as well as online. However, it is not so much the geography that is key here, but what comes with that geography, such as for example, language. Not everyone speaks or prioritizes English as the universal language across the globe. Corporations, and even governments of different nation states, will often provide products or forms in other languages pursuant to the region. Not doing so could cost a corporation an entire market. For example, Goldsmith and Wu (2008) state that Microsoft 
developed an English version of their product for Iceland since the corporate giant did not believe that 500,000 Icelandic users justified developing an Icelandic version when most Icelanders spoke English in any case. However, they were wrong and lost the entire market to Apple who developed and sold an Icelandic Apple computer available in either Icelandic or English. While the internet may suggest a globalized, connected world, corporations, governments, and audiences are still relating to the world from localized perspectives ${ }^{36}$ localization which is used as one motivation for geoblocking as a border tool.

Houri developed the software that took mapped physical boundaries and transposed them onto the internet to help with the process of localization for the sake of the convenience of the audience, but, also, to make things easier for advertisers to use online data to target their ads to online users. However, there is no single database that can on its own identify the location of all users; there are instead many databases based on regions. As a result, "when the various databases are cross-referenced and analyzed by powerful computer algorithms, the geographical location of internet users can be determined with over 99 percent accuracy at the country level" (Goldsmith \& Wu, 2008, pp. 60-61). This is essentially what Houri developed with his IP-cross reference geolocation database technology, which could then be used to actively code for region blocks into a website, online advertisements, a unique blog post or many posts on a website, or individual episodes of for instance the popular British show, The Great British Bake Off (GBBO) while on the openly accessible Channel 4 website, to name a few examples. Furthermore, Houri used this information to prove that Yahoo was aware of the ability to filter their users and capability of blocking them out from U.S. Yahoo. Houri reported that Yahoo's U.S. website

\footnotetext{
${ }^{36}$ Although, media corporations do so when it is most convenient for them. The Icelandic example shows how a company was thinking in a global context, prioritizing English as a connecting, global language, as opposed to the more local aspect and importance of Icelandic as the everyday language of the audience.
} 
would greet French users with French-language advertisements, proving that Yahoo could identify where someone was accessing the website from, and then tailor the site to that region at least regarding advertisements. Despite his objections over the efficacy of geo-location filtering and the many ways to bypass it, one of the early fathers of the internet, Vinton Cerf, ${ }^{37}$ reported that Yahoo could, in fact, filter French users from U.S. sites using Houri's IP-identification technology and by self-reporting nationality (Greenberg, 2003). On May 22, 2000, a French judge determined that Yahoo auction sites were illegal and gave the company two months to arrange logistics to adhere to the ruling.

While Houri was not quite the first or only one to develop this technology, many go as far as to call him the father of modern online geoblocking due to his early patent on the technology and his seemingly being the first one to note on record that the internet could be regionally blocked. He lay the foundations for the more sophisticated system that currently exists whereby people are blocked from media content online, such as music, movies, TV, video games, books, and streaming platforms themselves based on IP address. The Yahoo vs. LICRA case gives insight and further understanding into both the corporate and political roots of geoblocking application: corporations work from home country locales and do want to expand globally, but choose to enact region blocking when it benefits them, either to protect their intellectual property, maximize profits, or to avoid legal issues in other countries they operate in. The case of Yahoo vs. LIVCRA, however, also presents something another interesting fact. The information technology company, Yahoo, was taking advantage of globalization of technology, and even admits as much in a manner, when they argued against the French government's authority to take

\footnotetext{
${ }^{37}$ Judge Gomez, who presided over the hearing in France, allowed for each party in the case to elect a panel of experts to verify the technical validity of blocking content on the internet by geo-location. In addition to Cerf from the U.S., the two other panelists included Francois Wallon from France and Ben Laurie from the U.K.
} 
Yahoo to court. Houri's own story as a businessman who constantly travels between Paris and New York speaks to the globalization of people both physically and virtually and the discrepancies between the two. While walking the streets of Paris or New York, he is met with shops, ads, media content relevant to the area, but when he was online, it still connected him to Paris while in New York (Goldsmith \& Wu, 2008). For Houri, rather than the convenience of access, his interest was the internet's lack of regional perception to ensure he was offered the most relevant localized content for where he was in the world. It is common practice for advertisers to take into consideration the region of circulation when purchasing ad spots in any medium. Houri's reasoning was that it should not be different on the internet and he did not think it needed to be. People are used to doing business a certain way and the internet was not about to stop that. Houri offered businesses a logical solution to what he saw as a consumer problem like he would for any business not online by presenting his geolocation technology. This lawsuit revealed early tensions at work between corporations and government regarding the internet (discussed in chapter three), but also gives insight into the interests of corporations that led to further justifications for geoblocking of media content at a global scale.

\section{Geoblocking Origins and Evolution: Copyright}

Corporate geoblocking of media content is primarily concerned with copyright.

Constructing a timeline of geoblocking in the media industry before its application as an online

tool in 2000 means examining the history of copyright. As stated by Sabrina Earle (2016),

The advancement of the internet has helped create and enhance a globalized economy in which ideas are shared and items sold almost instantaneously... On one hand, the internet has created a place where collaboration and exchange can be done easily on international scale. On the other hand, however, industries attempt to hinder the viewing of copyrighted materials based solely on geographical location of the potential viewer. (p. $1)$. 
The same media product developed for a local market is exported to other global markets within a specific sequential order: a hierarchy of flow. Examining this earlier evolution of geoblocking in the context of the adoption of modern-day geoblocking in 2000 provides further critical understanding of the disparity between the localized, nationally bound infrastructure managing copyright and media distribution and pre-internet globalized distribution that led to the evolution of geoblocking on the internet. Examining this history reveals a battle between the old versus the new, a system comprised of a complex network of copyright contracts pre-dating the internet that has a proven track record, but that does not quite fit the new digital era.

According to the World Intellectual Property Organization (WIPO), intellectual property (IP) "refers to the creations of the mind, such as inventions; literary and artistic works; designs; and symbols, names and images used in commerce" (2018). When someone creates something like a song or a television program, such as GBBO, it is intellectual property. IP law is meant to protect against infringement or unfair gain of another's creative content. According to WIPO (2018), "By striking the right balance between the interests of innovators and the wider public interest, the IP system aims to foster an environment in which creativity and innovation can flourish" (par. 2, lines 2-4). The idea is that people are more likely to innovate when there is recognition and reward for their creations, such as financial gain. This is important to note because it is this principle that has justified continued protection of IP for decades and continues to direct protections across any innovations in production, but especially distribution and exhibition. However, at this point, it bears mentioning that copyright law, especially in the U.S., does not protect all created goods, such as clothes, shoes, bags, etc. In an article in WIPO Magazine, John Zarocostas (2018) indicates that "copyright law does not seek to protect or create a monopoly 
over useful articles," such as clothes and shoes and other general goods ${ }^{38}$. Unlike the media industry, where media productions are considered unique creative outlets beyond general use and, therefore, protected under copyright law, the fashion industry must rely on other legal applications to protect their IP, such as patents and trademarks.

IP is protected by patents, trademarks, or copyrights ${ }^{39}$ with written laws. While the Yahoo and LICRA case, in which French citizens were legally not permitted to purchase Nazi memorabilia, suggests that geoblocking was adopted to enforce local laws in other countries, Houri testified to geoblocking being used in the corporate sector to focus advertising. However, when it comes to the media corporate system and media content online, one of the main reasons for geoblocking enforcement is copyright. Copyright is connected to the system of media content licensing where an IP license can be purchased from the copyright owner for distribution rights. Distribution used to consider the local region and audience where the IP would be released, but as markets opened up, especially abroad, even before the internet, questions about the copyright owner's rights in global distribution had to be addressed and with the advent of the internet, questions about digital copyright emerged (Yu, 2016).

While there is no existing international law protecting copyright, in 1886 The Berne Convention for the Protection of Literary and Artistic Works brought together several nations to

\footnotetext{
${ }^{38}$ Zarocstas indicates that designs that can be separated from the useful item qualify for copyright protection in the U.S. This is similar in Europe in general, however, Europe does offer more protections for garments and accessories through registered and unregistered Community design rights.

${ }^{39}$ According to WIPO: "a patent is an exclusive right granted for an invention, which is a product or a process that provides, in general, a new way of doing something, or offers a new technical solution to a problem. To get a patent, technical information about the invention must be disclosed to the public in a patent application." https://www.wipo.int/patents/en/. According to WIPO: A trademark is a sign capable of distinguishing the goods or services of one enterprise from those of other enterprises. Trademarks are protected by intellectual property rights." https://www.wipo.int/trademarks/en/. According to WIPO: “Copyright (or author's right) is a legal term used to describe the rights that creators have over their literary and artistic works. Works covered by copyright range from books, music, paintings, sculpture, and films, to computer programs, databases, advertisements, maps, and technical drawings." https://www.wipo.int/copyright/en/
} 
ratify guiding principles on copyright law at an international leve $\mathrm{l}^{40}$ (WIPO, 2018). Currently, 176 countries are included in the list of members. While the agreement exists in an attempt to streamline international copyright law, copyright is still not governed the same in every territory, but what it does mean is that even if there are differences in one territory, a member state must honor the copyright of content from another member's territory and try to balance their local territorial law with that of the other. This system has been in place since the late $19^{\text {th }}$ century, and not even the internet will change the general premise of the system. The Berne Convention was ratified in 1886 and has only been revised eight times since (KEI Research Note, 2017). As such, a system of agreements about where and when media IP could flow was established and has been held firmly in place.

\section{Geoblocking Origins and Evolution: Region Blocking of DVDs}

When it comes to commercial media content, historically, permissions come from a network of complex agreements not only between corporations but between corporations and different governments, even between governments themselves. Together, an intricate model of copyright-based distribution was developed allowing media to flow through an ordered, linear, geographic system. In Amanda Lotz's (2017) Portals: A Treatise on internet-Distributed Television, Lotz indicates that television traditionally relied on a system of linearity, not only in terms of what kind of content was scheduled when, but even where to include a content's flow from broadcast to cable, to pay-for TV (like pay-per-view), to VHS, to DVD, to Blu-ray, and, even, eventually to streaming-video-on-demand (SVOD). However, that is where things begin to get complex for the linear media model, which I will expand upon later.

\footnotetext{
${ }^{40} \mathrm{https}: / /$ www.wipo.int/treaties/en/ip/berne/summary_berne.html
} 
Distribution does not only mean hardware and software, but also time and place - an existing, mapped region. In addition to Lotz's (2017) application of linearity of platform, there is also geography. As the previous section on copyright alludes to, content is not dispersed into the world at once everywhere. The world is split into geographical market regions and timetables that determines how media flows across national borders (the order of copyright-based distribution) - what goes where and when, if at all (Lobato, 2016; 2019). What Lotz (2017) describes as linearity in traditional TV connects to the linear method of flow of copyrighted media content concept and practice called windowing - delay periods not only between media content from one place to another, but also, delay periods between releases in format, such as when a film in theaters can be released to DVD or broadcast TV within the same regional market, let alone other regional markets (Nelson, 2014). Traditionally, the television and film industry practice the delayed or "window" release system in which releases are staggered over time from one territory to the next; there would usually be a delay between the release of a film in theater to VHS (later DVD and now digital distribution) (Epstein, 2005). This system became prominent in the 1980s to avoid self-cannibalization of content. New films could be released in theaters without competition from other popular films being released on VHS/DVD at the same time, and the system was expanded to account for competition from pay-per-view and television releases (Epstein, 2005). The delay system is also applied to releases of films and television programs to other countries requiring first obtaining legal rights to distribution of content in another country (i.e., market region). A production company in the U.S., such as the Disney corporation, can either buy up corporate holdings in another market region and use those as their distribution centers, or they can sell the licensing rights to a local distributor in that market. As Elisa Nelson (2014) puts it, "The goals of distribution in the film industry are generally to 
maximize value and revenue streams over the life of a property," reinforcing again a key element leading to continued adaption of geoblocking (p. 64). The geographically based distribution system was developed to maintain control of copyright and expand profits through the delay window system, which not only expanded an IP across regions, but across different forms of television and film distribution systems.

The territorially-based system of copyrighted media content is revealed when examining the DVD region code system - the story of territorializing that was supposed to be the first global playback medium - foreshadowed future concerns brought about by the internet before it was even developed. Global media scholar Evan Elkins (2019) states that "as the first widespread, globally successful digital home video platform, the DVD offered both opportunities and potential problems for the film and television industry" (p. 17). DVDs were more portable than VHS tapes, relatively affordable, offered more high-definition picture quality than VHS, and required players that were also more portable and less bulky than VHS players. Elkins states that DVDs offered the media industry and manufacturers an "opportunity to boost home video rentals and sales and usher global media industries into a long-promised digital age" (p. 17). However, DVDs were easily copied and their portability in fact made it easier to move illegally copied physical copies. Not only that, but the digital content could be copied from the disc and uploaded to the internet and then shared across peer-to-peer networks across the globe all at the same time, which “threatened to destroy the film and television industries' geographically segmented release schedules" (p. 17).

The film industry put pressure on electronics manufacturers (such as RCA, Sony, etc.) to implement digital rights management tools like Regional Playback Control (RPC) where players and discs are encoded with a "region code" (Elkins, 2019, p. 17). The world is divided into 
regional codes, which connects not only to the DVD, but the actual player of the DVD as well. Elkins (2019) reports that allocating countries to regions created much controversy, and for good reason. As Elkins states, “A territory’s placement within one of the hierarchically ordered regions was a statement about geocultural capital in the global DVD market," as established by a small group of media executives (p. 42). Region codes include: Region 1 (USA and Canada); Region 2 (Europe, Japan, South Africa, and Middle East, and Greenland); Region 3 (parts of South East Asia, South Korea, Taiwan, and Hong Kong); Region 4 (Australia, New Zealand, and Latin America - including Mexico); Region 5 (Eastern Europe, Russia, India, and the rest of Africa); Region 6 (China); Region 7 (Special Use code); Region 8 (Transport services such as cruise ships and airlines); and Region 0 or the "Universal" or "Regional All" code (Silva, 2020). If someone owns a DVD player bought in the U.S., then that player is a Region 1 coded device and is coded to play only Region 1 discs.

Since a universal code exists, the question then begs why can all media not be allocated to Region 0 ? Region 0 exists as a concession to software and hardware manufacturers and media businesses who felt the region code system was more of a burden and hindered their ability to expand their IP (Elkins, 2019). Elkins states this issue "indicates an ongoing tension between global fluidity and intellectual property control” (p. 34). In fact, region codes were not even necessary. They exist because they were explicitly designed and implemented into DVD standards, but people, "working for a cluster of major media corporations with specific, profitdriven motives built the entire technology" (Elkins, 2019, p. 34). Furthermore, media industry leaders persuaded governments to not only support region coding but to develop supporting legal frameworks that would enforce compliance from other industry professionals and the audience. While WIPO passed an international treaty on copyright in 1996, the U.S. passed the Digital 
Millennium Copyright Act of 1998 (DMCA) to comply. The DMCA created digital rights management (DRM) justifications to not only criminalized the unauthorized copying and distribution of a media product, but furthermore criminalized the distribution of technology used to circumvent copyright, but also circumvented protections on copyrighted productions whether any copying takes place or not (17 U.S.C $\left.\$ 506^{41}\right)$. DRM comes in many forms, and media productions have seen a vast evolution from RPC used to protect against illicit imports to intricate coding that controls how the audience accesses content, how many times the viewer can access that content, and where they can access that content. Geoblocking is a DRM technology for online media content. The development of the DVD region code system and the DMCA both have far reaching effects of control on new media companies like Netflix and the internet.

The copyright-distribution system that not only dictated the flow of analog and digital media distribution through region lockouts had been perfectly formulated and tested and had proven profitable for decades. At this juncture the internet enters the picture threatening the existing structure guarding intellectual property and profit margins. The top-down infrastructure of protections and control had long been in place to ensure law and order at economic, political, and even cultural levels with clear and protected borders that officiated over physical products. Physical borders help to enforce political and economic law and order. The internet, while opening avenues of business such as digital streaming and social media, has complicated old notions of distribution, making sure people access the agreed-upon specific content through the agreed-upon avenues of distribution at an agreed-upon time in an agreed-upon region that a distributor is paying for in licensing and/or franchise rights fees. The challenge then became how to reconcile a system that worked within physical parameters with a challenge such as the

\footnotetext{
${ }^{41} \mathrm{https}: / /$ www.govinfo.gov/content/pkg/USCODE-2010-title17/html/USCODE-2010-title17-chap5-sec506.htm
} 
internet with its accompanying host of other technological advancements. Incidentally, the Yahoo vs. LICRA case gave media executives that very answer. The geoblocking applications that Yahoo was court ordered to apply to ensure they were following French territorial law from offline to online was compatible with the very DVD region code and geographically based copyright distribution and protections model that was established well before the internet to eventually slow down media companies like Netflix who were starting to have a drastic effect on pre-established media systems and profits.

\section{The Netflix Revolution}

A deeper understanding of the history of copyright of media content both before and after digitalization ${ }^{42}$ and the connected DVD region code system ${ }^{43}$ helps one further navigate a critical understanding of globalization, the media market, and geoblocking when more deeply examining how Netflix disrupted the system to create its own globally enclosed system, and how it was eventually reined in from its expansion by legacy media companies to revert and respect the traditional offline systems in place before the internet. Examining the history of Netflix is not to focus so much on Netflix itself per se. This chapter (and dissertation) is not intended to be overtly critical of Netflix, although one cannot avoid the problematics of a corporate empire, which is discussed in more depth in chapter three. Rather, the intent is to use Netflix as a point of comparison to legacy media like Disney to illustrate tensions that geoblocking negotiates between the offline and the online for these different corporations. For more in-depth critical analysis on Netflix as a streaming platform, there are several essays included in works such as

\footnotetext{
${ }^{42}$ The "before" being laying the groundwork and established standards by which media advancements in production and distribution would be forced to adapt to, and not the other way around.

${ }^{43}$ Which illustrates the way new technologies are bent to serve predetermined infrastructures of copyright.
} 
The Age of Netflix: Critical Essays on Streaming Media, Digital Delivery, and Instant Access (Barker \& Wiatrowski, 2017). This chapter is merely utilizing Netflix's rise as a new media company as a lens through which to examine the tenuous relationship between media corporations and globalization and the internet. While media corporations benefit from the internet, it also presents them with challenges as well only insomuch as it made distribution global and dissolved delay windows unless otherwise opposed. This case study of Netflix's rise reveals how the above processes of copyright and region codes, that were already in place prior to the advent of the internet, were implemented to provide a manageable timetable of adaptive change for legacy media like Disney in order to catch up to a digital media environment and make it resemble and adhere to the principles of respecting regional media flows while still allowing them to take advantage of an online media market.

First, we must examine how Netflix became such an industry disruptor. Prior to its perceived worldwide takeover, Netflix was a rebel in the TV and film home rental industry, but one that was underestimated and not taken seriously. Where companies like Blockbuster and Hollywood Video were thriving with VHS and DVD rentals in-store, co-founders Reed Hastings and software executive Marc Randolph developed Netflix as a mail-order DVD rental store with a vision of an online movie rental company. When Netflix came to Blockbuster, offering themselves up for sale, not only did Blockbuster refuse them once, but twice (McDonald \& Smith-Rowsey, 2018). It did not help Netflix that a few years after their start up in 1997, Silicon Valley's high on the dotcom boom was brought crashing down during the "dotcom bust" in 2000, when many online companies went under. This moment seemed to indicate that online rental and sales options for industries, like film media, were not feasible, especially after Hollywood Video spent a hundred million dollars on Reel.com - a precursor to Netflix with its 
own recommendations system, "The Reel Genius," to combine with their VHS home-delivery (McDonald \& Smith-Rowsey, 2018). The operation proved logistically too expensive for Hollywood Video. As such, companies like Blockbuster and Hollywood Video and other legacy media companies like Disney and cable channels like HBO did not consider Netflix a serious threat when pitted against their years of established systems of media production and distribution order.

Netflix rented out only DVDs, the newest media format at that time. Compared to the size and weight of a VHS, discs were much cheaper to store and mail. In 1999, Netflix adopted its subscription-only service promising, for the first time, no late fees, and unlimited DVD rentals delivered directly to consumers (Netflix, 2020). What was interesting was how Netflix was using the media format that was specifically designed with region codes in order to prevent global distribution to operate a decentralized method of distribution, mail. At this point, the only disruptive aspect of Netflix was the online ordering system to obtain DVDs. Netflix did not yet challenge the precious delay window and regional order of distribution until it became a fully operational streaming service.

Companies like Hollywood Video and Blockbuster who had not utilized the internet as a method of distribution seriously enough ended up having to reactively adapt as Netflix suddenly started to gain more popularity for its online subscription model. Predictably, they adapted too slowly, were forced to play catch up to Netflix who had introduced consumers to an entirely new, convenient way of renting their content with the result that while Hollywood Video and Blockbuster eventually disappeared, Netflix was thriving, not only expanding its services from DVDs, but to offering the subscription streaming on one's personal computer or laptop in 2007. 
According to media historians and film scholars Kevin McDonald and Daniel SmithRowsey (2018), while Netflix caused a stir in the traditional model of video-on-demand home rental system in its focus on DVDs, home delivery, online subscription, no late fees, and eventual online streaming service, its most disruptive effect was on the traditional window delay release system of films and TV shows:

To the extent that Netflix has contributed to changes in existing distribution and exhibition models - in many ways realizing long-held predictions of a future in which all media is available on-demand across multiple platforms - the major media conglomerates have been less appreciative of its aptitude for technological innovation, often viewing Netflix more as a disruptive interloper than as a savvy competitor. If there is a singular Netflix effect, it may simply be that technology and entertainment are merging at an accelerating rate and seriously impacting the business and economics of mass media (McDonald \& Smith-Rowsey, 2019, p. 2).

In February 2013, not only did Netflix release its first original production, House of Cards (2013-2018), but it released the entire 13-episode season in one day, introducing the world to the phenomenon of binge-watching. ${ }^{44}$ This not only went against the grain of how media was historically distributed, but against the very way consumers had been taught and made used to consume TV media. The show was not only made available for online streaming, but for DVD rental as well, all on the same day. Netflix's experimentation with "day-and-date releases - the simultaneous release of a film across different exhibition platforms including video-on-demand" -left the "traditional gatekeepers of the theatrical window" furious (McDonald \& Smith-Rowsey, 2018, p. 4). Netflix was moving against a system that had been upheld for decades, as detailed earlier in this chapter. The way Netflix showed no fear or even concern over new media was in stark contrast to the way legacy media companies operated.

\footnotetext{
${ }^{44}$ The practice of watching several episodes of a television program in succession after another in a short period of time.
} 
However, one could argue that because the internet came before Netflix, it makes sense that Hastings and Rudolph were not as anxious or unsure about the internet the way legacy media were. They were operating in a culture that was pro-internet as young people working in Silicon Valley and were not trying to fit existing infrastructure to the internet rather finding ways to situate the internet onto the physical world. In comparison, Disney is 97 years old. ${ }^{45}$ Disney started as an American company that did not even reorganize its own company as a single, global giant until 1996 (Belkhyr, 2006). In Disney Animation: Global Diffusion and Local Appropriation of Culture (2012), Souad Belkhry analyzes the power of Disney as a media giant that hoards cultural capital through the production of its animated films and TV shows. While Disney had films and television distributed to other countries, Belkhry (2012) notes that Disney did not truly grow as a global media corporation until 1996 when Disney expanded its familyorientated Disney Channel to markets outside of the U.S., such as in the Arab world. Since then, Disney has invested into growing its brand into other regional markets, but it, along with other legacy media, were very wary of the internet, although not against the internet as a whole.

The main gatekeepers of traditional media are known as the Big Five: Disney (now owning assets of Fox), Comcast (NBC Universal), Warner Media (owning HBO and AT\&T), Viacom/Paramount, and Sony. These media conglomerates have always had a contentious relationship with Netflix, as it spoiled their own plans for digital media with their focus on highdefinition physical media formats (such as Blu-Ray and now $4 \mathrm{~K}$ ) and plans to develop their own online platforms. McDonald and Smith-Rowsey (2018) note that the big media corporations' "television networks were wary of new media in general - a broad distinction that included video games, interactive technologies, and web-based competitors like Netflix - as they struggled with

\footnotetext{
${ }^{45}$ The Walt Disney Corporation was founded October 16, 1923.
} 
declining ratings and fragmenting audiences" in a very similar way that the music industry was wary of digital technologies and the internet as well (p. 2). HBO was ahead of the pack releasing HBO on Demand, a companion subscription video-on-demand service for subscribers to the cable channel, in 2001; HBO then launched their streaming video service, HBO GO in 2010, which did require a subscriber to still be an HBO cable channel subscriber, however (Nye, 2001; Szalai, 2010); HBO did not address the "cord cutters" and "cord nevers" who were subscribing to Netflix or Hulu until 2015 when it finally launched an OTT subscription service, HBO Now, that did not require a subscription to the cable channel. (Thompson, 2014). ${ }^{46}$ Streaming service Hulu launched publicly in 2008 but started in 2007 as a venture into digital streaming as a partnership between NBC Universal, News Corp, and Disney (Moore, 2019). However, while both corporations currently still cooperate in owning and running Hulu, both have also launched their own, exclusive, SVOD platforms. Disney launched its own standalone SVOD platform, Disney Plus, in 2019, and NBC Universal launched, Peacock TV, in 2020 (Solsman \& Sorrentino, 2020; Solsman, 2020). It took legacy media corporations over 20 years to launch their streaming platforms. However, they have now managed to become real competitors to what seemed like years of unparalleled and unstoppable growth of Netflix. To do so necessitated changing the traditional way of doing their business. Many executives in the boardroom who developed treaties and agreements on copyright-based distribution, delay windows, and regional DVD lock-out systems are those who served legacy media companies like Disney, NBC Universal, cable channel executives, etc. Controlling release dates and platforms has always been key to maximizing profits, but also to respecting a global media infrastructure system that has

\footnotetext{
${ }^{46}$ Currently, HBO is consolidating its services and HBO Go is now deprecated and phased out so HBO can focus on their full service as HBO Max causing controversy with previously sponsored distributors of HBO content, such as Amazon Prime (Flint \& Rizzo, 2020)
} 
been in place for decades - a system that worked, at least for the Big 5. Even when Netflix pushed the boundaries of the system, national boundaries pushed back. This is the battle that is continuously waged between offline and online media that corporations both of old and new media are constantly battling to ensure market dominance either in their regions or globally.

\section{Global Expansion: Netflix vs. Legacy Media}

Netflix expanded from TV program release dates to films, narrowing the release window for theatrical releases, streaming films while they were in theater or releasing very shortly after theatrical release when the norm dictated several months. After it was first released in China on February 19, 2016, Crouching Tiger, Hidden Dragon II: The Green Destiny, the sequel to Crouching Tiger, Hidden Dragon (released in 2000), was released simultaneously in select U.S. IMAX theaters and on Netflix on the same day on February 26, 2016 as part of a production deal. However, the U.S. IMAX releases came with tremendous controversy with Regal Cinemas, Cinemark, and AMC theaters refusing to show the film on their IMAX screens if the film was streaming on Netflix on the same day (Solsman, 2016). Eventually, AMC theaters relented and permitted the film to appear on less than 10 screens of its 153 IMAX screens available. Netflix received similar pushback when its film Okja (2017), directed by famous South Korean director Bong Joon-ho, was not permitted cinema screenings on 93\% of South Korean cinema screens. Netflix was shut out by the top three theater largest chains (CJ CGV, Lotte Cinema, and Megabox) amid its planned simultaneous release of the film on its streaming platform as well as in cinema (Kil, 2017).

In 2017, the South Korean film industry practiced a delay window of at least three weeks from the time a film premieres in cinema to when it can be made available for streaming. 
According to CJ CGV, "Netflix's simultaneous opening policy disturbs the distribution ecosystem in South Korea" (Kil, 2017, par. 2, lines 4-5). It thereby could greatly disrupt the potential profit margin of other films. There is a fear that moviegoers would rather spend time streaming content from home, especially when a monthly subscription can potentially be cheaper than a trip to the movie theater especially for families. The entire process of staggered delay windows and linear TV and film was meant to avoid this very issue. While Disney and other legacy media have been willing to respect this system, Netflix was an internet-first company. The only reason it expanded to theater releases was because of the power that the film awards system still placed on the reputation of an IP. Netflix was forced to descend from their films' digital perch to be considered for awards like the Oscars.

Netflix's Okja was not well received at the world-renowned French film festival, Cannes Film Festival, where French theater owners claimed that only films that are debuted in French cinemas should be permitted in the festival for judging. Netflix only had plans to release the film in South Korean theaters, as the film was a South Korean/American production. However, unlike South Korea, which has a contractual three-week delay window between a film releasing in theaters to its release over streaming services, France has a three-year delay window mandated by law (Kil, 2017). ${ }^{47}$ These national regulations, as constituted by corporations and sometimes supported by governments, work to continuously control expansions of other companies or changes that could affect existing (profitable) systems.

\footnotetext{
${ }^{47}$ French media companies came together in 2018 to discuss reducing release delay windows in the media chronology system. French law on media chronology was last changed over nine years ago. Compared to other countries like the U.S. and the U.K., which now allow for shorter release of theatrical film to streaming service, France still has a very strict hierarchy of release from film: 1) after four months, a film can be released to DVD, video, and pay video and On Demand; 2) after 10 months, on pay TV channels (commonly, first on French pay TV channels); 3) after 22 months, broadcast to free TV channels; and 4) after 36 months, film can move to streaming services. The newest reform in September 2018 is not any less complicated and does not necessarily reduce the delay window either (for more see Scott, 2018).
} 
It is not that these companies are completely averse to online content delivery. As stated earlier, companies thrive on expansion, which does mean accepting new technologies, including the internet, so therefore, they are not principally against change. They are however very careful with how much and how fast change happens so that market share and profit margins are not negatively affected. Regarding change, the evolution to streaming was inevitable. The infamous music peer-to-peer website, Napster, had already proved back in 1999 that consumers were looking for media content online. Netflix merely followed in the footsteps of Napster, but where it failed, Netflix succeeded and took advantage of opportunities afforded to it by the internet. However, Netflix is not the epitome of a total new media success story. For instance, they are still forced to show some films in theaters to be considered for an award, which then also intrinsically tie them to delay window laws in different countries. Legacy media has shown that its strength lies in the system they helped develop with delayed window distributions, region codes, and copyright protections.

While Netflix has been slightly tamed by the forces of pre-existing copyright licensing of media content IP and distribution controversies surrounding geographic boundaries, Netflix has been working to push boundaries in negotiating legacy media infrastructure. This negotiation illustrates where the internet has allowed for innovative and porous media distribution at a global level, however, it also reveals the strong hold that geographical boundaries and pre-existing media systems have in being able to control how much flow can get past and how much cannot and must remain behind geoblocks to maintain regional zones and their associated audiences separate.

HBO - whether HBO Go, Now, or now its streaming platform rebrand, HBO Max - is not available outside of the U.S., nor is CBS All Access or NBC's Peacock. While Disney Plus 
was first available in the U.S. in November 2019, it launched in several other countries shortly after. Disney Plus increased from 27 countries to 30 by November 2020 (Chen, Cohen, \& Webb, 2020; Trenholm, 2020). While Amazon Prime Video boasts it is available in over 200 countries and territories, Netflix is considered more popular for a special reason; it is still considered the popular choice amongst streaming platforms not only because it is available in 190 countries, but for what it does with its library and original content in relation to those countries.

According to a WhistleOut report, while Amazon produces 91 original TV shows, HBO Max 14, Hulu 55, CBS All Access 28, Peacock 34, and even Apple TV 26, Netflix produces 461 original TV programs (in Griffith, 2020). Unlike the other streaming services, Netflix original programming also has a higher global reach at a single point of release with many Netflix "Originals" - programs it either commissions for production or funds with rights to first and global digital distribution - released across all Netflix libraries (up to all 190 regions) at the same time. Motivated by audience pressure for more content, Netflix has expanded their originals catalog, which gives it more control over first online distribution rights across any of their Netflix libraries - in so much as content does not prove a political threat to a government or culturally incentive to an audience. While Disney has been producing more original content for streaming, Disney only recently released its popular The Mandalorian (2019) across all its libraries in its second season. Disney, CBS, NBC, and HBO are still held accountable by preexisting copyright license contracts, which they helped develop and support with distribution companies of other countries outside of the U.S. After all, it is some of these foreign distributors who helped companies like Disney get footholds at all in their markets. While these companies, especially Disney, are slowly catching up to Netflix, they are doing it in such a way that still honors their decades-old systems with minimal change to anyone's overall profit margins. 
Netflix must work within this system as it works to expand globally and negotiate the IP offerings for its content libraries. Expanding its service to other countries means expanding its content distribution reach, making it more appealing to a global audience. When Netflix purchases the rights to a film or TV show, it seeks to purchase full global digital rights and the simultaneous streaming release to fit its vision of a global library - a global library of media content where audiences are not blocked by their geographic location, but blocked by the subscription pay wall; so, still a global library that is blocked, just not by geography. However, film and television media have been licensed separately not only by medium platforms (big screen versus small, straight to video, added DVD release, rent, or buy options, streaming platforms), but by country. When Netflix started operating it had to work within this system of distribution rights and licenses that dictated regional releases by geographic area at certain times. Even as Netflix pushed the boundaries of this system, it must still navigate this system to operate. Even further, if Netflix even succeeds in erasing geographic boundaries to open a global content library, that does not necessarily erase political boundaries of governments and the cultural boundaries of the audience - expectations of acceptable media content and languages they want to be able to access.

Beyond even competing with other media corporations, concerns over government oversight, and what the audience desires, rights holders to the original IP are sometimes wary of signing an exclusive, global digital distribution contract with Netflix since this might hurt their ability to optimize value through exclusive delay windows and other regional markets their IP could flow through. Many rights holders could profit off a first-time theatrical release and then again through streaming, but Netflix's operation threatens the possible recoup costs from any box office sales asking for a simultaneous release. Netflix has been able to somewhat push 
forward in this arena in film, but it has been more difficult to do so in television, since television media has strict structural mandates that have been in place for decades and are not as flexible as film since some countries may have several broadcasting outlets and systems long in place. The dream of global media may not be realized with the constant tensions existing between the internet and traditional legacy media corporations who use the systems of operations they created to continuously subsume any radical potential from the internet into a form that they can use and control for their personal corporate goals.

\section{Conclusion}

While Netflix was a trailblazer of digital content and globalizing online streaming, it has been subsumed into a controlled system that now sees its expansion limited as it increasingly seeks to expand its service to more countries and territories with little to no barriers while it maintains its own closed subscriber system. The traditional licensing and distribution system in combination with existing regional market system forced Netflix to encode geoblocking and other regional lockouts that will also ensure that Netflix maintains regional Netflix libraries. While Netflix tries to push against this by forcing rights holders looking to work with Netflix to sign exclusive global digital distribution contracts, the existing delay window system for theatrical releases and regional markets that could help maximize profits - whereas Netflix offers

only one price for a single, global drop - still proves strong enough to pull some creators away from Netflix and even into contracts with legacy media companies.

While the internet was Netflix's greatest asset to grow rapidly and faster than any other media company has, offline systems of media infrastructure and operations have slowed its growth and overall dominance as legacy media wrest back rates of change, allowing them the 
time to adapt, even though Netflix has forced them to adapt more quickly than planned. Systems that lead to the requirement of geoblocking enforcement, however, will continue to prevent Netflix from attaining the status of a truly global content library of any content.

As much as Netflix sells itself as a universal content access library, its library is cut and segmented into the boundaries that demarcate the physical spaces of geographic regional markets, with its members incapable of crossing those boundaries even as they all pay for the single service: Netflix streaming. ${ }^{48}$ As much as Netflix would like to be Napster ' $99^{49}$ - a universal digital library of music from around the world where anyone could access the vast offerings from anywhere in the world - having started as a legal corporation purchasing distribution rights for DVDs, Netflix face too many challenges and obstacles from existing media systems in other regional markets in the expansion of their online streaming service to do so. While Netflix was an initial disruptor, it can only disrupt so much at a time with the existing and cemented offline global media infrastructure still managing to dictate online evolution to a large extent.

While Netflix's digital technological and business model advancements did have significant effects and development in the physical world of media business, the physical still very much constrain Netflix. Geoblocking plays an important part in this regard as an online tool that upholds physical regulations and space of media infrastructures that has restricted Netflix from becoming too much of a disrupter too fast in the end - allowing the traditional media giants

\footnotetext{
${ }^{48}$ Even as Netflix subscribers can now move from one country to the next and open their account, the content library will change depending on the country.

${ }^{49}$ In June 1999, the vastly popular Napster, a peer-to-peer (P2) audio file sharing software where users downloaded music for free and illegally, pioneered by teenagers Shawn Fanning and Sean Parker, became the bane of the music industry, undermining its very foundations, with lasting reverberations of effects to the film and television industry as well, as consumers found new ways to distribute copyrighted content online. By 2000, Napster had 20 million users and four million songs in circulation across its users and at its peak, 80 million users (Lamont, 2013; Gowan, 2002). Not one of the downloads compensated royalties returning to the artists and producers of the songs, the rights holders. The music industry went after Napster and eventually managed to shut it down.
} 
to eventually catch up and take back some control - and possibly again dominate in the internet space that once seemed to only belong to the likes of Netflix. So, what does the future hold for not only Netflix, but the larger online media market? Will the erosion of time slots and delay windows and expansion of content beyond national markets equate to less geoblocking? Probably not. If the current copyright system ruled by the country-of-origin principle that was designed before the internet continues to be extended to the internet, then geoblocking will always be justified by media corporations who are either the rights holders or have purchased the rights to distribution from the rights holders. Delay windows may reduce, but they will not be erased due to the necessity to adhere to copyright. 


\section{Chapter 3: Geoblocking and Governments}

This dissertation examines the tensions that exists between economic, political, and social systems held together by physical and recognized borders and their utilization of geoblocking in response to the process of globalization that, through the internet, is threatening to dissolve of the solid, physical, territorial borders. Chapter two discussed the media corporate system protects its creative work with copyright that is legally enforced by national laws and how they utilize the national boundaries to fragment regional markets allowing for the best maximization of the life of a media artifact with staggered release window media flows. While chapter two alludes to aspects of government and geoblocking when examining corporations, such as the case of Yahoo vs LICRA, this chapter focuses more critically on the examination of the relationship between geoblocking and governments.

This chapter examines the motivations that lead governments to justify their use of geoblocking. It focuses on the political application of geoblocking by assessing the frictions between the corporate and government sectors from the perspective of government motivations. While there is also friction between the audience and governments, this aspect, along with other connections between the audience and corporations, are examined in chapter four. In this chapter, the focus is predominantly on why and how governments justify geoblocking. This chapter further illustrates that territorial political infrastructure works as a tool to help governments extend pre-existing territorial, nationally based law and order and how they even expand those controls to the internet. This chapter argues that geoblocking is a digital tool that governments appropriated from the corporate sector to actively use in the enterprise of government control of media content online to expand applications of law and order to their people, media corporations, and other governments. 
This chapter also examines how, while governments are not averse to investment from digital global media companies, they are anxious about the influence of these companies, whose offerings of media content from other countries may challenge the societal and legal norms established within their national borders. This chapter further critically analyzed the tension between government and the internet by examining the ways in which governments controlled entry of media content before the internet and the challenges in media flows, they are presented with currently.

This chapter focuses on examining the complicated aspects associated with empire (governments) and geoblocking through an analysis of the case of one of the few countries where Netflix is not available: China. While China may still be considered a "Third World" country, as Marko Ampuja, Juha Koivisto, and Kaarle Nordenstreng (2020) note, it has been added to the list of influential empires, which include the U.S., the U.K., China, India, South Korea, and Russia. China is one of the largest growing markets globally and, although claiming to still be a socialist country, is opening its borders more to capitalist economic investments that make China not only an importer of media content, but an exporter as well. However, unlike the U.S., the government of China has unique laws that dictate how foreign media corporations are permitted to do business in and with China that illustrates interesting ways in which the Chinese government has maintained more control over media industries and other governments. This case study is an interesting lens through which to examine globalization, digital media flows, nationality, cultural capital, and the management of official and illicit media flows both on and off the internet by both media corporations and governments that gives further critical insight into how governments have themselves adapted to increased digital connections of their people and the growing porousness of their digital borders versus their territorial ones. The case study also 
serves to examine the different methods of blockages and flows of information governments use in attempting to stem the rate of evolution from the digital to the real in continuing to enforce domestic laws and regulations in a continuously hyper-globalized world, such as the relationship between geoblocking, censorship, and surveillance, and managing control of power between government, corporations, and citizens.

\section{Geoblocking and Media-Cultural Imperialism}

It is relevant to discuss media-cultural imperialism in connection with government justifications of geoblocking media- their online border management of the flows of online media content and, therefore, the flow of foreign influence. Although the focus is here on the history and formulations of media-cultural imperialism, this chapter is not a study of mediacultural imperialism per se. The perspective here is that the fear of media-cultural imperialism is still very much in existence. Media-cultural imperialism becomes part of the process of globalization, and, as such, governments have their motivations for how they negotiate the benefits and the costs of these processes to their overall control and management of their empires.

Referring to the case of Yahoo vs LICRA discussed in the previous chapter, in this chapter the focus more on the other aspect of the case, specifically on the relationship between geoblocking and governments. This case illustrated how governments has the power to dictate what the internet should be: an extension of the nation-state they govern. In the Yahoo vs LICRA case Yahoo had to uphold French law forbidding the sale of Nazi memorabilia by Yahoo's auction sites not even based in France. The case revealed how the use of geoblocking itself could become mandated by national law, in this case French law, which corporations had to abide by. 
It showed how governments has the power to dictate to corporations what the internet should be and how business on the internet internationally should by conducted. Yahoo disagreed with the French court's ruling that the government of France had jurisdiction over the internet, a seemingly boundless and borderless space. Although media corporations have the protection of governments through various laws, Yahoo, however, is not a media corporation; it is an information technology company that does not specialize in media production. Media corporations rely quite heavily on governments to help them protect their ability to maximize profits through enaction of copyright laws as described in chapter two, and legacy media corporations rely on the territorialized boundaries of nation states to create regional markets to stagger media flows. There is a symbiotic relationship between media corporations and governments. Media corporations gain legitimized legal protections from governments of their intellectual property to ensure maximization of profits. Media corporations, in turn, "contribute to imperial projects of major states that aim to increase their geopolitical power vis-à-vis other states" (Ampuja et al., 2020, p. 31).

However, as both Elkins (2019) and Lobato (2019) note, governments are also anxious over the flow of cultural capital of companies from different regions - there is an anxiety, especially among developing countries about media and cultural imperialism. Media and cultural imperialism are closely connected concepts and some scholars use the terms interchangeably (Boyd-Barrett \& Mirrlees, 2020). Media and cultural imperialism can be used "to simply acknowledge that the media corporations (e.g., TV broadcasters) and media products (e.g., news stories and TV shows) of some countries were significant vehicles for economic and cultural influence in other countries" (Boyd-Barrett \& Mirrlees, 2020, p. 1). The countries that were considered significant have historically actually been focused predominantly on the U.S. During 
the 1960s and 1970s, media imperialism mainly referred to U.S. media power and influence and applied to "studies of the considerable influence of U.S.-based media corporations in and on the media systems and culture of other countries"50 (Boyd-Barrett \& Mirrlees, 2020, p. 1).

Furthermore, the term cultural imperialism became preferred over the last four decades as the study expanded to include aspects beyond the "media industries and products to encompass economic models, patterns of governance, educational systems, languages, ideas, norms, and values" (Boyd-Barrett \& Mirrlees, 2020, p. 1).

In "Media Imperialism: Continuity and Change", Oliver Boyd-Barrett and Tanner Mirrlees (2020) indicate that cultural imperialism expanded from the 1980s up to the 2000s to include the U.S. economic and military power in addition to its media power. Also, the authors note other "empires" have been included in the study of cultural imperialism, such as historically old empires in Britain, France, and Russia, but also "once subalternized or peripheral countries" (i.e., "Third World"), such as China, India, Brazil, and South Korea. In "Historicizing and Theorizing Media and Cultural Imperialism”, Ampuja, Koivisto, and Nordenstreng (2020) indicate that historically empires have been associated with the political system of colonialism where colonies would be governed by an imperial center - the Spanish empire, for example, that utilized a system of slavery, military, and political power to extricate wealth from its subject territories. However, the authors note that systems of direct imperial rule dissolved for the most part during the twenty years following the end of World War II in an era of decolonization. However, decolonization did not end imperialism - while a specific form of imperialism ended, another form evolved.

\footnotetext{
${ }^{50}$ This was mainly due to the "changing contours of world political economy following World War II" where the U.S. took control as the major economic and political force among industrial nations (i.e., "First World"), and became a leader of foreign trade and investment, thereby spurring on the expansion of the international capitalist economy. (Ampuja et al., 2020, p. 31)
} 
The idea behind colonies becoming free, independent nations and participating in modernization was that each country would benefit equally - countries were meant to have broken free from the unequal distribution and control of wealth and advances in technology, communication, etc. in the new global capitalistic system. However, in 1969, noted media critic and sociologist, Herbert Schiller, theorized that, in fact, the post-World War II industrial and international capitalistic system was characterized as a "power pyramid" (in Ampuja et al., 2020, p. 32). The power pyramid concept states that the international capitalistic system was a hierarchical system consisting of the U.S. at the top and exploited developing countries at the bottom. Schiller indicated that the "American expansionism" - the global extension of its commerce and values systems - was supported by its communication system. The U.S., for example, would offer conditional aid to developing countries and Western European countries healing from the war; if these developing and other countries adjusted policies that would open their borders to U.S. media exports, they could expect aid from the U.S. (Ampuja et al., 2020). The concept of American media and products extending into other countries became popularized as "Americanization."

However, there is criticism of this view of media imperialism, especially today where much has changed since the end of World War II. One of the main points of concern over the above is that media imperialism cannot be reduced to simply "Americanization." This reduction relies on the notion that America is not just one of the dominant superpowers, but the dominant superpower. This notion is already contradicted in this study in the choice of case study discussed later in this chapter - China, one of the largest continuing "developing"51 countries in the world, will be examined (Daye, 2020). As pointed out earlier, empires, and what we

\footnotetext{
51 The U.S. actually removed China from its list of developing countries in February 2020 removing favorable conditions that the U.S. applies to businesses from developing countries (Daye, 2020).
} 
understand with the concept of an empire, have expanded. There are now several empires across the globe, some with more power than others. However, empires now do not just consist of nation states. Schiller noted that although he identified an "American empire" in international communication, a key aspect of his conception of media-cultural imperialism actually included the role of media corporations who he considered "the engines of commercialization in the West" (in Ampuja et al., 2020, p. 33). Media-culture power moved from national (i.e., American, for the most part) to transnational corporate authority who viewed modern imperialism as capitalist expansion and not cultural Americanization. As such, some media-cultural imperialist scholars note that the reduction to "Americanization" erases the power of local production suggesting that developing countries are merely weaker and could be easily overrun by another, more dominant (Western) perceived culture. This is discussed in more detail in chapter four, but it is important to note it at this juncture as it connects to the overall argument that explains the motivation as to why governments justify the use of geoblocking - to maintain the sanctity and power of their empire, whatever that empire may look like.

While the criticisms serve the purpose of evaluating media-cultural imperialism and the overall encompassing power America once had as the dominant national superpower more critically, the concepts are still valid for use in examining practices such as geoblocking by governments. Whether the media-cultural imperialism conception of a dominant culture taking over weaker ones through media exports is right or wrong is not the issue here. There are governments who do give credence to the ability of foreign media to culturally colonize and assimilate their people, deterritorialize their borders, and destabilize national power hierarchies by undermining pre-established state norms and values and become a threat to authoritarian governments (Ampuja et al., 2020). 


\section{The Netflix Imagined-Community and Government}

At the 2016 Consumer Electronics Show (CES), Netflix co-founder and CEO, Reed Hastings took the stage as keynote speaker with a presentation on the company's crowning achievements up until that time. Hastings made several points, including that Netflix was "the first to release stories across a global footprint, allowing members, whether in Argentina or Finland, to be able to enjoy the same great story at the exact same moment" (CES, 2016, 7:197:29). For Hastings, Netflix's global reach went beyond media corporate success and towards connecting people: "We are just beginning to break down the barriers so the world's best storytellers can reach audiences all over the world...The possibilities of building connections between cultures and people are endless and important" (CES, 2016, 4:08-4:36). Netflix, said Hastings, was "at the start of a global revolution." Hastings believes that Netflix is not just about providing media to the audience, but about building a community connected by global media, not by nations - a community connected by the tag \#netflixeverywhere. In this CES (2016) presentation, Hastings suggested that Netflix can and does connect people into a connected imaginary - The Netflix nation. As Elkins (2019) states in his book Locked Out: Regional Restrictions in Digital Entertainment Culture, what Hastings has been building since 1997 is a company that is no longer "defined in national terms (a series of different Netflixes), but in terms of a global ubiquity and unification" (p. 74). Netflix is establishing an imagined community connected by globalized media. Members are not American, British, German, Egyptian, Chinese, Russian, South African, etc., but Netflixians. Hastings seems to be alluding to Netflix as a corporate nation state, imaginary with no allegiance to any one country - even the country it is based in - but only unto itself. His assertion of media being accessible simultaneously across the 
globe suggests a utopic ability to be unified to any other Netflixian anywhere in the world by watching the same film or TV show in different places in the world.

In his book Imagined Communities: Reflections on the Origin and Spread of Nationalism, Benedict Anderson (2006) defines a nation as a politically imagined community - people who group themselves together based on social and political similarities. He defines nationalism in terms of belonging to a country, a sovereign and limited state. It is not determined by personal connection from face-to-face experience, however, but precisely in that there is a connection developed across a group of people who will never even see or speak to one another. ${ }^{52}$ It is not to say that people do not see each other face-to-face, but that the vast majority may not see each other every day, or ever, and still feels connected to one another through a unifying principle(s) of the group. All people who perceive themselves as part of this group socially construct the nation. Unifying principles were designed and spread through a key aspect, which Anderson (2006) called "print-capitalism.” Anderson (2006) originates the possibility of imagined communities due to "print capitalism" where the printing press allowed for the mass printing of materials in vernacular which became an important impetus for circulation to proliferate. Through this circulation of a "common tongue", people with different dialects could understand one another leading to the development of a common discourse and the creation of people identifying by national identity. Anderson (2006) states that the nation became the unifying community:

Because, regardless of the actual inequality and exploitation that may prevail in each, the nation is always conceived as a deep, horizontal comradeship. Ultimately it is this fraternity that makes it possible, over the past two centuries, for so many millions of people, not so much to kill, as willingly to die for such limited imaginings. (p. 7)

\footnotetext{
52 This does not refer to digital space necessarily, but the idea that one can be geographically in another place another country - and still identify as part of a particular nation state due to those norms and values that will constitute the nation of that nation state and will be carried with someone wherever they may go.
} 
However, Anderson (2006) also argues that these communities "bore none but the most fortuitous relationship to existing political boundaries (which were, on the whole, the highwater marks of dynastic expansionism)" (p. 46). While the advent of the printing press and print capitalism with the adoption of vernacular language and nation helped to eventually topple dominant, dynastic rulers, such as the Roman Catholic Church, nation-states themselves merely rose as the dominant controllers of the people in its place.

Governments of nation states have long used print capitalism and other forms of media production to help strengthen the national imaginary as bound within some geopolitical national border to control the people. However, Anderson (2006) also stated that the imagined communities' perceptions of themselves will continue to evolve as social and technological changes continue. This perspective leads one to ask if the perceived Netflix Nation is the next evolution of imagined community that will topple traditional imaginaries of nation states. Indeed, if the internet is the next printing press? While the internet was certainly the next printing press in terms of its technological, social, political, and economic effects on society - positively progressive and developing some new ideas of globalized imaginaries - it, like the printing press, has also been largely subsumed by corporations and governments alike to control one another and the people in a digital capitalist system.

In Digital Capitalism: Networking the Global Market System (1999), Daniel Schiller defines "digital capitalism" as a broadening of "the effective reach of the marketplace" through digital goods and services (p. xiii). However, unlike Anderson's (2006) conception of print capitalism, which presents some positives at least to the development of national imaginaries, Schiller is critical of digital capitalism not as an era of digital elevation of society, but as an era of unprecedented expansion and control of multinational corporations, many of which are 
supported by the business interests of governments. In the CES (2016) presentation, Hastings described a Netflix imagined community that goes beyond member national identities, beyond the borders established by governments over generations that seems to be a utopia for its members. Schiller (1999) would disagree and argues the opposite stating that Netflix's imaginary community is a digital capitalist system of increased control of a population to maximize profits. I believe Anderson (2006) would be inclined to agree with Schiller. As much as Hastings tries to present the image of people unified across the globe by media, the Netflix intentions are as bordered as nation states are with media access locked up in the Netflix libraries and only available to their members worldwide at the same time if Netflix owns the global rights to that media or have some other ulterior financial reason to do so. Lobato (2019) states that an examination of Netflix "explores how familiar anxieties about national sovereignty are returning in a different guise through internet distribution" (p. 15). Where governments used print capitalism to manufacture the concept of bordered nation states, Netflix is using digital capitalism to manufacture their own bordered "nation" connected by media, but, essentially, for profit maximization. In addition, governments have already evolved to meet the challenge of the Netflix empire by using digital capitalism as well to extend their existing concept of nationalism from print capitalism to the internet and balance the tension that exists between one another and between themselves and corporations like Netflix.

If Netflix believed that media would connect its subscribers into an imagined community across different cultures for the sake of connection beyond one's national borders, then the case of the French independent film, Cuties (French: Mignonnes, 2020), indicates the strength of national cultural and social values. Cuties is a French coming-of-age film about an 11-year-old Senegalese French girl, Amy, raised in a traditional Muslim household who joins a dance group, 
Cuties, who perform dance routines that includes dance scenes where the young girls seem to simulate sex acts. As a result, it led to significant negative reaction among viewers in the U.S., and Netflix became embroiled in a social media storm calling for action against the streaming platform (Spangler, 2020). Netflix faced an online movement, \#CancelNetflix, after releasing a poster of the girls in sexualized poses and dealt with a multiyear high cancellation of subscriptions in the U.S. (Spangler, 2020) Even celebrities, such as Evan Rachel Wood (2020), came out against the film and the sexualization of children on social media. Government representatives, such as Senator Ted Cruz (Republican-Texas), have led a charge to take Netflix to court for potential violations of U.S. law and distribution of pornographic material, a case that is now pending in court. While director, Maïmouna Doucouré, who Netflix strongly defended, states the film is a social commentary about social media and sexuality for young girls, critics especially in the U.S. argue the film is a hypersexualization of young girls. This case illustrates how the notion that Netflix has as its own community, a sort of "nation" of its own, is not quite at the level of nationalism citizens of nation states embody, and Netflix's idea of people becoming followers of the Netflix Nation cannot rely on media as a unifying force.

\section{Sovereignty, Region Codes, and Streaming Media}

In chapter two the investigation of Evan Elkins (2019) on regional markets revealed the way territorialized geopolitics played a key role in determining the organization of the DVD region code system by media executives - which countries were placed in what region, determined the order in which media would flow; essentially, dictating who had the strongest cultural capital. When examining video-on-demand, Elkins (2019) states that it is an "arena wherein users, industries, regulators, and intermediaries engage in a tug-of-war between fantasies 
of a borderless, open internet and the sovereignty of nations and regions" (p. 76). The central focus of the tug-of-war - the point of friction - is the continual defense of the importance of existing borders and a need of governments to protect them.

Borders help to delineate the lines of sovereignty of a country - demarcating the area in which a government can enforce their laws and regulations. As discussed in an earlier section, region codes on DVDs were created by a group of media executives and leaders to help maintain the borders of sectioned markets, allowing each to sell to a nation's audience at different price points or different windows of buying, thereby maximizing profits. However, the region code system was also quite political. As mentioned, Elkins stated that the region code hierarchy took on the hierarchy of geopolitical conflicts and power. Where a country was placed in a region code said a lot about the cultural power of that country, and not necessarily where they were mapped geographically. However, beyond the statement of cultural power each country had, region codes on DVDs were supported and protected by governments through copyright law (like the DMCA in the U.S.) and trade agreements to be respected by each national territory. While manufacturers and consumers were not necessarily happy, region codes helped create cultural and geographical imaginaries that affected the way governments and people perceived their place in the cultural capital economy. Controlling certain regional media became as much part of the media industry's game to protect their IP as it was for governments to make statements about their own cultural make-up and control the flows of influence from other regional markets.

Then came the internet, which challenged the notions of regional marketing and of borders. As the Napster library of millions of songs collected from users across the globe showed, there were no regions on the internet - or, at least, there did not have to be. You could 
download a song from a user in America and play that song on your computer in China or even find a song from China and play it anywhere else in the world if you had a computer. Inspired by the Napster ' 99 Net, Netflix wants to institute a single digital library of content from around the world, available to everyone from anywhere in the world. While it must institute regional libraries - enforcing geoblocking of its different libraries because of the legacy of the copyright licensing and region codes that preceded it - Netflix is challenging the concept of regional media and as such, challenging governments, who are not all on board. Some governments are not only satisfied with their systems of borders, but they also intend to maintain them even as new online distribution threatens them. The key in maintaining a system is change, but the change must be controlled. As a result, geoblocking becomes a key tool to maintain their own interests of national identity and security.

\section{Netflix Nation vs. the Republic of China}

The entire CES (2016) keynote talk referenced earlier by CEO Hastings led up to a big moment where he surprised the audience with an announcement:

Because of the global reach of the internet, people have heard about our shows. They want to see Narcos and Jessica Jones, and The Unbreakable Kimmy Schmidt. Today, I am delighted to announce that while we have been here on stage, at CES, we switched Netflix on...in a hundred and thirty new countries. ${ }^{53}$

The crowd burst out into gasps, cheers, and applause as Hastings continued with his announcement saying that "...the Netflix service has gone live in nearly every country of the world but China, where we also hope to be in the future," at which point the cheers dissolved into laughter. More than four years after the CES talk, Netflix is still not available in China. In

\footnotetext{
${ }^{53} 39: 32-40: 20$.
} 
fact, Netflix is available everywhere around the globe except in Crimea, North Korea, Syria, and China ${ }^{54}$ Part of the problem for Netflix is the way in which the government of China controls the internet.

Lawrence Lessig (2006) examined the ways in which governments have been using code to parcel the internet to mirror their physical national borders. Coding is not specifically a government tool of control, but code is "control to the end of whatever sovereign does the coding" (Lessig, 2006, p. 114). Ideals set the infrastructure of the code: "The power to regulate is a function of architecture as much as of ideology; architectures enable regulation as well as constrain it" (Lessig, 2006, p. 282). If the architecture to the infrastructure does not support regulation, then government's power to effectively regulate is affected. Lessig states that the effective power would be "quite slight." On the other hand, even if a government's power is limited, with the right kind of architecture of control, that limited control can become effective and extensive. As illustrated by the case of China and Netflix, governments begin to use geolocation code as a function of architecture to border the internet according to their own geographical boundaries, much the same way media corporations were using coding in DVDs to establish the regional media flow patterns as established by existing national borders. Governments work to establish sovereignty in that existing space not only from other governments considered enemies of the state, but from multinational corporations as well.

\footnotetext{
${ }^{54}$ According to the Netflix bio on the World Economic Forum (2020), Crimea, North Korea, and Syria all face U.S. government sanctions preventing any U.S.-based business, such as Netflix, from completing any kind of business transactions with those countries. As such, Netflix has no choice but to enforce geoblocking and VPN bans to ensure the citizens of these countries are not able to access Netflix.
} 


\section{The Great Firewall of China and Blocking Media Content}

China figures prominently regarding aspects of the internet and control, especially in connection with surveillance and censorship. More specifically, the fascination (and trepidation) is focused on The Great Firewall (GFW). China built the Great Wall of China across a large section of China to protect the Chinese empire from outside forces coming from the Steppes. In the digital domain, China created The Great Firewall, a major internet blocking project, and a term adopted by the Chinese people and media ${ }^{55}(\mathrm{Li}, 2016)$. China was considered "an extreme example of control" prior to the digital era, but in the digital era it has been called "an extreme example of how and why the internet is becoming bordered by geography" (Goldsmith \& Wu, 2008, p. 90). However, while China is the perfect example of control, it does not try to control everything:

It is trying to create an internet that is free enough to support and maintain the world's fastest growing economy, and yet closed enough to tamp down political threats to its monopoly on power. The government is doing this by grafting Chinese nationalistic ideology onto the network itself, in the process literally changing the nature of the internet in China. Because of linguistic and cultural differences with the West, and because of the government's extraordinary system of monitoring and filtering, the Chinese internet is becoming less and less like its Western counterparts - it is pulling away from the rest of the world (Goldsmith \& Wu, 2008, p. 89).

At the 19th Communist Party Congress ${ }^{56}$, President Xi Jinping ${ }^{57}$ stated that China supports policies that work toward an open world economy and liberalization of the Chinese market to more foreign investors (Tan, 2017). However, these statements were made all the while still claiming the benefits of the socialist regime by which China functions. The collapse of state socialism in Europe from the late 1980s, however, undermined hopes of Western academics and

\footnotetext{
${ }^{55}$ The Great Firewall of China (Barme \& Ye, 1997) is cited as the first article where the term was coined, and then adopted by the people of China (Denyer, 2016)

${ }^{56}$ A gathering held once every five years ushering in possible leadership, but, especially, policy changes.

${ }^{57}$ Currently considered one of Chinese most powerful leaders.
} 
politicians who believed countries could develop without capitalism, which was increasingly becoming the global economic system (Ampuja et al., 2020). The government of China shows that a hybrid capitalist and socialistic economic system can be manageable even when several transnational corporations are involved. This system is surprisingly manageable. While it opens borders (both territorial and virtual) and allowing for foreign investments, it strategically prioritizes the Chinese government over all other interests. To manage this system the government of China has integrated the internet into its system and uses geoblocking as a method to surveil its people and corporations.

China initially did not see the internet as a system of control over its people or over multinational corporations; the proliferation of computers and the internet in China in the early 1990s were technological opportunities for economic growth (Li, 2016). However, while China seeks to compete in a global market (which means attracting investments from rich, foreign multinational corporations), those aspirations must not interfere with or disrupt existing ideologies of Chinese nationalism as dictated by the ruling party. As such, internet protocols were initiated to regulate the balance of economic gains against any perceived negative influence over the Chinese citizenry. In their analysis of China, Goldsmith and Wu (2008) state that "China wants to become one of the most advanced networking countries on earth while continuing to maintain control of information" (p. 100). According to Washington Post journalist Simon Denyer (2016), The Great Firewall "is an attempt to bridge one of the country's most fundamental contradictions - to have an economy intricately connected to the outside world but a political culture closed off from such 'Western values' as free speech and democracy” (par. 16 lines 1-3). Essentially, the government of China wants its cake, and to eat it, too. 
When it comes to blocked media content, many media sites that are blocked are coming directly from within China - they seem to be those sites that deal with sensitive democratic issues such as human rights ( $\mathrm{Li}, 2016)$. Many foreign-based websites (or their Chinese region counterparts) are blocked. YouTube, Vimeo, Facebook, Twitter, Google+ (and many more Google services, along with Google.com), are all blocked by China's Great Firewall (Li, 2016). Other notable sites blocked include Yahoo, Instagram, Tumblr, Wordpress.com, SoundCloud, and even TikTok. ${ }^{58,59}$ Technically, Netflix itself is not blocked by China. The website is accessible, but there is no service - there is no localized library made available and no log-in. The other Netflix libraries outside of China are geoblocked by Netflix and require a VPN to access (di Cina, 2019). According to a PCMag article, Matthew Humphries (2019) reports that over 30 percent of users in China regularly use a VPN to access content from outside the Great Firewall. Even as China attempts to continue to control access to outside sites with VPN bans, they are still in the top 10 markets that use VPNs. Users in China are crossing the digital wall. Hastings had stated in his CES talk that people have heard about Netflix (CES, 2016). This brings up a huge problem not only for China, but for several countries anxious over media content and its effect on the people. Controlling media access flows into a country was not necessarily easy prior to the internet, but the internet has certainly provided new challenges.

\footnotetext{
${ }^{58}$ While TikTok is a very popular social media app owned by China, two versions were created. One is available only in China for Chinese users, while the other version is made available in markets outside of China. This was largely due to the political controversy surrounding claims that China was collecting the information of American users, especially, inciting claims the app was a national security threat by then President Donald Trump who also threatened to have the app banned.

${ }^{59}$ For a more complete list of blocked websites, even including digital work tools, visit https://www.saporedicina.com/english/list-of-blocked-websites-in-china/ The site is active, although not exhaustive, but they continue to provide updates as the situation changes in China and as more users help by reporting sites that have become problematic or entirely inaccessible. Using sites like https://en.greatfire.org/analyzer, users can input URLS from outside of China and see if it would be blocked for users accessing from inside China.
} 


\section{Maintaining Cultural and National Identity in a Global, Online Media Landscape}

In her essay "China: The Techno-politics of the Wall," Jinying Li (2016) states that for a new generation of Chinese born in the boom of television, computers, and the internet, their increasing desire for global media is the major force that drives the fierce battle against the GFW (p. 115). Li states that there is a high demand for video content in China, and as much as the wall is political, it is also cultural. Lessig (2006) refers to cases where Europeans have called for a stop to "invasion of American culture, which pours over satellite television into the living rooms of European citizens" ${ }^{60}$ and areas of the Middle East where many countries fight (to this day) "to protect their culture from certain alien influences" (p. 300). While Netflix might be available in over 190 countries, this does not mean every country is happy about it. Lobato (2019) reports that shortly after Hastings's announcement at CES, in countries like Kenya and Indonesia there were complaints and threats to block Netflix based on content. The chairman of the Film Classification Board threatened to block Netflix due to the "shockingly explicit eroticism" of content made available on the global streaming service (in Lobato, 2019, p. 3). In the European Union (E.U.), which has a long history of regulating Hollywood corporations from dominating European culture, the news sparked plans of a European content quota for streaming platforms, including Netflix and Amazon Prime ${ }^{61}$. These reactions give insight into the divisions that exist between territorialized national markets and seemingly borderless global markets - there is anxiety over control of the entry of media into a country's market and over what kind of content it is.

\footnotetext{
${ }^{60}$ See his 17th note in Chapter Five: "Competition Among Sovereigns" of Code Version 2.0 on Bill Grantham's (1998) article "America the Menace: France's Feud with Hollywood" (Lessig, 2006).

${ }^{61}$ Discussed further in chapter four.
} 
China's leadership works hard to control the narrative of the nation-state both politically

and culturally but finds themselves undercut by internet access to sites that offer counter-

narratives. This is done not necessarily by sites themselves, but by the content uploaded by users onto sites, such as YouTube ${ }^{62}$ :

The division between what is inside and outside the GFW is marked by the peculiar function of YouTube as an effective distribution channel for Chinese underground films and videos that are barred from domestic release...For Chinese filmmakers and audiences, to release, share, and consume these underground documentaries is to challenge the wall, the existence of which is both the pre-condition for and the obstacle to evade censorship. It is disconnection and blockage, instead of connection and access, that highlight the intermediary function of YouTube as a political platform (Li, 2016, p. 116).

Lessig (2006) brings up the issue of citizens living in their home country while living "in the alien culture" through exposure to media content like television (whether online or not). There are over 360,000 Chinese students enrolled in U.S. schools. I have taught classes with students studying abroad from China in my media courses. I also use Netflix and talk about Netflix extensively. How many of these students have used the service in the U.S. and returned to China to continue watching Netflix, to continue watching U.S. media, even if illegally? However, for Lessig, it is more than just this that leads to government tightening of control over media, especially online. Lessig (2006) states "the alternatives offered by TV are alternatives of the imagination. The interactive life of cyberspace offers alternative ways of living (or at least some cyberspaces do)" (p. 300). Our daily life is political. Ideology is in everything, even our TV shows. "Cultures at one time isolated are later invaded when the barriers to invasion fall" (Lessig, 2006, p. 300).

\footnotetext{
${ }^{62}$ Users in China will utilize circumvention tools such as VPNs to trick YouTube into thinking they are accessing from another country outside of China, allowing them to upload their content. YouTube also allows for the ability to remain generally anonymous - while one needs a Google account to post onto YouTube, a person can use fake information to create a Google account and use VPNs and other advanced IP-masking technology. Google also does not operate in China and is not liable to hand over information of its users to the Chinese government.
} 
In 2005, Jonathan Zittrain and his team of Harvard Law researchers found that China operates the most extensive and technologically sophisticated filtering of information, focusing specifically on key perceived threats to the reigning Communist Party, such as information about Tibet including independence groups, human rights sites, any information about the banned religious movement Falun Gong, and the Tiananmen Square Massacre. The government justifies the wall as a "defense against Western 'dumping' of information on China" (Goldsmith \& Wu, 2008, p. 95). Since this is exactly how many governments, not just China, currently view the internet - as a source of providing media content they can more readily control in a way that would be otherwise - it is why there has been a massive resurgence in zoning the internet according to existing physical national borders. For China, it has been a matter of controlling the terms that dictated entry of corporations that could provide access to "alternatives to the imagination" that the Chinese leadership has been coding so diligently and carefully.

\section{The Price of Doing Business in China}

According to Will Martin (2017) in "These Will Be the 32 Most Powerful Economies in the World by 2050," an article in The Independent, reports by $\mathrm{PwC} \mathrm{-} \mathrm{an} \mathrm{international}$ professional service agency specializing in industry economic concerns - indicate that China will be the world's number one economy by 2050. Bloomberg View columnist Noah Smith (2017) opines that China is already the world's number one economy and will only continue to widen the gap between itself and the U.S. It is no wonder then that media corporations want to do business in China. Netflix will not be one of them even though they certainly attempted to be. Hastings (CES) said in 2016 that he hoped for Netflix to be available in China someday, and while industry audience members laughed, Netflix did attempt to insert themselves into the 
Chinese digital market. Where Netflix managed to negotiate national copyright and license distribution deals that at least saw other nations acquiesce to Netflix's entry into their digital borders, China has been far stricter on the level of control, not just over Netflix, but as mentioned previously, over any foreign corporation.

China wants the perfect cultural and political utopia as imagined by the ruling party, and with an extension of digital controls tied to territorial laws, they are succeeding. In addition to the government of China implementing its own state-run network, which already made entry into Chinese market difficult for Netflix, China also mandates that any state and non-state-owned corporations - especially multinational corporations - must be made complicit in the system with no room for argument (as the state makes it so). Any foreign digital company, especially, must have a physical presence in China. The government also requires foreign companies to make trade and organizational partnership deals with Chinese corporations. In 2017, Netflix partnered with iQiyi - a streaming service majority owned by the search engine Baidu, China's most popular search engine and the second largest behind Google, which, while not state-owned, is fully complaint with the Chinese government laws and mandates on censorship of internet searches and search results (Kharpal, 2019). This is an ingenious level of control that exemplifies a unique form of geoblocking that goes beyond digital space, enforcing a physical geolock on foreign companies into China - it is a contractual tether between the existing national boundary of China and the internet designed to rein in foreign companies, especially foreign internet companies.

With a brick-and-mortar connection location in China, foreign companies now open themselves up to enforcement by Chinese law more so than they would have if they simply had a website URL open to the Chinese people. Yahoo faced a similar problem during their litigation 
with the LICRA lawsuit in France with an office branch located in France as discussed in chapter two, but unlike China, which has much stricter laws that could lead to prison sentences, the French court threatened the CEOs with costly fines that could have been avoided by simply leaving the country but would affect any future business not only in France, but even Europe as a whole, since France was a member of the E.U. Had Yahoo not had any physical branch locations in France at the time, it is possible Yahoo could have reacted more aggressively to the French case and ruling. Yahoo had stated that they felt the French government were overreaching in its attempts to police the internet, infringing on Yahoo and even other netizens on their rights to freedom of expression. However, with a physical base within French borders, Yahoo was already liable to local French law, so the court only saw it logical that even as an internet company, Yahoo still had a legal right to abide by French law. China leaves no room for ambiguity making it clear that if anyone wants to do business within China - physically or virtually - they need to be connected to China in such a way that makes legal application concrete.

As part of the "Golden Shield"63 program, China balances external controls with internal systems that includes control of the business sector through both state and non-state-owned compliance, as well as "self-discipline pacts" signed by multinational corporations who venture to do business in China. All must adhere to one simple rule: block what the state tells them to block. In the end, both systems are designed with the function to surveil and censor for the sole purpose of maintaining existing Chinese sovereignty on both a local and a global scale both offline and, especially, online.

\footnotetext{
${ }^{63}$ A larger program that encompasses many fields of control with the internet being one such area. Public utilities is another, for example. Implemented by the Ministry of Public Security, the program seeks total internal control systems that encompasses both the political and everyday routines of Chinese citizens. In his article for The Washington Post, "China's scary lesson to the world: Censoring the internet works" (2017), Simon Denyer describes the Golden Shield as "a giant mechanism of censorship and surveillance" in regards to the blocking of any websites deemed as counter "to the Communist Party's narrative and control...." (par. 9, lines 1-2)
} 
As such, understanding why Hasting's expression of his goal of Netflix gaining access to China incited laughter at the 2016 Consumer Electronics Show (CES) requires a closer look at how the government of China regulates foreign media, specifically films. It is so arbitrary that in 2007, China's strict regulation of entertainment imports, including foreign films, was deemed a violation of the World Trade Organization (WTO) agreement. However, only in 2012 did China agree to open its film market to foreign films after years of noncompliance and inaction and only to avoid U.S. WTO actions against China's film importation policies. A deal reached with the U.S. allowed for the import of 34 films each year - up from the previous limit of 20 films. A foreign film has two possible routes to gain access to China's film market: coproduction with a Chinese company or subject the film to review by the State Administration of Press, Publication, Radio, Film and Television (SAPPRFT). Regardless, all films exported to China must adhere to the principles of the Chinese Government Constitution and maintain "social morality" as determined by SAPPRFT. SAPPRFT consists of government representatives, filmmakers, and academics. All are members of the Chinese Communist Party and the agency's director, Cai Fuchao has a long career as a propagandist, serving as the deputy director of Beijing's propaganda department from 1998 to 2008 (O’Connor \& Armstrong, 2015).

Although China relaxed its restrictions on foreign media somewhat, according to media and cultural studies scholar Wendy Sue, “the PRC [People's Republic of China]'s stance regarding Hollywood has shifted from 'containment to competitive cooperation,' but even so the state sees itself in a 'post- Cold War cultural War' where the PRC needs to maintain hegemony in global discourse" (in Muzhao, 2019). This statement is in line with China Film Co-Production Company (a branch of SAPPRFT) President Zhang Xun's assertion, made at the 2013 U.S.China Film Summit, that "We have a huge market and we want to share it with you [but] we 
want films that are heavily invested in Chinese culture, not one or two shots.... We want to see positive Chinese images" (O’Connor \& Armstrong, 2015, p. 9). Coproduction, however, does not guarantee distribution. SAPPRFT remains involved during the conception, shooting, and distribution of all coproduced films, and can refuse to distribute a film even if it is coproduced by a Chinese company.

Coproduction is an important goal for film studios as movies coproduced in China do not count as foreign films, allowing American filmmakers to bypass the 34-film limit and bring in 43 percent of ticket sales, rather than the 25 percent given to foreign films that are not coproduced. Between 2002 and 2012, a total of 37 films were coproduced between the U.S. and China, while five coproduced films made it to screening in 2013. Creative commitments necessary for obtaining coproduction approval can include having at least one scene shot in China, casting at least one Chinese actor, receiving a minimum one-third of the movie's total investment from Chinese companies, and, in general, illustrating “positive Chinese elements” (O’Connor \& Armstrong, 2015).

U.S. filmmakers self-censor scenes, dialogue, images, and themes they fear will jeopardize their film's chance of receiving Chinese approval for import. In seeking SAPPRFT's approval, some U.S. films make alterations to scripts, scenes, and casting with China in mind. The film Gravity (2013), for example, appealed to Chinese audiences by portraying China's space program in a positive light: a stranded astronaut saves herself by utilizing a fictional stateof-the-art Chinese space station and lands on Earth in a Chinese space capsule. The film went on to gross $\$ 71$ million in China, 10 percent of its worldwide total gross and 16 percent of its total foreign gross (O’Connor \& Armstrong, 2015). 
Iron Man 3 (2013) initially sought coproduction with DMG, but Disney was unhappy with concessions this arrangement would require and opted instead to release two versions of the film: an international version and a Chinese version. There are, in fact, four extra minutes of footage in the version released in China which feature:

(1) product placement for Gu Li Duo, a milk drink from an Inner Mongolia-based dairy company; (2) Chinese actress Fan Bing Bing playing a nameless assistant to Dr. Wu, the doctor who uses Chinese medicine to help Iron Man; (3) more product placement appearances by two Chinese electronics makers, TCL and Zoomlion; and (4) a shot of cheering, happy Chinese schoolchildren on TV with Iron Man (Grimm, 2015, p. 156).

Iron Man 3 debuted to a record-breaking \$2 million midnight premier in China. In "The Superhero Symbol: Media, Culture, and Politics" (2019), Muzhao posits that for Iron Man 3, the government of the PRC, its businesses, and its audiences constitute at least three parties with divergent interests and interpretations. While the state invested in the film as a part of its developmentalist and soft power goals and the dairy industry sought greater advertising reach, audiences use the trope of a superpower to articulate concerns about the cost of unbridled development.

What this shows is that the Chinese government has a clear history of censoring and controlling the influx of media production from outside China. According to Grimm (2015), "The Chinese censorship regime is better viewed as a patchwork of various regulations and measures covering all forms of media, including newspapers and periodicals, the internet and satellite television" (p. 164). The Chinese government is blocking themselves against what they perceive as the onslaught of media-cultural imperialism from outside China, in particular from the West. They have extended this tight control on media flow on the internet using geoblocking to limit what citizens can see at various times. In light of Hollywood's uphill battle to gain access 
to Chinese viewers, it is no wonder that Hasting's audience responded with laughter at the thought of Netflix encroaching on Chinese internet territory, and no wonder they failed.

However, it is not made clear in any interviews or press releases or even scholarly articles that Netflix's attempts to penetrate the Chinese market failed due to Netflix possibly being unwilling to bend to China's laws on control over media content and distribution unlike some Hollywood film producers, as described above, however, it cannot be discounted as a possibility either. According to iQiyi CEO Gong Yu, while Netflix and iQiyi had an agreement to distribute Netflix licensed content in China, due to "the verification system and users' tastes, the effect wasn't that great," ending the partnership (quoted in Kharpal, 2019). The verification system was not clarified, and neither was the statement on user's tastes. What is more interesting, however, is Peter Yu's (2016) statement that while the agreement with Netflix ended, iQiyi "partnered more with the six traditional major studios, in the U.S. and other regions." Hollywood legacy media companies, like Disney, have been attempting to navigate the very complex political, cultural, and ethical maze that is doing business in China while maintaining a positive public image back in the U.S., especially with the increasing antagonistic relationship between China and the U.S. during Donald Trump's presidency, and with other regions that do not look lightly on China's more authoritative control and censorship of media content (Stankiewicz, 2020).

Disney's popular resort in China, Disneyland Shanghai, for example, only exists as a joint venture between the Chinese state-owned company Shendi and Disney, and if Disney upsets the Chinese government, it could result in termination of the venture and the IP ownership over Disneyland Shanghai defaulting to Shendi completely (Jacobson, 2020). With Disney’s sights on expanding their streaming service Disney Plus to more global regions, it is sure to tread carefully as it continues to pump content into China for theatrical release and take advantage of 
licensing content for digital streaming to iQiyi and other streaming services in China until a sanctioned Disney Plus version may be available in China. Netflix, on the other hand, while being unable or unwilling to work within China's virtual borders, has opted to target other Asian markets like India, Korea, Japan, and Indonesia and Mandarin speakers outside of mainland China (Stankiewicz, 2020). Globalization of economies has meant that multinational companies like legacy media Disney or new media Netflix must turn to foreign markets outside of the U.S. to continue growth, and other countries can benefit from these companies investing in their borders, especially in the form of branch offices and hiring from the local workforce and taxes from revenues. The internet has allowed for new methods of media distribution that has complicated the ways old media companies and governments used to establish their trade contracts and both are continuously navigating how to best take advantage of the benefits of the internet, but not while at the cost of their profits or one's national sovereignty.

The ruling government in China has developed one of the most large-scale geoblocking projects that bridges the gap between the way the government-controlled business in and into China before the internet to after and adapted in such a way to maintain its imagined communities in the way they it has always seen fit. What studying geoblocking and China shows us in respects to Netflix and the Chinese market is that governments are not necessarily against new media corporations, even global ones. Governments are not even really afraid of the internet or all the myriad of channels of media flow, not as long as they can find ways to continue to force the internet into the systems they already operated off of in the comfort and sovereignty of their national borders. Geoblocking has been the perfect tool to help governments maintain their territorialized systems of governance the same way legacy media has maintained levels of control of their old distribution models around region codes and delay windows and can have 
direct effect on media content. However, it also reveals a consistent tension. Governments must always maintain a watchful eye on internet technology advancements and will have to adapt, but, at least, tools like geoblocking can help them gauge and somewhat control the rates of change happening around them to buy them the time they need to both become something more with new technologies while all the while still being the same.

\section{Conclusion}

As stated in chapter one, there are net utopianists who believe the internet is not a state governed space. However, the internet was born because of the U.S. government. First funded by the United States Department of Defense (USDoD) in 1969 to build a robust, reliable, and stateof-the-art communications network across computers, The Advanced Research Projects Agency (ARPA) ${ }^{64}$ developed The Advanced Research Projects Agency Network (ARPAPNET), which allowed them to complete packet switching ${ }^{65}$ across heterogeneous computers of different users geographically dispersed in many areas - this is considered the birth of the internet (Dennett, Feinler, and Perillo, 1985). Originally part of ARPANET, the Military Net (MILNET) - the designated area of the internetwork for unclassified military documents for the USDoD separated from ARPANET to form its own network in 1983 citing security reasons. ARPANET was specified as an experimental research network mainly for academics (Dennett et al, 1985). What this history illustrates is the internet was always a controlled and administrated network, established for specific government purposes, specifically - predominantly, militaristic advantages in the case of emergency situations - long before Houri came in as an expert witness

\footnotetext{
${ }^{64}$ Also sometimes referenced to as the Defense Advanced Research Projects Agency (DARPA).

${ }^{65}$ A form of digital network communication that transforms data into groups of convenient and smaller sized blocks - packets - that can then be transmitted and shared.
} 
for the Yahoo versus France case establishing modern day geoblocking. However, at least, in the beginning, even the military left the academics and early-adopters to their own devices on other open networks spaces. Today, that is not the case. The internet may be large and expanding exponentially, but it is a networked system of networks that have clear, identifiable boundaries that make linking to one another accessible (Barabási, 2014), but that media corporations and governments, especially, want, need, to control.

So, if we accept, then, the internet as both open and closed, it better explains both the form and function of geoblocking. Geoblocking is then viewed a necessary tool to help make sense of the openings and closings - to map them out in a way that governments can better make sense of them and control them. "Geoblocking, from this perspective, is a phenomenon that brings together various actors, each with particular logics of action, and maps their corresponding territorialities onto the internet" (Ashraf \& León, 2016, p. 42). Ashraf and León (2016) state governments expand their concept of physical boundary to the internet through a system of censorship and control in order to bring the internet in line with geographical assumptions that make up the international state system: territory, borders, and sovereignty. Governments manage this with the development and institutionalization of "laws and technical systems to territorialize cyberspace" as seen illustrated in the examination of China (Ashraf \& León, 2016, p. 43).

Governments are struggling against the new globalized economy that is traversing their own boundaries, while many nations have a dire need to continue financial growth (as well as in other areas of life). They are fighting against the changing landscape where notions of what is a border and a people are in flux and in constant change. Governments have long had to balance the need for change with what kind of change in order to exist and stay relevant - regimes, 
governments, empires, rise and fall; it is all about maintaining that balance between rise and fall. This means constantly making the concept of nationality relevant to the people (the citizens). However, while spurring on continued technological change - especially digital enhancements, such as the internet - governments are slow to adapt to political, economic, and sociological changes happening as a result. Not being able, or willing, to keep up with the pace of change the new advancements bring, governments instead opt to institute systems of "blockages and flows of information" to maintain a semblance of control - geoblocking is a system that has allowed governments to maintain some solidity to what are becoming more porous national boundaries online (Lobato, 2016).

However, while the internet may be bordered, the way those borders are conceptualized do not translate to the way governments identify (visualize) boundary lines, heightening anxiety concerning governmental control - or lack thereof - of any section of the internet, let alone the entire imagined space. It would seem the discourse surrounding the politics of the internet is whether it should be free or not. However, if one understands the internet as a system that was never free to begin with, then the question should not be whether it is free or not. The real question in the end: who gets to govern it and how? This chapter and the previous already reveal how media corporations and governments are the two major governing forces and how they are using advanced technological tools, like geoblocking, to help them govern over the internet.

Governments work to stake claims to networks to help them establish border lines on the internet that can in some ways more remotely resemble their already existing territorial borders, which, in turn, is what legitimizes sovereignty. This is their struggle: the internet has a multitude of different "maps," but governments need to ensure it can force it to conform to the geographical boundaries already in place to maintain law and order. Geoblocking can be used as 
a compliance tool to ensure that in the age of the seemingly "boundless" internet, certain laws and judgments could still be rendered territorially - it allows them to both lay claim over and control a zone or zones of networks (Trimble, 2016). In her article "Geoblocking, Technical Standards and the Law" (2016), Marketa Trimble states, "As long as the world operates on the basis of national laws, there will be a need to replicate national borders on the internet to comply with these corresponding physical limitations" (p. 54).

Lessig (2006) argues that governments will have to come together and make negotiations "about how law will regulate and about any norms that they will impose on private ordering" ( $p$. 293). As long as governments are in competition with one another on an ideological level, they might never come to a single agreement. Each have already agreed upon their individual sovereignty, which has seen the world constantly (re)bordered physically to map out the physical territory belonging to each. The concept of sovereignty merely expanded to include digital space as well. As such, governments will always regulate. Laws exist to regulate many things within borders: the sale of alcohol, pornography, gambling, etc. As such, why not also regulate the same online? The concepts of boundaries, nation states, and citizenship are at an evolutionary precipice as technological changes especially, continue to advance people further and faster into ever increasing digital realms that do not quite translate to the way the real world is organized and regulated. 


\section{Chapter 4: Geoblocking and the Audience}

The previous two chapters explained how geoblocking manages the preexisting infrastructure of media corporations and governments designed for a territorialized world onto the digital world. In chapter two, on geoblocking and media corporations, I examined how geoblocking developed from Houri's system that tracks IP addresses that would then provide a user with more relevant ads - it localized the internet for commercial purposes. According to Houri, it helped shape the virtual to mirror how consumerism works in the physical. It provided convenience for both corporations and consumers. Furthermore, it illustrated how geoblocking was then adopted by media corporations to transpose the pre-existing offline, nationalized, territorial media market systems to the internet. This bordering of the internet allowed legacy media to adapt to changes in media production and distribution brought on by the internet, maintaining their general existing procedural infrastructure, and forcing would-be revolutionary corporations like Netflix to work within their systems. In chapter three on geoblocking and governments, I examined how governments, while contented to gain economic benefits from international trade on the internet stimulated by expanding globalization, utilize geoblocking to, simultaneously, manage the flow of foreign capitalistic systems from transnational corporations on the one hand and the erosion of their existing territorial national boundaries online on the other hand. It showed how governments adopted existing laws offline to be applied on the internet in the name of fighting media-cultural imperialism and to protect national cultural identity and values from large foreign (i.e., predominantly American) media corporations.

In this chapter, I examine the relationship between audience motivations and geoblocking. As stated previously in chapter one and made evident in chapters two and three, the audience does not get to utilize geoblocking directly in the way that corporations and 
governments do. Typically, corporations and governments enact policies of geoblocking that affect the audience. However, audiences have developed reactions to these policies and this chapter examines and analyzes the tensions between the audience and corporate and government media policies involving geoblocking. Here the focus is on the ways in which audience motivations support or attempt to counteract corporate and government justifications of geoblocking. Analyzing this aspect gives insight into which audiences know about geoblocking, if they are accessing local or global content, and what that means for how the internet is shaped, and why and how it affects the relationship of the audience with media corporations and governments.

If corporate motivations for geoblocking largely focus on maximizing profit and government motivations focus on protecting territorial sovereignty, what then would the motivation of the audience be? Audience motivations can be slightly more complex than those of corporations and governments, who, generally, are in support of geoblocking. General audiences do not make capital profit from media, but that is not to say audiences are not in support of or against large media corporations necessarily. While there have been revolutions against authoritarian regimes where audiences revile the tight controls of their governments of their media, that is not to say there are audiences who do not support government media policies that restrict or allow access to media content. Through several case studies, this chapter lays out the complex map of motivations of the audience and analyzes which audiences are for geoblocking, which are against it, and which do not even know about geoblocking and why.

Audiences aware of geoblocking can pressure governments to dissolve corporate geoblocking for motivations surrounding cross-border movement of goods and media (crossborder portability), online privacy concerns, and language and cultural discrimination of media 
content and access. The case study of the E.U.'s "Digital Agenda" initiative (Stamatoudi, 2016), where an update of pre-existing European territorial laws around freedom of movement and access into the digital age was attempted, is used to focus on the aspects of geographic discrimination in cross-border portability and language and cultural discrimination. This case illustrates the increased anxiety over media-cultural imperialism over corporate empires like Netflix with calls for guarantees brought on by media content production that is representative of especially minority groups in a planned European "Digital Single Market."

Economic discrimination is examined in the case of HBO versus Australian cable where a cable provider stated their licensing rights were threatened by HBO's newest online portal, HBO Now, since it did not do enough to block Australian citizens from paying for the service. The Australian audience complained about economic discrimination of media access by these local providers inflating the cost of local subscriptions. There is also an analysis of the kind of content audiences desire with Australian audiences particularly looking for access to the global HBO hit Game of Thrones (2011-2019). This case had large repercussions that affected the way Netflix approached the issue of online piracy and global audiences using VPNS to access different Netflix libraries.

The above case connects to connections on social media. To examine social media, audience, and geoblocking, the case study involves Netflix's American fans of The Great British Baking Off and the show's social media accounts. The program airs three days on U.S. Netflix after it airs in the U.K. but is reported on by a single show social media account, which now has followers from more than just the U.K., but all at different delay windows. This case study reveals the social connections audiences attach to their media usage and the global connections even localized content is making and the possibility of increased awareness of geoblocking 
among American audiences, which ties to the last section in this chapter. In the last section in the chapter, there is more examination on American audiences and geoblocking and present a short examination of data results from a preliminary survey I completed.

\section{The Audience, Discrimination, and Geoblocking}

\section{Geographic Discrimination: E.U. Audience and Cross-Border Portability}

In 2014 the European Commission (EC) launched “The Digital Single Market” (DSM) strategy addressing "the best possible access to the online world for individuals and businesses" (European Commission, 2020, par 1, lines 2-3). Part of the DSM strategy included addressing the issue of geoblocking. The DSM was designed to address three pillars: 1) access - which includes e-commerce, parcel delivery, geoblocking, copyright, and value added tax (VAT); 2) environment - which includes telecoms and media, online platforms, and security and personal data; and 3) economy and society - which includes data economy, standards, skills, and egovernment (European Commission, 2020).

The DSM strategy was led by the European Commission (EC) president, Jean-Claude Juncker in 2014 who drew up and initiated 30 legislative proposals on the DSM (EC, 2020). By the end of the mandate in 2019 , the commission succeeded in securing agreements for all but two of the legislative proposals ${ }^{66}$. One of those proposals that did not pass concerned geoblocking. In a 557 to 89 vote on June 2018, the European Parliament (EP) voted in favor of a regulation to ban geoblocking, but not for all kinds of content (Deutsche Welle, 2018). While the EP voted in favor of banning geoblocking of online shopping websites of general goods and services making it easier and more affordable for cross-border purchasing and delivering for E.U. citizens, SVOD

\footnotetext{
${ }^{66}$ All proposals and their status before and after the commission can be viewed at: https://ec.europa.eu/commission/sites/beta-political/files/euco-sibiu-a_digital_single_market.pdf
} 
providers like Netflix and Amazon are exempt from the ban, including other content providers that offer online subscription services (Deutsche Welle, 2018). In an initial EC (2015) research report titled "Why We Need a Digital Single Market" it is indicated that 315 million Europeans use the internet every day. Of the Digital Market, only $4 \%$ was from E.U. cross-border online services, while $42 \%$ were of individuals in their member states, and $54 \%$ were U.S.-based services. E.U. audiences were losing because of the geoblocking rates occurring across member states, and, as such, the E.U. economy was losing out to U.S.-based businesses. Furthermore, the report indicated that in $52 \%$ of attempts at cross-border orders, the consumer was geoblocked from completing their purchase. Prior to the vote, an EC survey of retailers and digital content providers reported that $38 \%$ of retailers selling consumer goods used geoblocking while $68 \%$ of digital content providers geoblocked E.U. member state consumers (European Commission Press, 2016). The retailers would geoblock based off of agreements with suppliers and distributors that some felt could restrict competition in the DSM, however, 59\% of the content providers indicated that they were under contractual agreements due to copyright forcing them to geoblock different E.U. audiences.

As mentioned in chapter two, copyright of general goods, garments, bags, shoes, etc. is not necessarily protected compared to media products that are considered creative expressions. While the E.U. does offer some copyright protections for industries not included in traditional media copyright protections, such as unique fashion designs, however, in general, the fashion industry relies on patents on textiles and unique designs and trademarks (Kaspekiewicz, 2017). As such, it is easier to discontinue geoblocking for the sale of goods and services that do not fall under traditional copyright versus those that do. Comparatively, as illustrated in chapter two, media corporations (especially if they are the rights holders of content) hold the right to country- 
by-country release and are quite motivated to protect their copyright system, which they believe is the key to maximizing profit.

However, according to the initial 2015 EC report, one in three Europeans reported interest in accessing digital media content from their home country when they went abroad, and one in five were interested in accessing digital media content from other E.U. countries. In another 2015 analysis report (College of Europe, 2016) European consumers reported that "geoblocking, per se, should not be justifiable" (p. 12). Consumers were especially concerned about their ability to access cross-border content and price and pay discriminations online businesses in different member states would impose (College of Europe, 2016). In a 2019 updated report (Kantar Public), only $8 \%$ of E.U. respondents were trying to access cross-border content, but the number has doubled to $15 \%$ in 2019 , however, of those in the age range of 15-24 years of age, $28 \%$ reported trying to access cross-border content, especially audio-visual and music content. Furthermore, $44 \%$ of the respondents reported attempting to access cross-border audio-visual and music content due to a lack of availability in their own member country and $39 \%$ reported wanting to access cross-border content to have a wider choice of content at their disposal (Kantar Public, 2019). What these report results tell us is that there are audiences who are impacted by geoblocking due to regulations and policies driven by capitalistic interests and protected by governments.

Reda (2020) states that the inability to dissolve geoblocking of digital media content in the E.U. was largely due to heavy lobbying from the film industry, such as Disney, who relied on their argument of copyright protections to see the proposed legislation on geoblocking media content fail. It is not just Disney who gains from the traditional territorial system of licensing media content rights. In Europe, the Society of Audiovisual Authors, the Association of 
Commercial Television in Europe, and even the European independent film industry lobbied for the preservation of the principle of "country of origin" - selling film rights country by country. Here is a connection back to chapter two when discussing the concerns of imperialistic corporations. Some smaller, often independent content providers worry that geoblocking is exactly what is protecting them from large media empires, such as Netflix, and preventing them from taking over in Europe entirely. Their argument: if territorial rights were to be removed and audiences would be permitted to access content across borders freely without any restrictions, it would remove their ability to maximize profits across different territorial markets, which means far less revenue overall from rights sales, which is not a big problem for much larger productions, like Netflix and Amazon, but is a constant concern for smaller, independent film production studios (Reda, 2020). John McVay, chief executive of PACT, ${ }^{67}$ made a point that removing geoblocking would benefit larger streaming organizations, especially Netflix and Amazon Prime, due to their large corporate and global funding that allows them to invest in much more content, and the best content, at a single price that would not affect their overall bottom line the way it would affect much smaller online streaming services in Europe (Spence, 2015). Furthermore, this was defended not only as a revenue loss for independent producers in Europe, but a concern over the cultural heritage especially of minority groups across Europe, discussed further below regarding cultural discrimination.

According to anti-geoblocking advocate and former Member of European Parliament from Germany, Julia Reda (2020), despite the consumer (audience) cross-border demand for cultural works, ${ }^{68}$ European film producers still work on the territorial rights model. However,

\footnotetext{
${ }^{67} \mathrm{PACT}$ is a trade association representing commercial interest if independent U.K. TV, film, digital, children's and animated media companies (from PACT https://www.pact.co.uk/about-us.html)

${ }^{68}$ Reda constantly refers to media content as "cultural works."
} 
Reda notes that sometimes the demands of the audience are not always what media producers deem profitable for their business. However, if a system has been working for so long, why change it? Or at least, why change it so fast? Therein lies the central obstacle for removing geoblocking. While media organizations and governments benefit from the territorial system of doing things, they will always ensure the internet is controlled to reflect the existing territorial model. In the E.U., the principle of free movement has always physically expanded on traditional territoriality that is not represented in their digital borders, and the argument concerning geoblocking becomes one more of dealing with media corporations and unifying on copyright strategies across member states.

The E.U. promises freedom of movement within its physical borders but blocked the free movement of services online by allowing digital, territorial borders to persist. The E.U. promises freedom of expression and access to information for its citizens and residents. However, as Reda (2020) points out, geoblocking undermines these rights by enforcing geographic boundaries on the free flow of information, especially in the form of cultural and educational material. Reda (2020) states:

It is self-evident that geoblocking constitutes a form of discrimination of content, differentiating the offer based on geographic boundaries. Proponents of geoblocking may argue that the practice is not discriminatory, as it is not strictly based on nationality, but on temporary geographic location, which the consumer can influence. This view does not take into account the very real financial, educational and cultural restrictions on freedom of movement within the E.U. (sec 5.3, par. 1, lines 1-5)

\section{Cultural Discrimination: Language and Cultural Heritage}

While cultural discrimination is tied to the essential principle that geoblocking can be geographic discrimination, especially regarding the concept of online cross-border portability (Reda, 2020), geoblocking as cultural discrimination requires its own section of analysis as it 
gives further insight into the tensions that exist between audiences and media corporations and governments. When it comes to concern over protecting cultural heritage, for example, governments and the audience seem to align the most when it comes to motivations behind regulating geoblocking (either dissolving or upholding it). Media corporations will also align with audiences and their needs here since it is the audience who fuels their profit, in the end. However, media corporations have certainly taken the concept of serving different cultural and language communities and segment markets from primarily helping protect these audience concerns to maximizing their profits and manipulating prices in different regions, which is discussed in the next section, economic discrimination.

So, audiences are concerned about protecting their culture in their media - in chapter three, I analyzed Anderson's (2006) explanation that print capitalism helped develop and spread nationalism (for better or for worse) as mass media helped establish connected myths and values that could bring together a group into an imagined community. We can therefore deduct that media has become rather personal and important to many as artifacts that uphold their national and cultural identities. For many countries, a key aspect to the people's culture is language. Beyond the concern of media-cultural imperialism forcing the spread of a media capitalist society - as described in chapter two and particularly regarding China in chapter three - came the concern over the dominance of an infiltrating language from one country into another country through media. Examining geoblocking as discrimination against language reveals how audiences also relate to media differently and, as such, affect how the internet is shaped to reflect their needs, thereby, indicating cultural bordered spaces on the internet. However, these spaces are not homogenous. This aspect is illustrated in the E.U. case study shows that the E.U. as a coalition of 27 member countries with many audiences in these countries not only speaking 
languages other than English or a primary only language other than English in a country, but also moving freely, as per E.U. policy, from one country to another.

In the E.U. case, Reda (2020) reports that travelers, exchange students, commuters, language learners, long-term migrants, and linguistic minorities are groups disproportionately affected by geoblocking. Geographic language minorities are particularly disenfranchised when it comes to accessing online content in their native languages. Reda (2020) provides the example of the island of Åland, a Swedish-speaking community in the Baltic Sea that belongs to Finland. While this community has no trouble accessing TV or radio content on traditional broadcast media, they struggle to access online content in their native language. This issue exacerbates when audiences of a language community travel abroad temporarily or emigrate to another country - whether in or outside of the E.U. However, Reda (2020) and others (as noted above) do not believe that geoblocking should be an issue as part of the free movement of people, goods and services, and information in the E.U. The issue largely connects to media corporations again who see no economic value in extending content online or access to language minority content when someone of that community is outside of that region. According to media corporations, an IP's reach can only be extended as far across different regional markets as there are economically viable audiences for content. This is purely business, but economic viability of an audience puts minority languages at risk of disappearing. There is an increased concern over the extinction of certain languages as the cultural content in those languages becomes unavailable due to the demand being too low to be economically viable (Reda, 2020).

An analysis therefore shows that the issues of cross-border portability and accessing the media content in one's native language online when traveling is a major concern for audiences, but not so much for corporations. The number of domestic tourists in Europe rose from 656.7 
million in 2018 to 682.2 million in 2019 (Lock, 2020b). However, Reda (2020) states that it is the most marginalized groups who are discriminated against the most in cross-border travel in the E.U., such as migrant groups, who still rely on news programs from their home country to keep connected with their cultural traditions.

Reda (2020) notes that counter arguments that state migrants can merely return home fail to consider low-income migrant groups and the economic disparity between these groups and more affluent groups in Europe who are privileged with more mobility. For example, Reda (2020) points to the E.U. policymakers and administrators as privileged groups who often have homes in Brussels, the E.U. headquarters, and have the disposable income to not only return to their home countries but even to travel to other owned properties as well. However, while Reda (2020) argues that geoblocking negatively affects the vulnerable groups, the arguments of the European film industry concerning geoblocking state the opposite - that geoblocking actually helps protect cultural diversity in Europe because it forces larger, transnational corporations to cater to different market regions. In a DSM system with no demarcated regional markets in Europe, there could be an increased focus on not only English-language content, but, specifically, American content. Both have viable arguments for and against geoblocking. The concerns of larger, multinational media corporate content providers, the European film and TV industry, and the culturally diverse European audiences are balanced by the EC agreement to institute a quota system, which obligates streaming services operating in the E.U. to dedicate at least $30 \%$ of their on-demand catalogs to local, European content (Vivarelli, 2018). In addition, Netflix and Amazon are required to fund European TV and films produced in Europe through several different methods: 1) commissioning content; 2) acquiring content outright; or 3) paying into national film funds; however, this option adds a surcharge to the subscription fee, which is a 
model Germany enforced with Netflix (Vivarelli, 2018). However, even before this, Netflix was already reportedly producing close to $30 \%$ European content, which is made evident by the growing list of content available from E.U. countries. However, Reda (2020) believes Netflix still focuses predominantly on larger cultural European groups and members, especially those more affluent than others. While Netflix did not seem to have an issue with the E.U. possibly removing geoblocking, it is not in support of the E.U. quota system.

Netflix argues that they were already investing in European content and would continue to do so, especially since their data shows ${ }^{69}$ they have the ability to take European content and release it as Netflix global originals, even non-English shows. Their data also reveals that their audience not only enjoyed the content but seemed to be demanding it. As Netflix Chief Product Officer Greg Peters, notes: "We now have multiple data points that show we can take nonEnglish shows, produced here in Europe... and by bringing them to the global audience that we have, in the right way, with great subtitles or great dubbing... we can build a huge global audience for these shows" (quoted in Cullen, 2018, par 2, lines 3-5). The German science fiction global phenomenon Dark (2017-2020), for example, was tremendously popular even in the U.S. where English-speaking Americans are notorious for generally not receiving foreign-language content positively especially when subtitled and not dubbed (Collins, 2018).

Localization, especially in connection with language, is important. We saw this clearly in the example discussed briefly in chapter two of Microsoft's failure to provide Icelandic speakers its operating system in Icelandic, assuming that because a large portion of the small country spoke English, they would accept easily the English-language version, leading to Microsoft eventually losing the market to a competitor (Goldsmith \& Wu, 2008). When it comes to media

\footnotetext{
${ }^{69}$ Netflix did not release this data to the public.
} 
content, however, Lobato (2019) states that it can be difficult to know how local audiences want their television to be and how sentiment around that may differ across regions because, typically, audiences do not feature prominently in local content debates. However, the E.U. is not the only region that shifted position on this issue and included their consumers directly in the debate of local versus global content and protections of culture in media either enforcing geoblocking or enforcing quota systems. In Canada, for example, there have been increased initiatives in 2018 for the protections of indigenous knowledge and culture in the Canadian IP system in connection with the United National Declaration on the Rights of Indigenous Peoples (United Nations, 2020), which "states that Indigenous peoples have the right to establish their own media in their own languages and to have access to all forms of non-indigenous media without discrimination" (par. 5, lines 1-3). The goal is to ensure indigenous cultural diversity is preserved. Canada is expanding their IP law to reflect the language of and UN protections of this declaration to include terms like traditional knowledge (TK), which includes "know-how, skills, innovations and practices developed by Indigenous peoples related to biodiversity, agriculture, health and craftsmanship," and traditional cultural expressions (TCEs), which includes "tangible and intangible forms in which TK and culture are expressed and may include oral stories, artwork, handicrafts, dances, fabric, songs or ceremonies" (Government of Canada, 2020). Canada does not, however, enforce a quota media production system on Netflix, but it does require Netflix to produce a localized Netflix Canadian platform that features Canadian produced content first over content from other countries (Lobato, 2019). Netflix's activity in Europe shows that while it is a transnational corporation that preaches globalized content libraries, it does not discount the power of localized content, but not necessarily out of any sense of altruism. In 2017 Netflix signed an agreement to invest $\$ 500$ million in TV and film spending in Canada, but the plan was 
vague on certain details, such as amounts of indigenous content versus otherwise general Canadian content (Ballingall, 2017), and was criticized for Netflix seemingly dodging tax and local content obligations required by local Canadian broadcasters and cable operators in exchange for the investment (Vlessing, 2019). However, Netflix did announce a pact with imagineNative, The Indigenous Screen Office (ISO), and Wapikoni Mobile in Canada to develop programs and workshops for indigenous peoples' media productions with the aim of the stories reaching not only indigenous communities in Canada, but those and more across their global licensed library (Gruenwedel, 2019).

Unlike the E.U. and Canada, however, America has no quota system of any defined “American" media content on Netflix or any other media corporation. Where the E.U. and Canada enact media policies focused on cultural preservation (especially when it comes to language), American policy is not concerned with accessing media content or cultural heritage but rather national values instead. This can be a complicated issue, such as with the Cuties (French: Mignonnes, 2020) case detailed in chapter three where American audiences became incensed over the release of the French film in the U.S. after a poorly marketed poster revealed minors in sexually explicit poses leading to calls to boycott Netflix. In the U.S. this was a case of disagreement on content matter than can be used in political dispute over Netflix and not necessarily spear-headed as one of culture or geoblocking, although it could easily have become a discussion over cultural differences in the representation of sex in different regions, but that was not the issue debated in U.S. press or brought up by U.S. government representatives. The focus was not on audience reaction as a question of cultural differences but rather on using audience reaction as leverage against Netflix. This content is currently not on the recommended page of any Netflix U.S. library. 
The data therefore shows that audiences do affect how media companies use geoblocking with their demands. Localization of "a product to a local market could make it more appealing to consumers in that market by making it feel closer to their own cultural experience" (Elkins, 2016, pg. 197). Films and television shows typically go through localization processes that delays release dates. Sometimes, the delay window helps give a production time to produce a dubbed version from the main language of content to that of the next market region release. However, Elkins (2016) states that while this can be a positive of geoblocking, which prevents access from another linguistic region while it is being processed as the media airs elsewhere, one cannot deny or ignore the primary reason for the system's continued implementation: profit. While localization of content is indeed a good reason for regional segmentation, one of the primary drivers for region codes and geoblocking of online media content remains profit.

However, Elkins (2016) explains that "geoblocking helps sustain a 'localized' approach to international expansion wherein products are adapted to local markets" and accessing adaptions versus original productions are not necessarily negative either (pg. 197). Nintendo, for example, did help make video games more appealing to a larger audience by localizing Japanese video games not only into the English language, but by replacing dialogue and even some imagery to make it more relevant and relatable with objects and phrases more familiar to U.S. audiences when it pushed into the U.S. market; however, they certainly made more money as well in the U.S. market by preventing dedicated fans of Japanese games in the U.S. through geoblocking from playing the original Japanese game and by charging more in the U.S. market for the same game, and yet even more for those who purchased an imported original-language video game, if available. As such, the analysis therefore shows that geoblocking as used by corporations is not so much for localization of content and to avoid cultural discrimination as 
demanded by audiences and governments, but to justify economic market segmentation for increased profit margins.

\section{Economic Discrimination}

Another form of discrimination emanating from geoblocking is economic. While this aspect was already touched on above with Reda (2020) referring to lower-income migrants especially lacking funds to travel back and forth and as a result struggling to access media content from their home country, the case in the E.U. does show more of a focus on cultural and language protections in relation to online media content access. Economic disparity appears to be more a concern for online shopping for E.U. audiences, but the price differences between online media streaming platforms did seem negligible overall. However, in Australia, geoblocking largely becomes an issue of economics and politics as opposed to an issue of protecting cultural heritage.

When HBO Now first released as an online streaming platform for HBO content that required no cable subscription in 2015, Australian consumers were excited to have direct access to popular HBO shows like Game of Thrones (2011-2019) (Reilly, 2015). However, as noted in chapter two, HBO, even HBO Now, was not designed for a global audience. Although HBO is a transnational corporation, HBO Now is available for audiences in the U.S. and certain U.S. territories only. It was designed to address the issue of cord cutters - audiences canceling cable subscriptions and opting for subscribing to SVODs like Netflix - in America. However, while HBO Now did put in place geoblocking parameters, they did not include VPN detection to identify users circumventing geoblocking using VPNs. At the same time, HBO's social media channels are not geoblocked and are open to audiences globally. With news spreading online and making its way faster on the internet to Australians about HBO Now, Australian audiences 
swarmed the site and successfully subscribed to this service even with Australian credit cards in an altogether seemingly legal fashion (Grubb, 2015). However, Australian audiences already had a local cable provider offering them access to HBO content, Foxtel Play (Foxtel), it just came at a much heftier price than subscribing to HBO Now directly online - even with the cost of currency conversions.

At the time, Australian audiences could subscribe to HBO Now for 14.99 U.S. dollars per month and with the addition of paying for a good geoblocking circumvention tool like Getflix, cost about 20 U.S. dollars per month (Grubb, 2015). Comparatively, Foxtel charged Australians 30 U.S. dollars per month for standard-definition; to have access to high-definition (which many preferred for watching epic fantasy series, such as Game of Thrones), the Australian audience had to subscribe to Foxtel's more expensive 12-month cable option, totaling around 660 U.S. dollars (including equipment and installation) (Grubb, 2015). In 2015, Americans were paying around 100 U.S. dollars for cable subscriptions and a selection of premium cable subscriptions. HBO cost between 15 and 20 U.S. dollars before HBO Now, but it did not include extension of HBO content online (unless HBO on Demand was purchased, but that required a cable subscription). The important fact to note here is that the media market's cost for media, physical but also digital, is quite drastically inflated in Australia causing frustration for Australians who feel their only recourse of action to fairly priced media content access is through online piracy. The economic discrepancy on media content became known as the "Australia Tax" (Lobato \& Meese, 2016). In a Productivity Commission inquiry report (2016), “Intellectual Property Arrangements," it is noted that the international price discrimination was actually supported by geoblocking, which fragmented the digital market into more rigid territorial boundaries, and, on average, Australian audiences were paying 50\% more for goods, including online media content, 
than audiences in the U.S. However, much like the E.U. found when it tried to dissolve geoblocking of digital media content, the system of copyright contractual agreements forced some copyright holders to either not sell in the Australian region or license out their copyright to another territorial vendor in Australia, such as the cable company Foxtel. Lobato and Meese (2016) report that by 2012 geoblocking became a largely political issue in Australia, and geoblocking created a national debate around it with politicians taking advantage and slanting the issue as a discrepancy between U.S. multinationals ripping off Australians and placed geoblocking as anti-competitive tool.

In 2015, Australian cable channel, Foxtel, which pays exclusive distribution licenses to screen HBO copyrighted content in Australia for first distribution rights, argued the HBO Now service was not properly blocking out Australian users thereby causing severe economic losses to their profits margins while HBO gained twice fold (both in taking the licensing money and accepting subscription payments from Australians online who circumvented geoblocking). Trying to prevent a legal nightmare, HBO later relented and soon users received emails notifying VPN subscribers:

It has come to our attention that you may have signed up for and viewed video content on the HBO NOW streaming service from outside of the authorized service area (the United States, including D.C. and certain US territories... We would like to take this opportunity to remind you that the HBO NOW streaming service is only available to residents of the United States, for use within the United States. Any other access is prohibited by our Terms of Use (in Grubb, 2015, par. 3, lines 1-3; par. 4, lines 1-3).

However, the Australian audience claimed they would not need to use VPNs if they were offered faster and more affordable access to global content legally. Lobato and Meese (2016) states that due to the high costs, the Australia Tax, and slow delivery of first-release content, Australian audiences see themselves as "second-class" media citizens. 
Lobato and Meese (2016) note that where the country is situated in the world has much to do with how screen culture developed in Australia affecting the situation with $\mathrm{HBO}$, the audience, and Foxtel. While Australia is large in landmass and similar in size to Europe, in population, it is quite small with 25.52 million people as of 2019 versus Europe's 747 million (Plecher, 2020; Clark, 2020). The nearest other country is Papaua New Guinea. Unlike Europe, with a tradition of cross-border satellite TV, in Australia, a colonial broadcast model has endured over the years copying the BBC system in the U.K. for their national public-service broadcaster, even featuring BBC content prominently (Lobato \& Meese, 2016). While there are three commercial free-to-air stations and two public-service broadcasters, there is only one pay-TV provider in Australia, Foxtel at the time. The Australian government does mandate a quota requirement on local broadcasters to carry at minimum 55\% local programming fee at prime time. Media imports are dominated by the U.S. and the U.K. with U.S. content proving exceptionally popular due to Australia's allegiance to the U.S. post-World War II and the fact that Australia became a high-margin export country for American content (Lobato \& Meese, 2016). Australians became used to free-TV offerings and imported television, especially U.S. TV. The only problem was the long delay of up to several months to some years for content to be aired on local broadcasting stations after originally airing in the U.S. Television primate time seasons in the U.S. do not correlate with those in Australia, occurring in the summer at the end of the year, so local TV holds off until their prime ratings season begins. As a result, Australian audiences also started finding ways to access blocked media content online. This frustration of waiting for content to becomes available becomes a common thread among many countries where their audiences are circumventing geoblocking and even using VPNs to even circumvent 
their own local Netflix library (if it is available) to access the U.S. Netflix library. For these users the issue is not so much a lack of access as it is about denial of relevant access.

According to data on the Unofficial Netflix Global Search (uNoGS, 2020), as of January 2020 Thailand surpasses all Netflix region libraries with 7268 titles (4,923 films and 2,345

series). ${ }^{70}$ The rest of the top four largest media libraries include Canada with 5891 (4,071 movies and 1,820 series), U.S. with 5,888 titles (3,953 movies and 1,935 series), and the U.K. with 5,865 titles (3,860 movies and 2,005 series). In July 2018, Japan was in the number one slot with 5,963 titles (4,621 movies and 1,342 series) (Cook, 2018). While the number one position often fluctuates, the position was dominated by the U.S. library from 2007 until about 2016, when streaming content became more profitable and more platforms established themselves as competition in purchasing rights for streaming rights for movies and series. One factor has remained relatively constant; however, the U.S. always seems to boast the highest number of TV series of any country with the U.K. library having grown exponentially and now either always being close to or even equal to the U.S. library. It is this TV series library that is most sought after by audiences outside of the U.S. (Cook, 2018)

As noted in chapter three, VPNs, especially before 2015, were a grey area of legality since many people use them to access the internet in public areas safely through for instance a private network, which is a fairly legal use of VPNs, and an issue of online privacy concern for audiences. However, in Australia, prior to 2015, "the geographic price discrimination is one reason why the practice of geoblocking carries such cultural resonance for Australian consumers" and why circumvention became such a common practice that even politicians joked about their own circumvention of geoblocking in parliament (Lobato \& Meese, 2016, p. 123).

\footnotetext{
${ }^{70}$ As of access date 1/30/2020.
} 
However, the HBO issue with Foxtel came at an unfortunate time when emails from Sony Pictures were leaked including messages complaining about Netflix not doing enough to geoblock their content (Lobato, 2019). Suddenly, online streaming services became more anxious over ensuring geoblocking of copyrighted media on their platforms, resulting in a shift in the entire discussion on the legality of VPNs, spurring not only concerns about accessing content from outside regions, but also for the clearly legitimate use of VPNs for protecting user privacy online ${ }^{71}$. The HBO in Australia case led to a much larger movement against SVODs with wider repercussions on Netflix who also became stricter about blocking VPN access to the U.S. Netflix library from members outside of the U.S., especially while Netflix targeted a more global audience rather than the U.S. audience first. Lobato (2019) notes how these grey area audiences using VPNs to circumvent Netflix U.S. was not unknown to Netflix. Not only was Netflix perfectly aware of this situation, but they used it as barometer of interest in other markets they did not service yet. However, after the HBO issue and the Sony email leak, and with Netflix expanding into more regional markets and still relying on copyrighted content from sources like Sony, Netflix had to change its unspoken blind-eye policy and officially announce their new geoblocking and anti-VPN stance as company policy in 2016 (Lobato, 2019). While Americans overall did not seem aware of geoblocking, Lobato (2019) notes that news media focus and social media discussions on Netflix's new policy announcement seemed to have led to an increase in public awareness, if not on geoblocking itself, then on the existence of different

\footnotetext{
${ }^{71}$ The issue regarding audience privacy and VPNs was especially fraught with anxiety from users in 2012 and again in 2015 when the Australian government discussed anti-piracy policies that would protect copyrighted goods (Lobato \& Meese, 2016; Gurbb, 2015). However, in 2012, the Australian government, while implanting copyright protections made it clear to their citizens that they would not include criminalization of using geoblocing circumvention tools since it was so nationally significant not only to regular audiences, but even to those working in government (Lobato \& Meese, 2016). This is considerably different from the U.S. DMCA discussed in chapter three, which very clearly criminalizes using circumvention tools to access copyrighted material.
} 
geographic markets resulting in a growing market of websites listing what media content is available on which Netflix libraries globally.

The analysis of the above indicates that there are still audiences in regions who want access to content beyond their local offerings, and specifically, the U.S. or other cross-border media content such as the U.K. library. While audiences were content with the long delay system and a limited offering of U.S. content of the past, it no longer worked when countries such as Australia connected to the internet. Coupled with the popularity of social media (discussed further below) the model of long delays no longer holds steady while the whole world is in direct conversation with one another on social media platforms. With local audiences "hooked into global TV fandom in real-time through Twitter, internet forums and fan websites" audiences can no longer tolerate the long delays leading audiences to turn to circumventing geoblocking tools by illegally downloading media content or using VPNs to access online media content (Lobato \& Meese, 2016, p. 122).

\section{The Audience, Social Media, and Geoblocking Social Media and Spoilers}

The example on economic discrimination in the previous section involving $\mathrm{HBO}$ in Australia, showed that while economics is a factor in the motivation for audiences to put pressure on governments and media corporations to change their policies, another aspect from that case was a major factor for Australian audiences to jump at the chance for access to HBO Now using VPNs, namely the issue of the delay window. Australian audiences also complained that during this delay window they would see spoilers ${ }^{72}$ of their shows on social media (Lobato \& Meese,

\footnotetext{
${ }^{72}$ A spoiler of TV and film media content is revealing information about the plot that can be significant.
} 
2016). In “The Battle Against Geoblocking: The Consumer Strikes Back", Sabrina Earle (2016) notes that while delayed content will eventually find its way into geoblocked territory ${ }^{73}$, this creates a situation where content could be spoiled by audiences online, such as on social media. While some argue that audiences could just refrain from the internet and social media, Earle (2016) says that this has become rather complex with how ubiquitous and ingrained internet usage is in most people's lives.

While spoilers probably may seem a negligible concern, a "first-world problem" one could argue, compared to the other motivations listed above, how people participate with others in relation to media and how they participate with media can have important ramifications for all aspects of life: personal, economic, and political. In Connected Viewing: Selling, Streaming, and Sharing Media in the Digital Era, Jennifer Holt and Kevin Sanson (2014) present connected viewing as "a multiplatform entertainment experience and relates to a larger trend across the media industries to integrate digital technology and socially networked communication with traditional screen media practices" (p. 1). Connected viewing sees the migration of media and attention across multiple screens leading to changes in media flows, but also challenges previous traditional business models. Holt and Sanson (2014) describe this "connected viewing" as "more than digital distribution; it is the broader economic system in which digital distribution is rendered possible and new forms of user engagement take shape" (Holt \& Sanson, 2014, p. 1). Social media makes viewers feel connected to the production, part of the birth of the media product, and studios are not blind to this engagement that viewers are looking for, recognizing

\footnotetext{
${ }^{73}$ Although, this may not always be the case as some markets are either just not profitable or for other reasons, such as political censoring, etc.
} 
the avenue of advertising content through user-generated content ${ }^{74}$. Production companies even ask actors and actresses about their social media, including their follower numbers, in determining whether someone will be a good cast for a role, and will even include stipulations in cast members' contracts about content of the production that must be posted and content that may not be posted to personal social media accounts (Schulman, 2018).

However, an analysis of the case of Netflix and access to The Great British Bake Off (abbreviated GBBO or GBBS ${ }^{75}$ in the U.S.) in the U.K. and the U.S. shows that a significantly reduced delay window has not helped reduce the complaints concerning spoilers and even possible increased awareness of geoblocking among U.S. audiences. Earle (2016) indicates that in the age of digital media content and online content platforms, audiences are expecting near instantaneous access to media content. However, not only does it seem to be timing issue, but access to everything associated with an IP. For example, in the case of GBBO, audiences outside of the U.K complain about spoilers since they follow GBBO's social media accounts - which, like HBO, are open to anyone who can access the social media platform regardless of location but also about accessing all franchise content related to GBBO. Global GBBO audiences became aware that they were not getting access to certain specials that the official accounts were posting about on their socials. Specials, such as The Great Sport Relief Bake Off, The Great Comic Relief Bake Off, and The Great Stand Up to Cancer Bake Off, among others, are not distributed to the

\footnotetext{
${ }^{74}$ User generated content can be variety of elements from posts consumers make on social media to writing stories (fan fiction) or making art (fan art) about content or brands we enjoy, or even do not enjoy. The pro in this kind of arrangement is free advertising. Brands can use social media posts and share them and not have to pay a cent. The con is that control is out of the hands of the producer and owner concerning the content. In his book Convergence Culture (2008), Henry Jenkins describes how fans can create content around a property that may not fit the brand identity a company is building, such as adult-themed fan works that may include sexually explicit descriptions or drawings of characters from the now Disney Star Wars productions or of Warner Bros'. Harry Potter. While fan works have existed well before the internet, sharing on social media has become easier, prevalent, and far more visible.

${ }^{75}$ The Great British Baking Show in the U.S.
} 
U.S. market by Netflix. It did not help that celebrities famous on other popular Netflix titles were being featured on some of these specials causing a coming together of very active global audience fandoms.

On March 24 $4^{\text {th }}$, 2020, Netflix's Queer Eye "Fab Five" member Tan France posted on Instagram notifying his 3.9 million followers ${ }^{76}$ from around the globe of his upcoming appearance on The Great British Bake Off charity spin-off, The Great Celebrity Bake Off for Stand Up 2 Cancer (SU2C). However, while many seemed excited, others were deflated reading the caption: “My episode of the @britishbakeoff is on tonight, in support of @su2cuk!! I hope you'll be watching. (UK only)" (France, 2020, emphasis mine). Of the 372 replies, four were users lamenting that they did not live in the U.K., 39 were asking how to view it in the U.S. or when it could be viewed in the U.S., two reported no access from Canada, one asked how to access from Germany, and two lamented not being able to view from Australia. ${ }^{77}$ On the official GBBO Instagram page, a post (2020) advertising France's episode reports 240 comments, which included 79 comments asking for access in the U.S. and one comment each for access from Canada, Amsterdam, Brazil, and Hungary.

Due to Netflix's acquisition of digital distribution rights of GBBO in the U.S. from PBS in 2018, GBBO has garnered larger followings and success especially with U.S. audiences, so much so, that the unassuming baking show from the U.K. is described as "part of U.S. culture" (Baker, 2019). The audience fervor for faster access may very well have pushed Netflix to obtain the exclusive U.S. digital distribution of GBBO as a "Netflix Original" from the new U.K. rights owner, Channel $4,{ }^{78}$ and airing series 10 (collection 7 on U.S. Netflix) episodes in the U.S. only

\footnotetext{
${ }^{76}$ As of July 2020.

${ }^{77}$ Not included in the count are replies to comments, which are still counted.

${ }^{78} \mathrm{GBBO}$ is produced by Love Productions, but was originally licensed for distribution by the BBC before Channel 4 bought the rights for distribution in the U.K.
} 
three days after airing on Channel 4 on Netflix U.K. As noted previously in this chapter, audiences do have power in influencing media corporations to make certain media titles available to them, especially if they can show they are a large enough economic profit market. Conversely, as the "Cuties" example in chapter three indicates, groups can cause an uproar against media corporations and content, even trending on social media, so that it garners far more publicity than before, which can lead to negative effects, such as canceled subscribers and a push for removal of the content.

GBBO fans in the U.S. shared a similar experience with Australian audiences who suffered months to years for content when it came to waiting for GBBO content to air in the U.S. Prior to the current short distribution window, GBBO fans in the U.S. and other territories waited months to even years for episodes that were sometimes still a series or even two behind the U.K. While GBBO distribution rights have been sold in 196 territories and in 20 territories for localized versions Netflix's "Original" in the GBBS title only refers to its rights in the U.S (Plunkett, 2015) . BBC Worldwide still retains global distribution rights of GBBO until 2028, ${ }^{79}$ which limits Netflix's ability to make it a truly Netflix Original in the way it does with Queer Eye. Both Queer Eye and GBBO have tremendous popularity, but audiences are still struggling for access to GBBO content whereas there is less struggle for Queer Eye.

\footnotetext{
${ }^{79}$ Due to a licensing deal where BBC Worldwide still retains the international rights to the show - they reserve the right to license franchise versions in other countries and have first-negotiation rights for international distribution outside of the U.K. and the U.S. until 2028 (Nissim, 2016). There are over 30 franchises of GBBO across the globe, but for some reason, the original, British, version remains popular in the U.S. with an American version failing and limited now only to a holiday special.
} 
According to the uNoGS (2020), GBBO is viewable in one Netflix region, the U.S., ${ }^{80}$ while Queer Eye is viewable in over 32 Netflix regions. ${ }^{81}$ Furthermore, while Netflix owns digital distribution rights for GBBO across several of its markets, that does not include any specials beyond the Christmas specials, ${ }^{82}$ which brings back previous competing bakers from the series. The GBBO SU2C episodes are only available for viewing on Channel 4's website, ${ }^{83}$ which is geoblocked for fans outside of the U.K. While the episodes are blocked on Channel 4 and not made available on Netflix, the social media pages not only of GBBO, but of those celebrities that use their socials to promote their episodes and the bakers, are open for all to follow and see glimpses of content they cannot access. Fans, even from the U.S., note confusion at the disparity between seemingly global media content and lack of actual access. As such, it is not uncommon even for these U.S. audiences to turn to illicit means of media content access, such as unofficial streaming sites or downloading from peer-to-peer sites.

\section{The American Audience}

The E.U. and Australian cases were predicated on audience knowledge of and experience with geoblocking. For any policy changes to take place and for the possibility of a shift toward a conversation of a system that sees the dissolving of geoblocking of digital media content to exist there must first be awareness of it. If geoblocking were to be removed at a more global scale,

80

https://unogs.com/search/The\%20Great\%20British\%20Bake\%20Off?countrylist $=21,23,26,29,33,307,45,39,327,331$ ,334,265,337,336,269,267,357,65,67,392,268,402,408,412,447,348,270,73,34,425,46,78

${ }^{81}$ It is possible it is more, but the reporting on the site is based on audience reporting and VPN access to different libraries, but at the time of reviewing in July 2020, Queer Eye is confirmed in at least 32 Netflix libraries. https://unogs.com/search/Queer\%20Eye?countrylist=21,23,26,29,33,307,45,39,327,331,334,265,337,336,269,267,3 $57,65,67,392,268,402,408,412,447,348,270,73,34,425,46,78$

${ }^{82}$ While GBBO proper series is airing now within a few days from airing in U.K., the Christmas specials are still airing one year off in U.S. Netflix and other Netflix libraries versus when these episodes air in the U.K.

${ }^{83} \mathrm{https}: / / \mathrm{www}$.channel4.com/programmes/the-great-british-bake-off 
American audiences would have to be included. This is especially so since the American market is still a large and lucrative market and a majority of the media corporations (online and or otherwise) originate from and are still based in the U.S., including Netflix. American audiences may, indeed have the most power to influence the media corporations and government regarding geoblocking, but then awareness of the use of geoblocking needs to increase.

While there is no conclusive quantifiable data on this issue from any American government research or other groups, I conducted my own preliminary online survey which indicated that American audiences who had accessed the internet from at least one country outside of the U.S. had a higher rate of knowledge about and experience with geoblocking than those who did not ${ }^{84}$. Of a total of 166 respondents who noted the U.S. as their primary location of internet access, 74 (44\%) reported never having accessed the internet outside of the U.S. Of these 74 individuals, 24 (32\%) reported they could not identify that they had ever been blocked access to online media content because of their geographic location while a surprising 43 (58\%) reported they could identify they had been blocked access to media content online because of their geographic location ${ }^{85}$. However, of these 74 individuals, only 25 (33\%) could identify this process as geoblocking whereas the majority at $49(66 \%)$ could not. The fact that $58 \%$ of these individuals who have never accessed the internet outside of the U.S. could identify they had been blocked access to media content was a significantly high number compared to the general American audience with their knowledge and experience of being geoblocked being low to near non-existent, outliers notwithstanding.

A comparison of this data to those individuals who have accessed the internet from at least one other location outside of the U.S. as their primary location indicates that out of 91

\footnotetext{
${ }^{84}$ Survey directions and full set of questions available in Appendix.

${ }^{85}$ Seven (10\%) individuals reported that they were not sure.
} 
individuals, only $12(13 \%)$ could not identify that they had ever been blocked access to online media content compared to the large majority of $67(74 \%)$ who could ${ }^{86}$. Furthermore, of the 12 $(13 \%)$ individuals who reported that they could not identify if they had been geoblocked, all but one could not identify the process as geoblocking. Of the $67(74 \%)$ who identified accessing the internet in at least one more country outside the U.S. and who could identify they have been blocked because of location, only 27 (40\%) could identify the process as geoblocking whereas $40(60 \%)$ could not.

The most interesting aspect of this preliminary data is that there is a $16 \%$ difference between those individuals who identified accessing the internet only from their primary U.S. location versus those who have accessed at least one other country from the U.S. as primary location of internet access who could both identify they had been blocked access to online media content because of their geographic location. This is much lower number than what I had anticipated based on available scholarly research, however, the survey was released on my Twitter account. Since I am an immigrant to America from South Africa, the way I relate to media and the internet correlates with the way Reda (2020) describes many migrant and other immigrant families do in Europe, often connected to the home country through family or through media-cultural connections that one cannot expect migrants and immigrants to merely let go of when in a new country. My followers do reflect a more globally aware American audience, including many of my American students (some of whom have not yet had a chance to travel outside of the U.S.) who I have been lecturing about geoblocking since 2017. Many of my academic colleagues follow me on Twitter who could also have been participants who frequently travel to conferences outside of the U.S. However, the preliminary data points to some

\footnotetext{
${ }^{86}$ Twelve (13\%) individuals reported that they were not sure.
} 
interesting aspects that begins to open up more questions about whether physical travel is necessary for more awareness connecting to the aspects of portals, such as social media, acting as virtual visiting spaces where audiences are getting exposed to more content outside of their geographic regions. However, my survey did not ask if participants were aware of geoblocking because of social media, but this chapter addresses some points that we already know about how audiences are connecting to global media on social media and using it as a space to even voice their dissatisfaction when there is a lack of access.

In Convergence Culture: Where and New Media Collide, Henry Jenkins (2008) warns media producers that the media landscape has changed and that we are a "convergence culture, where old and new media collide, where grassroots and corporate media intersect, where the power of the media producer and the power of the media consumer interact in unpredictable ways" (p. 2). Jenkins (2008; et al. 2013;) states that pervasive social networking connects audiences on an almost unparalleled level and notes how audiences want to be a part of a conversation - a discussion - but can only do so appropriately when they know the context. Jenkins (2008) warns media owners that their traditional ways of thinking about media ownership and copyright (and I add the rights that come with that, such as distribution rights) are not in line with the expectations and even feelings fans (audiences) associate with media content. HBO experienced this in Australia with audiences subscribing to their service when they had not intended the HBO Now online platform for release in that market. This is experience by HBO is exactly the point: the way media corporations used to think, strictly territorial, around their media properties is not in line with the more flexible mindset of the audience, especially as audiences are connecting more with audiences from outside their own localities over social media. This implies that corporations will have to think carefully what and how they geoblock 
content. In chapter five, I will discuss this more in terms of concluding what kind of environment would be necessary for the removal of geoblocking of digital media content and the effects that predictably could be seen for media corporations, governments, and the audience.

\section{Conclusion}

This dissertation examines geoblocking's role as a tool that was developed in reaction to dissolving offline territorial borders online because of globalization. In this chapter, the relationship between audience motivations and geoblocking was investigated. Although the audience does not directly utilize geoblocking, corporations and governments enact policies of geoblocking that affect the audience and the information show how audiences developed reactions to these policies. An analysis of the ways in which audience motivations support or attempt to counteract corporate and government justifications of geoblocking show one of the key factors is which audiences know about geoblocking. For an audience to act against geoblocking they must be aware of it as it evident in the case of Australia versus HBO.

To know why audiences would be for or against geoblocking examining audience motivation for using or opposing was important, and as illustrated by the information, it is a complex issue. We saw that general audiences do not make capital profit from media. Rather, audiences use media to engage in the commerce of culture - the import and export of it. Just as governments seek to protect their physical borders from commercial infiltration from other countries and corporations, some audiences have a vested interest in protecting digital borders from cultural incursion. On the other hand, some audiences are in favor of exposure to other cultures. Those in "fandom," for example, depend on timely and relevant access to media to interact with their peers internationally. 
This chapter showed that audiences have complicated reasons mostly against unjustified geoblocking with mostly non-American audiences making room for justified geoblocking. This finding is not accidental. The bulk of available research on geoblocking revolves around audiences outside of the U.S. When it comes to geographic, cultural, and economic discrimination of geoblocking against audiences, American audiences are often used as short points of reference in comparison to the audiences more affected by it, such as European and Australian audiences. Even audiences in more privileged markets, like Europe compared to Australia, are still considered peripheral audiences compared to the U.S.

Audiences aware of geoblocking can pressure governments to dissolve corporate geoblocking for motivations surrounding cross-border movement of goods and media, online privacy concerns, and language and cultural discrimination of media content and access. The case study of the E.U.'s "Digital Agenda" initiative (Stamatoudi, 2016), illustrated the increased anxiety over media-cultural imperialism over corporate empires like Netflix and balancing government policies with audience needs and wants. The E.U. promises freedom of movement within its physical borders and while it could resolve the issue of geoblocking for online shopping of general goods and services, was unable to remove geoblocking of the corporate media sector due to the protections afforded by territorial copyrights - transnational media corporations lobbied for the continued protections of copyright and their right to the regionally segmented market system in Europe. However, the case revealed an unexpected complication with the small, independent European film industry in support of geoblocking as well, but in the name of protecting the cultural heritage of local film from these large transnational corporations. They are concerned that geoblocking is exactly what is protecting them from large media empires, such as Netflix. Audiences should not be bothered then with the inconvenience or 
discriminations posed by geoblocking because the independent European film industry needs it more, which is a valid point. However, Reda (2020) indicates that, unlike Netflix and Amazon Prime, the independent films do not even garner releases outside of their regional, national market, so audiences in all of Europe do not benefit as much in the end. However, when it comes to geoblocking as a tool to protect local media content and through that cultural heritage, governments and the audience overall do seem to align in their support that there must be some oversight of transnational and larger local corporations. However, for corporations, serving different cultural and language communities and segment markets is more related to maximizing their profits and manipulating prices in different regions than from the desire to help protect these audience or even government concerns.

Audiences are concerned about protecting their culture in their media. Geographic language minorities are particularly disenfranchised when it comes to accessing cross-border online content in their native languages such as the Swedish-speaking people of the island of Åland discussed in this chapter. The European film industry argues that geoblocking helps protect cultural diversity like this group because it forces larger, transnational corporations to cater to different market regions. However, the independent film companies are correct that it is possible that in a DSM system with no demarcated regional markets in Europe, there could be an increased focus on not only English-language content, but, specifically, American content, and focus on only the larger and more economically profitable culturally linguistic groups in Europe from transnational SVODS. To combat this, the E.U. resorted to a quota system to try and protect culture in their media. Others, like Canada, do not enforce a quota on Netflix, but requires Netflix to produce localized Canadian produced content in corporate to government agreements, 
which do, however, cause friction with local production as governments seem to promise tax cuts to large transnational media companies in return.

However, Netflix's activity in Europe, and even countries like Canada (despite the possible tax break reasoning), shows that while it is a transnational corporation that preaches globalized content libraries, it does not discount the power of localized content and works to offer that content to its different markets. While Netflix is still in the business of profit, they have pushed more so than most of the larger transnational media organizations in offering different language content, minority-focused media for local regions and globally. As long as this system provides Netflix with profit, it will continue to do so and be open to offer more, as more audiences can influence them, especially by showing their economic viability, or if audiences push to get their governments involved. In this regard the research shows that geoblocking helps sustain a localized approach to international expansion online wherein products are adapted to local markets and accessing adaptions versus original productions are not necessarily negative.

Economic discrimination was examined in this chapter through the case of HBO versus Australians. Foxtel, the Australian Cable provider, criticized HBO for arguably not doing enough to block Australian citizens from subscribing to HBO NOW, a service intended only for U.S. audiences. The Australian audience complained about economic discrimination since their cost of media access by these local providers is inflated compared to what Americans have access to and what they were able to access when signing up for HBO NOW through a VPN. This case also showed the kind of content audiences desire specifically and how they will bypass geoblocking to obtain it. Australian audiences particularly wanted access to the global HBO hit Game of Thrones (2011-2019). This case had large repercussions that affected the way Netflix 
approached the issue of online piracy and global audiences using VPNs to access different Netflix libraries, particularly the U.S. library, which always seems to boast the highest number of TV series of any country since it is this TV series library that is most sought after by audiences outside of the U.S. (Cook, 2018) The analysis of the case indicates that there are still audiences in regions who want access to content beyond their local offerings, and specifically, the U.S. or other cross-border media content such as the U.K. library.

While audiences were content with the long delay system and a limited offering of U.S. content in the past before the internet, it no longer works when audiences are connected to the internet. Coupled with the popularity of social media, the model of long delays no longer holds steady while the whole world is in direct conversation with one another on social media platforms. As Lobato \& Meese (2016) stated, with local audiences "hooked into global TV fandom in real-time through Twitter, internet forums and fan websites" audiences can no longer tolerate the long delays leading audiences to turn to circumventing geoblocking tools by illegally downloading media content or using VPNs to access online media content (2016, p. 122). My deduction is to agree with scholars such as Henry Jenkins (2008), who warned media producers that the media landscape has changed and the strict separations that once existed between the media corporations and audiences have blurred as media corporations rely on user-generated content, but at the price of losing the control and ownership of their media content the way they previously conceptualized it before the internet, especially. It is now clear that pervasive social networking connects audiences on an almost unparalleled level and audiences want to be a part of a conversation with one another online. The territorial way media corporations used to think around their media properties is not in line with the more flexible mindset of the audiences of today, especially as audiences are now connecting internationally in real time over social media. 
This point is illustrated by the final case study in this chapter involving Netflix's American fans of The Great British Baking Show and the show's social media accounts. The program airs three days in the U.K. before it airs on Netflix U.S. but is reported on by a single show social media account, which now has followers from more than just the U.K., but all at different delay windows. Audiences now have social connections attached to their media usage and make global connections with even localized content. Even Americans who have never traveled outside of the U.S. are posting their confusion over content disparity in their region versus what they're seeing in another, posting their frustration at noticing they are being blocked immediate access to content because of their geographic location. This implies that corporations will have to think carefully what and how they geoblock content, or rethink copyright. Governments like the E.U. are working to rethink copyright, but as this case also showed, it will take the cooperation of the copyright holders (who are not always media corporations) to change the system. 


\section{Chapter 5: Conclusion}

An important question posed by this study is why and how have traditional, older models of media distribution that were based on physical national borders, persisted after the advent of the internet, a new medium allowing the ability to access media globally and beyond physical borders. The answer is that media corporations, governments, and the audience are responsible for its persistence. While all three groups use or are affected by geoblocking as a control mechanism in order to serve their varying motivations and needs for maintaining control over accessibility of content and information, which at times align and at times are in conflict with one another, this study shows an uneven power distribution exists with media corporations and governments maintaining most of the control and that they have the ability to dictate audience behaviors online to match their expectations and model offline.

This chapter provides a summary of key aspects of the dissertation on corporate, government, and audience motivations regarding media that leads to the application of or erasure (or attempted erasure) of geoblocking and shows the levels of power and discrepancies between the way things are expected to be offline versus how they are online. It shows how geoblocking essentially acts as the digital border control mechanism interpolating between all these motivations and the pre-existing economic, political, and social practices around media content distribution and access from an era before the internet to an era after the internet's inception. Secondly, the limitations and areas of future studies are discussed. Lastly, this conclusion reflects on the impact of eliminating geoblocking and why it probably will not ever happen. 


\section{Geoblocking and Media Corporations}

A review of the research in chapter two shows that while media corporations cooperate with government law and use geoblocking to help mitigate each government's different media policies, essentially, media corporations are motivated to use and maintain geoblocking to maintain their profit margins; more specifically, media corporations use geoblocking on the internet to maintain their profits tied to systems of territorial copyright of Intellectual Property (IP) pre-dating the internet- making sure an open internet is bordered to reflect their regional market media distribution system that allows them to price discriminate as a property is moved from one region to the next.

In the media corporate system there is friction between old media infrastructural systems and new systems, especially the internet, with legacy media corporations in constant battle with media corporations operating primarily online, such as Netflix, for control over the audience, and the audience equals profit. Geoblocking is utilized to help negotiate between old media and new media infrastructures by shaping the internet to move from an open, networked system to a closed system that resembles the existing regional markets and ensure continued, maximized profits.

Before the development of the internet, media content found its way across national borders in approved and illicit pathways or channels. Approved channels were dictated and approved by media corporations who developed the national, territorial system of media distribution and access, especially through copyright, which later became a key reason for the utilization and enforcement of geoblocking (Lobato, 2016; Yu, 2016). While no international copyright exists, countries generally agree to support one another's claims on copyrighted material, including the copyright holder's right to "country-by-origin" access of their IP (WIPO, 
2018). Copyright is based on the territorial principle of "country-of-origin" that gives the copyright holder the power to dictate how and where their copyrighted content will be distributed. Copyright holders are not always media corporations, who can purchase a copyrighted IP or license it, but there has been an increased move of corporations producing their own IP. Copyright holders can sell the license to their content to one distributor in one country and again to another in another country, or they can choose to release it in only one country and not another, or a set of countries - the point is, they, essentially, have the most power in determining where, when, and how they want their IP accessible. Thus, the territorial, nationalbound system of media content release was developed, which was later further enforced into the digital age with the region code system for the development of DVDs that were released not only for a particular region, but at a particular time - the delayed-window system determined that media content was released in a linear fashion in a certain order on both platforms by region.

However, while copyright holders do have control of their property, sometimes, distribution is in control of the government, which could dictate where an IP can even enter regardless of whether a copyright holder wants their IP distributed there or not. A such, media corporations do work at times with governments in a symbiotic relationship that can benefit both. Media corporations entreated the support of governments to enforce policies to protect both the channels of distribution and the media content itself by regionally designated markets and systems of territorial copyright laws and contracts. These protections are designed to help ensure media corporations can act legally against illicit access of their copyright. Illicit pathways are spaces of media content spillover, where copyrighted content finds its way in a region either before its due publication date or in an entirely restricted regional market (Tremble, 2014). However, economic, political, and societal changes wrought by the advancements in media 
technologies in print, telecommunications, radio, and television as well as the technological advancements in transportation including trains, planes, and boats, seem to pale in comparison to the changes caused by the internet which connects people globally instantaneously.

Where older media corporations relied heavily and almost implicitly on systems designed by fixed national borders, such as the regional market system and delayed window release of content, new corporations like the online media streaming company, Netflix, entered the media market and started to disrupt the usual order of distributing media. Netflix was unique in the era of media corporations in the late 1990s, opting to let users subscribe to an online DVD rental service that charged no late fees and that delivered the DVDs by mail. Eventually, Netflix dissolved the delay-window system as it grew into an online video streaming platform and dropped seasons of their original programs all at once as opposed to spreading episodes out in the traditional episode per week release system, which would see some regions like Australia waiting months or even years before an IP from another region, like the U.S., would reach their broadcasters. In addition, audiences proved reluctant to accept the traditional national boundaries transposed to online media access with a propensity to access media content not available to them legally utilizing geoblocking circumvention tools like peer-to-peer downloading websites or VPNs to trick a website into reading a local IP number instead of the IP registered outside of the region.

The violation of copyrighted content was normally never quite the issue it has been since the advent of the internet, and was, historically, accepted as commonplace with share culture among peers common with physical goods (Lessig, 2004; 2006). While large black markets would be cracked down on by governments at the behest of media corporations, in general, small black markets would still thrive as well as personal sharing. Even when digital rights 
management tools enforced by the U.S. Digital Millennium Copyright Act (DMCA) made it so DVDs could not be copied without some effort, people could still share those physical products with one another, and they could be sold at black markets (Trimble, 2014). As long as these illicit pathways of media access did not hurt the revenue stream of media corporations or threatened government economy and their ability to regulate business, media corporations were happy to move on with business as usual. With the advent of the of the internet things changed. The media content spillover occurring on the internet became a large-scale profit concern for media industries, as the informal sharing economy could now load and access millions of media content at one time online versus the small-scale levels offline. The internet, although initially designed for military use to have a decentralized network of communication, became a space of permeable nodes of knowledge and communication. It was seemingly open, and audiences soon discovered the internet as a channel of illicit access to previously prohibited copyrighted media content from their local territories and beyond.

More advanced control and segmentation of corporations operating on the internet became a reality in 2000 as evidenced by the case of Yahoo vs. LICRA where the French government ordered Yahoo to block French users from accessing their auction websites to purchase Nazi memorabilia. The purchase of Nazi memorabilia is illegal in France and several other E.U. member nations, which does make it more manageable for government to oversee the sales and purchases of such good within their border. However, online sales of the prohibited material became a larger issue. While Yahoo stated French users already had their own localized Yahoo site, French courts accused Yahoo of not doing enough to block the access of other Yahoo sites to French citizens. Cyril Houri proved that Yahoo could block access to their sites based on a user's geographic location, which became the building block for modern day 
geoblocking (Goldsmith \& Wu, 2008). Modern day geoblocking was not only the answer to negotiate with governments, but to also deal with issues of advanced illicit access to copyrighted material, challenges to the issue of eroding regional bordered markets from offline to online, and control of the flow of changes to their system that could damage profits.

\section{Geoblocking and Governments}

This chapter detailed how governments in turn are motivated to utilize geoblocking by extending their pre-existing legal systems that corporations and the audience abide by to the internet, as well as protecting against perceived increased encroachment of media-cultural imperialists in the form of transnational corporations spreading Western (i.e., mostly U.S.) ideals and values across their borders through online media expansion.

As described in the chapter, while the concept of imperialism - which historically refers to an economic, political, and culturally colonial power - went out of favor after a period of decolonization where it was believed developing countries with newfound independence would benefit from modernization and capitalism systems, transnational corporations (mostly from the U.S.) became the new empires along with several countries in addition to the U.S. turning into superpowers, such as China, Russia, India, and South Korea (Ampuja et al., 2020). Anxieties over media-cultural imperialism seemed to have returned after the advent of the internet with corporations like Netflix aggressively expanding into other markets across geographical borders, and also bringing in more content from other countries, notably, the U.S. As a result, geoblocking is utilized as a tool that expands the physical boundaries with which governments limit the exposure of their people to outside influences in the digital realm, creating digital national imagined communities to complement the existing physical boundaries. 
However, at the same time, while governments are concerned about this aspect, they can benefit from the investments from transnational corporations. The two can cooperate with another where media corporations gain legitimized legal protections from governments of their intellectual property and territorial distribution delays to ensure maximized profits, while governments benefit from media corporations" contributions "to imperial projects of major states that aim to increase their geopolitical power vis-à-vis other states" (Ampuja et al., 2020, p. 31). For example, the Iron Man 3 (2013) produced by Marvel Studios ${ }^{87}$, distributed by Disney, where a special version was produced for China with four extra minutes of content featuring productplacement of a local milk product and featuring two uniquely created Chinese characters to support Iron Man.

However, while this example may seem like a company merely offering localization options, geoblocking can be used as a tool for more direct government censorship as illustrated further by the case of China, which has walled of the internet with The Great Firewall, blocking their people from access to several online sites, such as Facebook, Twitter, YouTube, and more. Disney did not produce a localized version of Iron Man 3 out of altruistic concerns of the local people, but because it was the only way they would be permitted by the Chinese government to distribute in Chinese theaters as part of the controlled media environment where only so many foreign films are permitted for import every year. However, there is continued friction between governments and audiences who want access to more foreign content. China had to open its borders more to develop economic superiority but tries to maintain the same political environment as before resulting in problems monitoring and controlling their own people. At the same time, multinational corporations who want to do business in their growing economy face

${ }^{87}$ Owned by Disney. 
more public scrutiny than before with news traveling even faster with globally connected news sources and social media online. Many people outside of China, in fact, were unhappy with Disney submitting to the Chinese government by adding footage for a Chinese version of the film and even Chinese audiences did not respond well to being pandered to so obviously.

This illustrates the constant friction between media corporations and governments and audiences as each balance their needs and controls in an increasingly global network era. They are fighting against the changing landscape where notions of what a border is supposed to be and how it should control people are in flux. The government has expanded this power and control online using geoblocking to ensure their people do not access any other unapproved foreign content. China was considered "an extreme example of control" prior to the digital era, but in the digital era it has been called "an extreme example of how and why the internet is becoming bordered by geography" (Goldsmith \& Wu, 2008, p. 90).

\section{Geoblocking and the Audience}

In chapter four, this study showed that the audience do not directly utilize geoblocking. Media organizations and government are the two forces that utilizes geoblocking to block the audience, but the three can negotiate terms amongst one another. Audiences have the least amount of power when it comes to utilizing geoblocking directly and are thus the most vulnerable for media corporate and government manipulation and control. However, indirectly, audiences can direct the level of geoblocking they face through economic pressure or social disruption. The audience has a set of complex motivations that determine whether they are in support or against geoblocking including geographic, economic, as well as cultural discrimination and social inclusion in popular culture events by avoiding media content spoiler 
on social media. Motivated by any or all these reasons, audiences can influence media corporate marketing decisions and government policies on geoblocking that is being used to limit their media content access across borders. This study showed that where the audience is located will affect which motivations are more important or prominent to connect with media content access online. The issue of audience reaction to geoblocking centers around issues of geographic, cultural, and economic discrimination.

\section{Geographic Discrimination}

In Europe, geoblocking, a major concern for European audiences, is an issue of complex geographic and cultural discrimination. While an economic factor is involved, the issue is more associated with the concept of the geographic make-up and geographic principles of freedom of movement in the E.U. The European Commission (EC) was eventually charged with a referendum to work on a strategy towards the E.U. "Digital Agenda", which was designed to update Europe's territorial laws around freedom and movement to access of goods and services and media content online along with other aspects, such as promising more online privacy security for Europeans (Stamatoudi, 2016). By the end of 2019, the EC drew up and initiated 30 legislative proposals and secured agreements for all but two, with one of the failures being the legislative proposal on the ban on geoblocking of online media content (EC, 2020). The legislative proposal to secure geoblocking bans on online shopping websites for other goods and services was successful because they are not copyright protected the way media content is, which is guaranteed special protection of unique, creative expressions that go beyond general use. Media corporations lobbied to defend their territorial copyright and uphold the country-of-origin principle, which allows copyright holders to dictate territorial release. However, the E.U. is a 
union of 27 member countries with every country still maintaining its own sovereignty and the ability to dictate their own policies on copyright or media. The fact is that the internet has changed things and E.U. citizens can now not only move physically between countries but also remain connected with their home country through online portals. This is what is frustrating for media corporations and governments. The map of the internet does not necessarily match that of the drawn territorial boundaries, which has led them to enforce economic and other regulatory laws to force the internet to resemble physical boundaries. However, people are now moving virtually in ways they could not previously do physically, which cannot be easily controlled. As such, the E.U. and other countries face having to negotiate meeting the new behaviors of their citizens without giving up too much of their own control.

\section{Cultural Discrimination}

Reda (2020) notes, regarding the European audience, that cross-border portability of media content - the ability to access one's home region content while in another member state was not just a matter of accessing media for entertainment. It was more about supporting and protecting E.U. principles of diversity by protecting the needs of language communities, such as long-term migrants, immigrants, exchange students, language learners, and tourists. Examining geoblocking as discrimination against language reveals how audiences also relate to media differently and, as such, affect how the internet is shaped to reflect their needs, thereby, indicating cultural bordered spaces on the internet. However, these spaces are not homogenous. There are several cultural and language groups in Europe, and it becomes a matter of cultural imperative to protect minority languages who are suffering from geoblocking practices. This research has shown that the online regional media system is unfairly targets English-speakers 
and transnational corporations will target regional zones with both large English-speaking communities and larger language groups. Therefore, there is increased concern over the extinction of certain minority languages as the cultural content in those languages becomes unavailable due to the demand being too low to be economically viable for media corporations.

It was in fact the independent film industry in Europe who came to the defense of geoblocking copyrighted media content and maintaining the regional media distribution system on the same principle of cultural protection as Reda highlighted (2020). They argue that at least with geoblocking, transnational corporations are forced to develop platforms for each regional area and must then localize towards those regions. A proposed E.U. Digital Single Market would not have any guarantees that large transnational corporations would be willing to create more diverse European content and serve the multitude of language communities rather than focusing on even more English content. They also argued that it would damage their ability to profit from their own films as they rely on the territorial system for both national funding for their films, but also the right to then charge different prices for different regions.

This case highlighted the incredible complex issue surrounding geoblocking as one group states it hurts them and threatens their cultural heritage while another disagrees. The small language communities claim geoblocking is unjustified while the independent film industry claims geoblocking is justified. So, who is right? Both have excellent points, and both are actually correct. The situation goes both ways, which is what left the E.U. in a quandary, in addition to have large corporations like Disney, Amazon, and Netflix lobbying against the proposal, in succeeding to gain an agreement on the proposal of banning copyrighted media content. However, the E.U. agreed that large transnational corporations had to meet production quotas of 30 percent European media content on their platforms. 


\section{Economic Discrimination}

For Australian audiences, different from other audiences, the issue is more economic with that audience suffering some of the highest local media inflation of imported media and therefore they turn to cheaper options by subscribing directly to foreign media platforms online, like HBO Now, complicating the issue of territorial copyright agreements that existed prior to the internet but still dominate the media market system. This case study underscored how media audiences have moved in unpredictable ways online that do not match the expectations of media corporations. Neither HBO nor local cable provider, Foxtel, expected audiences would turn away or even try to access HBO Now's online streaming platform when it went live in 2015. The research shows that Australians have a history of struggling for media content due to the isolated location of the country and the development of a small local media broadcasting system that left Australians the choice of only three public broadcasters and one cable company at the time (Lobato and Meese, 2016). Imported media became very costly, and local providers tend to inflate the cost of media content with this inflation of media content becoming known as the "Australian Tax."

Despite Australian citizens claiming they would not need to purchase HBO subscription outside of their territory if prices were more affordable in their regions, HBO feared further legal issues and cracked down on geoblocking circumvention, such as VPNs, causing a ripple effect of similar policies in place with other transnational online media corporations, such as Netflix. While the Australian government must uphold copyright to protect even their own Australian media producers, and, as such, uphold Foxtel's legal claim, and make a firmer stand on copyright protections, it did not, however, criminalize circumvention of geoblocking unlike the U.S., where government policies criminalize any circumvention to access or copy copyrighted material. 
However, since Americans are in a more privileged market, they do not necessarily lack in choice regarding media content access.

\section{Social Media and Spoilers}

For Americans, the issue is neither geographic, cultural, or economic necessarily, since they are the audiences living in the most media-privileged market economy. While most Americans, in general, seem not to be aware of geoblocking as supported by Lobato (2019) as well as my own preliminary survey for this research, there is evidence to suggest this has been changing especially since 2016 with the highly publicized coverage of Netflix's geoblocking and VPN-blocking policies. Although this were directed more towards audiences outside of the U.S. it did get covered in U.S. media and was shared on social media. However, this seemingly did not lead to any major media corporate or government policy changes in the U.S. as in the E.U. or Australia. Whether that would ever happen remains to be seen, but for now, audiences around the globe are accessing content from outside of their regions (legally and illegally), even Americans, who also seem to be consuming foreign content, such as The Great British Bake Off (GBBO), which is very popular with American audiences on Netflix U.S. The show's social media is also popular, but it is operated by its local producers for U.K. audiences first, but it is open for anyone to follow. While Americans do not have to wait months or years for an episode of GBBO now, but only have to endure a three-day delay from the U.K. airing, it feels like years the way some of the audience react on social media. Earle (2016) indicated that the networks of online portals and access to information has primed audiences to access global content instantaneously. While Netflix did work to resolve this issue and reduce the delay-window, it is still not enough to avoid spoilers on social media. In addition, Americans audiences have also discovered previous 
seasons have not been aired in the U.S. and that there are charity GBBO events as well that are not aired in the U.S. but featured in discussions on social media. It has caused frustration and confusion, but not yet enough to see American audiences go to the government to force changes of delay policies for media corporate systems. If American audiences were to become more aware of geoblocking, one can expect a change in the discussions about copyright and geoblocking the way we do in other regional areas at a global level.

\section{Limitations of this study}

The topic of geoblocking as a formal field of study and as an academic research topic is still new. There is not a proliferation of studies available on the topic. For example, when searching "new media studies" in Google, not only are the first results "scholarly articles for new media studies" but it includes an entire Wikipedia entry dedicated to the academic discipline, followed by the first result from a program at Eastern Connecticut State University along with several other programs both in undergraduate and graduate programs. Comparatively, when one searches for "geoblocking studies" (or the alternate spelling "geo-blocking studies") the first result is not a link to "scholarly articles on geoblocking" on Google Scholar but leads to The Conversation website - a nonprofit, independent news organization publishing news articles written by academic experts. The link leads to "Articles on Geoblocking", which has five articles on the topic ${ }^{88}$. The second result after that is to the E.U. website on the EC's DSM policy page on geoblocking. There were two quality scholarly papers, including Earle's (2016) work, which I have referenced in this dissertation. While limited scholarly works are available, this study confirmed that this is an area of increased importance and attention among scholars.

\footnotetext{
${ }^{88} \mathrm{https}: / /$ theconversation.com/us/topics/geoblocking-5299
} 
The field of geoblocking is spread out over several different disciplines including law, politics, communication and media, globalization, information technology, and computer science. This study focused on the topic more from a humanistic, cultural perspective, which is not a negative perse, since it focused on the complex relationship between the economic, political, and cultural. However, lacking knowledge about the technical aspects of geoblocking from a computer sciences perspective, especially when researching who creates code for geoblocking software was a limitation. While this study addressed some of the technical aspects of geoblocking and connected it to the larger examination of media, the internet and globalization, a lack of coding-level knowledge was a drawback. Most of the information in this study on the issue came from non-traditional tech scholars - neither Lessig (2006) or Lu (with Goldsmith, 2008; 2011) came from a computer science background although their years of research on technical fields make them reliable scholarly resources for this study. A more thorough coding-language level knowledge from computer science scholars could benefit future research on this topic.

Quantifiable data helped in this study to make connections between audience media use and geoblocking such as the E.U. audience surveys. However, most quantifiable data on geoblocking and consumers is published through governmental organizations such as the E.U., but similar data is non-existent for American audiences. Future research on this topic should attempt to generate quantifiable data on a larger scale to address continuously evolving trends in global flow and access of digital media content. For future study, it would also be beneficial to gain access to Netflix ratings data, including the countries from which audiences are watching different content, especially their global originals. Netflix is notorious for not sharing data, even with scholars, although they have released some viewing data over the years. This data is very 
limited and only ever includes what Netflix categorizes as "member households" views - they never indicate the viewership per regional market. They release these numbers mostly on their Netflix originals - especially those that have actual global release. This in and of itself is a fascinating consideration for the future of television and film metrics with legacy media relying largely still on regional market ratings - a territorially-bound system by legacy media corporations, even those with their own streaming services, like Disney, because, as mentioned in chapter two, their media, while having the ability to go global, is designed by window-delayed regional release systems ${ }^{89}$ while Netflix is practicing on a more global localized content delivery plan. Until Netflix does a complete about face and grants scholars and researchers access to their data, however, they will have to rely on third-party services and their reporting, such as Parrot Analytics, to provide audience regional comparisons. However, these data analytics services cannot report accurately on the actual ratings. Parrot Analytics notes its data is a "global measurement standard that integrates signals across consumer research data sources, $\mathrm{P} 2 \mathrm{P}$ streaming/downloads and social media" to develop their "content demand" ratings for insight reports that they can then track on a region-based analysis. ${ }^{90}$ While Netflix certainly considers regions, because, as mentioned in the dissertation, Netflix is still bound by regional market media law already established pre-internet, they seem to expand on it. For example, their latest Top 10 Popular in Your Region list focuses on what is popular within a certain regional market, such as, Netflix U.S. versus Netflix India, however, the content itself is not always from that region. However, these lists are not shared on public record by Netflix either. Mostly, media

\footnotetext{
${ }^{89}$ This is a hierarchical system that mostly benefits the U.S. audience. However, it should be noted that the U.S. media corporations are not the only ones doing this - it is a global system adopted by many regions. As such, when GBBO first released, it was designed for U.K. audiences, for example, and so do all shows that are produced by U.K. production companies that always create to a particular audience first - usually, their primary regional audience. Netflix's content creation development has been pushing back against this with their content taking on creating from a seemingly global-appeal perspective first.

${ }^{90} \mathrm{https}: / / \mathrm{www}$.parrotanalytics.com/measurement (accessed 10/10/2020).
} 
reporters, third party data services, or devoted fans have been working to compare Netflix Top

10 libraries by accessing different Netflix regional libraries to report on them through official media reports or even through social media.

\section{Areas of future study}

Further study and research should include a large scale, ethnographic, global study on audiences and their knowledge and experiences with geoblocking. It is clear from the research that more people are becoming publicly aware of geoblocking. Lobato's work (2019) mentions it briefly but does not necessarily cite any audiences specifically other that a prevalence of news media articles from 2016. This dissertation identified examples of audiences pressuring their governments to act against unjustified geoblocking, such as in the case of the E.U. referendum on the DSM. While the European audience and government were not successful, however, because of strict copyright, it did highlight issues with territorial copyright in the age of the internet. There should, however, be a more focused study on geoblocking and U.S. audiences to further support my assertion that audiences must know about geoblocking in order for any media policy of value on geoblocking (and copyright) to take place. Currently, the issue of the strict copyright controls and how they affect the audience in the U.S. is shaping in the arena of usergenerated content on platforms like YouTube and Twitch where users who load videos of them playing copyrighted video games or videos that use video game soundtracks content have been the victims of copyright infringement claims and either have their videos removed or accounts suspended $^{91}$ (King, 2020). This does not connect to geoblocking specifically, however, which

\footnotetext{
${ }^{91}$ The issue surrounding media content published on social media is a bit more complex than copyrighted media content as not all user-generated content is copyrighted protected content and, as such, not liable to geoblocking enforcement. The copyright battle between content creators on sites like YouTube and Twitch present an interesting aspect for other studies on the topic of copyright and the disappearing share culture and fair use. However, copyright
} 
does illustrate the difference between the American audience and their relationship to copyright, media content access and creation, and geographic markets versus others, such as those in the E.U. and Australia. As such, it would be of interest to conduct a larger study that examines the U.S. audience cultural make-up and examine the kind of content access and connect with their knowledge and experiences with geoblocking and correlate to any action against media corporations or governments.

Another area of future research could also focus more specifically on investigating and analyzing the connection between audience and use of social media and media and geoblocking. While there are studies on geoblocking that include social media, such as Holt and Sanson's (2014) Connected Viewing: Selling, Streaming, and Sharing Media in the Digital Age, they do not make direct correlations to social media, media content awareness and access, and geoblocking. While this dissertation does work to address this issue in some respects, it was not the central focus and would add to the fields of internet studies and new media studies in examining audience behavior on social media and media content and possible linked media corporate and government adaptions.

\section{Discussion and analysis of the research}

\section{Eliminating Geoblocking}

Before the internet, media corporations and governments developed systems of media production, distribution, and exhibition that revolved around national borders - a system based

owners argue that they are justified in claiming DRM claims of copyright infringement on YouTube because especially when the video is monetizes - has advertising play before, during, or after, or when a content creator is being sponsored by a product corporation, which does not benefit the copyright holder per se (King, 2020). Essentially, media corporations argue these content creators are unfairly gaining profit off someone else's creative work. As stated before, I believe in copyright, but this case presents interesting future analysis for allowing copyright to take over so long that no derivative works become permitted at all. 
on physical boundaries and production that still gave each level autonomous control one over the other, but, especially, government and corporate control over people (the audience).

Globalization threatens this system as audiences, technologies, and economies supersede national boundaries to become more intertwined. The internet intensified the process of globalization sending it into overdrive as once firmly respected and physically controlled boundaries became more porous and traversable online, allowing for open spaces on the internet not controlled by media corporations and governments. Geoblocking developed as a control mechanism by media corporations and governments to close-in the open internet spaces, thereby forcing the internet to resemble the physical, territorial world; the free, open, and intangible digital to become tangible and, therefore, controllable and bordered. As such, the internet is actually not open, but a space of walled-off nodes of information dominated and controlled mostly by media corporations and governments. While media corporations and governments rely on upholding laws and policies put in place before the internet, geoblocking essentially helps them maintain and manage evolving powers of infrastructure between the offline and the online with audiences afforded little power beyond convincing media corporations and governments to change how they practice geoblocking, if they even are aware of it being used on them.

Examining access of online media content through geoblocking reveals a continued uneven distribution in concentration of power. While audiences can influence the decisions of corporations and governments - the deck is still stacked in the favor of corporations and governments. What power audiences are believed to have may only be to pressure through social and economic means - lobbying governments and boycotting networks. This uneven power distribution leaves audiences at a disadvantage with media corporations and governments dictating the shape and purpose of internet and parameters around global access on the internet 
that leaves little to sometimes no room for audience innovation, essentially choking the way audiences shape their own experiences online.

How can a change in this power structure come about? Is it possible for a digital revolution in which the audience rises to storm the digital barricades of geoblocking? When it comes to imagining the elimination of geoblocking, the power does, in fact, lie with the audience, but if the audience is not even aware of geoblocking, how can they even begin to conceptualize or advocate for a world of global media content access, a world without geoblocking? I do not believe it is possible for geoblocking to be dissolved globally if not all audiences are aware of it. I do not believe all audiences have to experience geoblocking to empathize with those who do, but experience is also a more visceral and direct way to learn about something and its effects. For example, American audiences as the often primary target of media production are arguably less affected by geoblocking than others and, as this study has shown, are overall less aware of geoblocking. Marketa Trimble (2014) states that the degree to which audiences circumvent geoblocking influences how media corporations and governments will regard their territorial media policies. The audience's frustration over geoblocked content access and their illicit accessing acts as economic pressure that affects not only the profit margin of media corporations, but the economy of local government. However, as a prime market for corporate industry, American audiences must become aware of this form of control and censorship and, as Americans have historically done before, revolt against this tyranny. They have the power to put pressure on the government and corporations to change existing policies and ways of business.

Audiences cannot rely on the altruism of media corporations who claim to be for the audience. Netflix claims it is for the people, but it is ever for the profit. At first Netflix appeared 
to be determined to shirk the business model that limited flow of content based on pre-internet boundaries with Hastings exalting the wonders of the Netflix Nation. Then in 2016 Netflix announced it would focus on geoblocking and VPN banning as a company-backed policy. In that moment, any thought of Netflix as a revolutionary global media corporation that was going to bring people together across the globe through media was quashed. In that moment, Netflix became like any other legacy media corporation who are motivated by one thing, profit. However, that is not to say that Netflix did not have the right idea when it comes to rethinking the territorially controlled model of old media and government that they subsumed into the online space using geoblocking. Netflix is a global network of connected nodes of information consisting of their different regional content libraries. A possible end to geoblocking lies in companies such as Netflix's corporate model of decentralized library catalogs.

While there are borders around these catalogs, the borders between these catalogs are not entirely closed. For example, if I traveled to France today, rather than my Netflix account saying my account is no longer available because I am accessing it outside of the U.S., my Netflix account will shift from the U.S. location catalog to the French location catalog. Even though the Netflix catalogue itself is not global, a Netflix subscription is global. That is rather revolutionary and is reminiscent of the open possibilities of the early internet in the 1970s and 1980s where academics and early-adopters of the internet were connecting with one another over decentralized, connected portals. However, the truly revolutionary power in this model is lost due to the territorial copyright system that restricts Netflix's ability to open all content to all its libraries along with government restrictions on how the platform must localize for each region necessitating the need to enforce geoblocking. Governments enforcing localization of platform rules exhibits the anxiety around not only cultural imperialism and the influence of other 
countries, but the fear of globalization as a convergence force - the idea that everything and everyone is moving towards a sameness in all things.

A new model of global media content access, however, does not mean a platform needs to look the same. That is the misnomer and misleading meaning of a "Digital Single Market". There is no internet utopia; there is not completely open and unregulated "global village" internet allowing access to anything and everything, but neither does this mean we are relegated to a dystopian transnational corporate invasion of cultural colonization or assimilation that requires putting up digital and physical border walls. It is not a matter of local versus global. We can have both. Netflix is already almost there, but it just needs to change one thing: allow the audiences the choice to access other regional libraries without having to travel physically to these regions. There are, of course, caveats, especially from media corporations and governments that are unlikely to be met.

In the introduction of this study, I quoted Wagman and Urquhart (2014) as saying, "where you access the internet says a lot about what kind of internet you experience" (p. 126). But what if this was not the case? What would the impact be? Why would it matter? Why does it matter now? This dissertation through its examination of governments, corporations, and audience use of geoblocking and the impact of geoblocking on these entities has determined the answer to center around balance of power, access to information, and internet freedom. A truly open internet has the power to profoundly influence commerce, politics, and culture. However, with audiences able to access media content anytime and anywhere governments and corporations would be forced to drastically change policies and regulations expeditiously with little chance to ensure these changes benefit them maximally. I am not advocating dissolving copyright. Like Lawrence Lessig (2006), I too believe copyright holders should be compensated 
for their works, but copyright holders in the current system hold too much power - copyright timeframes are too uneven across the globe and with media corporations hoarding more copyright controls in original programming they are amassing unfair power and control to cultural works that would see increased enforcement on derivative works online, especially. As stated in the introduction, flow of media makes globalization possible. A free and open internet engenders globalization allowing audiences more power, access, and freedom.

However, as established correctly so, not all audiences benefit by the dissolution of geoblocking and the advent of rampant globalization. This research elucidated that minority cultures are at risk of assimilation and annihilation if subsumed under the barrage of media from other larger more powerful countries and the rampant control of media corporations in an uncontrolled capitalistic system that thrives on globalization can take advantage of minority groups culturally and economically. As this study has demonstrated, however, governments, corporations, and some audiences are not trying to stop globalization, indeed an impossible feat, but rather geoblocking is used as a control mechanism to slow the change brought about by globalization. So long as globalization occurs in a controlled fashion, these parties can ensure the changes it brings about are mostly in their favor.

Governments use geoblocking to slow globalization to maintain law and order. Citizens (the audience here) consent to the rule of their governing body or as stated in the U.S. Declaration of Independence, "Governments are instituted among Men, deriving their just powers from the consent of the governed" (National Archives, 2020). Therefore, it is important for governments to maintain a strong sense of nationality in their people. Citizens with a strong sense of national culture and identity are more likely to acquiesce to government rule. The advent of the "global citizen" through free-flowing information puts this compliance at risk. This 
dissertation has demonstrated that a world watching Game of Thrones or Great British Bake Off at the same time may sound inconsequential, but this in fact has far reaching impact as it poses the danger of deteriorating the physical boundaries governments depend on for control.

The risk is also great for corporations. Just as the music industry was not prepared for the changes brought about by digital media, the film and television corporations had hoped to first introduce more physical advancements in media distribution before being forced to address the access and freedom provided by the internet and globalization. For decades, physical media distribution through region specific markets had allowed corporations to control what was seen, when, and where it was seen, thus allowing for the most advantageous circumstances not for the viewer, but for themselves and their stakeholders. Rather than allowing globalization to change existing policies designed for the physical so that there is more access and freedom of information, corporations have utilized geoblocking to ensure that the virtual must follow the same policies that govern physical media despite this new medium having vastly more possibilities for freedom and innovation. If current laws regarding intellectual property and copyright were to change to accommodate the digital space and a global audience, it will be forced to change for physical media as well and corporations stand the risk to lose revenue.

Making visible this infrastructure of who controls blockage and flow of information and why shows that if audiences were to upset this power balance it would result in changes akin to that of the Enlightenment and Industrial Revolution. Governments and corporations censor what audiences see and when because they want to avoid this upset of power. So long as audiences at large, and specifically American audiences, remain uninformed about geoblocking, the internet as a free and open source of information and potential power to people that comes with that, will continue to be an unreached reality. 


\section{Appendix}

\section{Survey Directions}

\section{Doctoral Dissertation Survey Research: Geoblocking/Geo-blocking}

My name is Elaine Venter, and I am doctoral student in Cultural Studies at Claremont Graduate University. I am conducting research to determine people's familiarity with geoblocking/geoblocking, if people bypass geoblocking, and in what context.

This survey consists of up to 11-13 questions based on responses and will take no longer than 10-15 minutes to complete.

There are some questions asking about the illegal activity of bypassing geoblocking. Please note, that no personally identifiable information is collected with completion and submission of this survey. All responses will be kept anonymous and no one will be identifiable in the research. No information such as name, age, address, or IP addresses are collected in this survey.

You may choose to exit the survey at any time. Participation is voluntary.

Completion of the survey is appreciated.

If you have any questions, please email eventer@coloradomesa.edu

My dissertation committee members: Dr. Eve Oishi (Dissertation Chair); Dr. David Luis-Brown; Dr. Mark Andrejevic.

\section{Survey Questions}

1. What country do you identify as your primary location from which you access the internet?

- USA

- Other (please specify only one country):

2. How long have you lived in the primary location you access the internet from?

- $0-5$ years

- 6-10 years

- 11-15 years

- $15+$ years

3. Besides your primary location, what other countries have you accessed the internet from? If none, list NONE. 
4. Have you ever been blocked from accessing digital media content because of the location from which you were accessing the internet?

- Yes

- No

- Not sure

5. Did you know blocking digital content by geographic location is called geoblocking/geoblocking?

- Yes

- No

6. Do you know why digital content is sometimes geoblocked/geo-blocked?

- Yes

- No

7. In a few words, please note why digital content is sometimes geoblocked/geo-blocked.

8. Do you know how to bypass geoblocking/geo-blocking?

- Yes

- No

9. Have you ever bypassed geoblocking/geo-blocking?

- Yes

- No

10. In a few words, please explain in what context you have bypassed geoblocking/geo-blocking.

11. How often do you bypass geoblocking/geo-blocking per week?

- 0 times

- 1-2 times

- 3-5 times

- 6-8 times

- 9-10 times

- $10+$ times

- Every few weeks (specify times):

12. How often do you bypass geoblocking/geo-blocking per month?

- 0 times

- 1-2 times 
- 3-5 times

- 6-8 times

- 9-10 times

- $10+$ times

- Every few weeks (specify times):

13. How often do you bypass geoblocking/geo-blocking per year?

- 0 times

- $1-2$ times

- 3-5 times

- 6-8 times

- 9-10 times

- $10+$ times

- Every few weeks (specify times): 


\section{Bibliography}

Ampuja, M., Koivisto, J., \& Nordenstreng, K. (2020). Historicizing and Theorizing Media and Cultural Imperialism. In O. Boyd-Barrett \& T. Mirrlees (Eds.), Media imperialism: continuity and change (pp. 31-41). essay, Rowman \& Littlefield.

Anderson, B. (2006). Imagined communities: reflections on the origin and spread of nationalism. Verso.

Andrejevic, M. (2013). Infoglut: how the digital era is changing the way we think about information. Routledge.

Appadurai, A. (1990). Disjuncture and Difference in the Global Cultural Economy. Theory, Culture \& Society, 7(2-3), 295-310. https://doi.org/10.1177/026327690007002017

Ashraf, C., \& León, L. F. A. (2016). The Logics and Territorialities of Geoblocking. In R. Lobato \& J. Meese (Eds.), Geoblocking and global video culture (pp. 42-53). essay, Institute of Network Cultures.

Baker, V. (2019, January 27). Why Americans love the Great British Bake Off. BBC News. https://www.bbc.com/news/world-us-canada-46846771.

Ballingall, A. (2017, September 28). \$500-million Netflix deal anchors Canada's culture plan. thestar.com. https://www.thestar.com/news/canada/2017/09/28/500-million-netflix-dealanchors-canadas-culture-plan.html.

Balsamo, Anne Marie. Designing Culture: The Technological Imagination at Work. Durham: Duke UP, 2011.

Barker, C., \& Wiatrowski, M. (2017). The age of Netflix: critical essays on streaming media, digital delivery and instant access. McFarland \& Company, Inc., Publishers.

Barlow, J. P. (1996, February 8). A Declaration of the Independence of Cyberspace. Electronic Frontier Foundation. https://www.eff.org/cyberspace-independence.

Barme, G. R., \& Ye, S. (1997, June 1). The Great Firewall of China. Wired. https://www.wired.com/1997/06/china-3/.

BearMyIP by TunnelBear. Ip assigned chart [Figure]. https://bearsmyip.com/images/ipassigned-chart.png.

Belkhyr, S. (2012). Disney animation: Global diffusion and local appropriation of culture. Journal of Human Sciences, 9(2), 704-714. Retrieved from https://www.jhumansciences.com/ojs/index.php/IJHS/article/view/2229

Bolter, J., \& Grusin, R. (2000). Remediation: understanding New Media. MIT Press. 
Boyd-Barrett, O., \& Mirrlees, T. (2020). Introduction: Media Imperialism: Continuity and Change. In O. Boyd-Barrett \& T. Mirrlees (Eds.), Media imperialism: continuity and change (pp. 1-10). essay, Rowman \& Littlefield.

Burke, R. (2016). The Future in a Vault of Plastic: Physical Geolocking in the Era of the 16-bit Video Game Cartridge, 1988-1993. In R. Lobato \& J. Meese (Eds.), Geoblocking and global video culture (pp. 94-106). essay, Institute of Network Cultures.

Bursztynsky, J. (2020, May 5). Disney says it now has 54.5 million Disney+ subscribers. CNBC. https://www.cnbc.com/2020/05/05/disney-reports-33point5-million-disney-plussubscribers-at-end-of-q2.html.

Carr, N. G. (2011). The shallows: what the internet is doing to our brains. W.W. Norton.

Castells, M. (2013). Communication power. Oxford Univ. Press.

Castells, M. (2015). Networks of outrage and hope: social movements in the internet age. Polity Press.

CES. (2016). Reed Hastings, Netflix - Keynote 2016. https://www.youtube.com/watch?v=15R3E6jsICA\&t=1s.

Clark, D. (2020, September 28). Population of Europe 2020. Statista. https://www.statista.com/statistics/1106711/population-of-europe/.

Clover, J. (2019, August 21). Net neutrality: ISPs are throttling Netflix traffic. Broadband TV News. https://www.broadbandtvnews.com/2019/08/19/net-neutrality-isps-are-throttlingnetflix-traffic/.

Chen, C., Cohen, S., \& Webb, K. (2020, October 7). Disney Plus: All your questions answered about Disney's ad-free streaming service. Business Insider. https://www.businessinsider.com/disney-plus.

Coleman, E. (2011). Hello avatar: rise of the networked generation. MIT Press.

College of Europe. (2016). Analysis of part of the public consultation on geo-blocking. file://C:/Users/Elaine/Downloads/Analysisofpartofthepublicconsultationongeoblocking.pdf

Collins, K. (2018, November 7). Netflix's plan to get everyone watching foreign-language content. CNET. https://www.cnet.com/news/netflixs-plan-to-get-everyone-watchingforeign-language-content/.

Cook, S. (2018, June 4). Netflix Libraries Around the World: How Netflix Libraries Compare. Flixed. https://flixed.io/netlfix-libraries-around-world/. 
Coombe, R. J., Wershler-Henry, D. S., Zeilinger, M., Wagman, I., \& Urquhart, P. (2014). "This Content Is Not Available in Your Region": Geoblocking Culture in Canada. In Dynamic fair dealing: creating Canadian culture online (pp. 124-132). essay, University of Toronto Press.

Cullen, C. (2018, November 9). Netflix announces boost to European content. euronews. https://www.euronews.com/2018/11/08/netflix-announces-launch-of-more-europeancontent.

Davies, J. (2019, June 27). 'Netflix opened the paid market': Why German broadcaster ProSiebenSat.1 launched an OTT app. Digiday. https://digiday.com/future-of-tv/netflixopened-paid-market-german-broadcaster-prosiebensat-1-launched-ott-app/.

Daye, C. (2020, May 20). China remains developing nation. Global Times. https://www.globaltimes.cn/content/1188958.shtml.

Dean, J. (2010). Blog Theory: Feedback and Capture in the Circuits of Drive. Polity.

Dennett, S., Feinler, E., \& Perillo, F. (1985). ARPANET Information Brochure.

Denyer, S. (2016, May 23). China's scary lesson to the world: Censoring the internet works. https://www.washingtonpost.com/world/asia_pacific/chinas-scary-lesson-to-the-worldcensoring-the-internet-works/2016/05/23/413afe78-fff3-11e5-8bb1f124a43f84dc_story.html?utm_term=.fdafc0946d8d.

Deutsche Welle. (2018, July 2). EU Parliament bans geoblocking, exempts Netflix and other streaming services: DW: 07.02.2018. DW.COM. https://www.dw.com/en/eu-parliamentbans-geoblocking-exempts-netflix-and-other-streaming-services/a-42475135.

Digital Millennium Copyright Act of 1998, 17 U.S.C. $\$ 506$.

di Cina, S. (2020, August 19). How to Watch Netflix, Amazon Prime or Hulu in China. Sapore di Cina. https://www.saporedicina.com/english/watch-netflix-hulu-bbc-iplayer-overseas/.

Earle, S. (2016). The Battle Against Geo-Blocking: The Consumer Strikes Back. Richmond Journal of Global Law and Business, 15(1), 1-20.

Elkins, E. (2016). The USA: Geoblocking in a Privileged Market. In R. Lobato \& J. Meese (Eds.), Geoblocking and global video culture (pp. 190-199). essay, Institute of Network Cultures.

Elkins, E. (2019). Locked out: regional restrictions in digital entertainment culture. New York University Press.

Epstein, E. J. (2005, July 25). Hollywood's death spiral. Slate Magazine. https://slate.com/culture/2005/07/hollywood-s-death-spiral.html. 
European Commission. (2015, May 6). Why We Need a Digital Single Market. DSM Factsheet. https://ec.europa.eu/commission/sites/beta-political/files/dsm-factsheet_en.pdf.

European Commission. (2020, October 29). Shaping the Digital Single Market. Shaping Europe's digital future - European Commission. https://ec.europa.eu/digital-singlemarket/en/shaping-digital-single-market.

European Commission Press. (2016, March 18). Press corner. European Commission - European Commission. https://ec.europa.eu/commission/presscorner/detail/en/IP_16_922.

Flint, J., \& Rizzo, L. (2020, May 27). HBO Max Is Left Out of Amazon's, Roku's Platforms at Launch. The Wall Street Journal. https://www.wsj.com/articles/hbo-max-leaves-at-t-atodds-with-amazon-and-roku-11590597190.

France, T. (2020, March 24). Tan France Instagram: Bake Off Post. Instagram. https://www.instagram.com/p/B-HwtMmgbaP/.

GBBO. (2020, March 24). GBBO Tan France GBBO Post. The Great British Bake Off Official Instagram Page. https://www.instagram.com/p/B-HqCBnAFpw/.

Gitelman, L. (2008). Always already new media, history, and the data of culture. MIT Press.

Goldsmith, J. L., \& Wu, T. (2008). Who controls the internet?: illusions of a borderless world. Oxford University Press.

Government of Canada. (2020, July 20). Introduction to Intellectual Property Rights and the Protection of Indigenous Knowledge and Cultural Expressions in Canada. Intellectual Property Strategy. https://www.ic.gc.ca/eic/site/108.nsf/eng/00007.html.

Gowan, M. (2002, May 18). Requiem for Napster. PC World. https://www.pcworld.idg.com.au/article/22380/requiem_napster/.

Greenberg, M. (2003). A Return to Lilliput: The LICRA v. Yahoo! Case and the Regulation of Online Content in the World Market. Berkeley Technology Law Journal, 18, 1191-1257.

Griffith, E. (2020, July 22). Netflix Has the Most Original TV Shows, but Disney+ Shows the Best Originals. PCMAG. https://www.pcmag.com/news/netflix-has-the-most-original-tvshows-but-disney-plus-shows-the-best-originals.

Grimm, Jessica (2015) "The Import of Hollywood Films in China: Censorship and Quotas," Syracuse Journal of International Law and Commerce: Vol. 43 : No. 1 , Article 6. Available at: https://surface.syr.edu/jilc/vol43/iss 1/6

Grubb, B. (2015, April 18). HBO Now cuts off Australian Game of Thrones geo-dodgers. The Sydney Morning Herald. https://www.smh.com.au/technology/hbo-now-cuts-offaustralian-game-of-thrones-geododgers-20150418-1mnt5q.html. 
Gruenwedel, E. (2019, June 12). Netflix Announces Pact With Canadian Indigenous Filmmakers. Media Play News. https://www.mediaplaynews.com/netflix-announces-pact-withcanadian-indigenous-filmmakers/.

Hall, Stuart. "The Rediscovery of 'ideology': Return of the Repressed in Media Studies." Culture, Society, and the Media. Ed. Michael Gurevitch, Tony Bennett, James Curran, and Janet Woollacott. London: Methuen, 1982. 56-90

Hall, Stuart. "Signification, Representation, Ideology: Althusser and the PostStructuralist Debates." Critical Studies in Mass Communication 2.2 (1985): 91-114.

Hersko, T. (2019, June 13). Nearly Half of U.S. Consumers Are Frustrated With a Bloated Streaming Market. IndieWire. https://www.indiewire.com/2019/06/too-many-streamingservices-television-decentralization-1202149596/.

Holt, J., \& Sanson, K. (2014). Connected viewing: selling, streaming, \& sharing media in the digital era. Routledge, Taylor \& Francis Group.

Horrigan, J. B., \& Duggan, M. (2015, May 30). Home Broadband 2015. Pew Research Center: internet, Science \& Tech. https://www.pewresearch.org/internet/2015/12/21/homebroadband-2015/.

Humphries, M. (2019, January 9). China Starts Issuing \$145 Fines for Using a VPN. PCMAG. https://www.pcmag.com/news/china-starts-issuing-145-fines-for-using-a-vpn.

IANA. About us. IANA. Retrieved March 2018a from https://www.iana.org/about.

IANA. Number Resources. IANA. Retrieved March 2018b from https://www.iana.org/numbers.

ICANN. ICANN History Project. ICANN. Retrieved March 2018 from https://www.icann.org/history.

Jacobson, D. (2020, October 6). Opinion: 'Mulan' Epitomizes the Dilemma of Doing Business in China. U.S. News \& World Report. https://www.usnews.com/news/bestcountries/articles/2020-10-06/commentary-mulan-disney-and-the-dilemma-of-doingbusiness-in-china.

Jenkins, H. (2008). Convergence culture: where old and new media collide. New York University Press.

Jenkins, H., Ford, S., \& Green, J. (2013). Spreadable media: creating value and meaning in a networked culture: with a new afterword. New York University Press.

Kantar Public. (2019). Flash Eurobarometer 477a: Accessing content online and cross-border portability of online content services. European Union.

file:///C:/Users/Elaine/Downloads/fl_477a_en.pdf 
Kasperkiewicz, J. (2017, February 21). Fashion Design Protecion in European Union:

Unregistered Community Design. Fordham Intellectual Property, Media \& Entertainment Law Journal. http://www.fordhamiplj.org/2017/02/22/fashion-design-protection-europeanunion-unregistered-community-design/.

Katz, B. (2020, August 5). Thanks to Quarantine, Amazon Is Gaining on Netflix's Numbers. Observer. https://observer.com/2020/08/netflix-subscribers-stock-amazon-prime-videosubscribers/.

KEI. (2017, June 18). The Berne Convention revisions for limitations and exceptions to copyright. Knowledge Ecology International. https://www.keionline.org/copyright/berneconvention-exceptions-revisions.

Kharpal, A. (2019, May 10). Netflix has a China strategy - but it doesn't involve launching there soon. CNBC. https://www.cnbc.com/2019/05/10/netflix-has-a-china-strategy-it-doesntinvolve-launching-there-soon.html.

Kil, S. (2017, June 7). Netflix's 'Okja' Shut Out of Hundreds More Screens in South Korea. Variety. https://variety.com/2017/film/asia/korea-cinemas-deny-screens-to-netflix-okjabong-joon-ho-1202456655/.

King, A. (2020, December 10). Nintendo Is Removing YouTube Videos Containing Its Game Soundtracks. Digital Music News.

https://www.digitalmusicnews.com/2020/12/09/nintendo-music-youtube-copyrightstrikes/.

Lamont, T. (2013, February 24). Napster: the day the music was set free. The Guardian. https://www.theguardian.com/music/2013/feb/24/napster-music-free-file-sharing.

Llamas-Rodriguez, J. (2016). Tunneling Media: Geoblocking and Online Border Resistance. In R. Lobato \& J. Meese (Eds.), Geoblocking and global video culture (pp. 25-31). essay, Institute of Network Cultures.

Lessig, L. (2006). Code: Version 2.0. Basic Books.

Lessig, L. (2004). Free culture: how big media uses technology and the law to lock down culture and control creativity. Penguin.

Lewis, J. (2017). The Piratical Ethos in Streams of Language. In J. A. Schwarz \& P. Burkart (Eds.), Popular communication, piracy and social change (pp. 60-76). essay, Routledge, Taylor \& Francis Group.

Li, J. (2016). China: The Techno-Politics of the Wall. In R. Lobato \& J. Meese (Eds.), Geoblocking and global video culture (pp. 110-119). essay, Institute of Network Cultures. 
Lobato, R. (2016). Introduction: The New Video Geography. In R. Lobato \& J. Meese (Eds.), Geoblocking and global video culture (pp. 10-24). essay, Institute of Network Cultures.

Lobato, R. (2019). Netflix nations: the geography of digital distribution. New York University Press.

Lobato, R., \& Meese, J. (2016). Australia: Circumvention Goes Mainstream. In R. Lobato \& J. Meese (Eds.), Geoblocking and global video culture (pp. 120-129). essay, Institute of Network Cultures.

Lock, S. (2020a, February 21). Number of outbound tourists from the U.S. 2002-2019. https://www.statista.com/statistics/214771/number-of-outbound-tourists-from-the-us/.

Lock, S. (2020b, November 19). Number of domestic arrivals in the EU 2008-2019. Statista. https://www.statista.com/statistics/614407/number-domestic-arrivals-spent-inaccommodation-in-the-eu/.

Lotz, A. D. (2017). Portals: a treatise on internet-distributed television. Maize Books, an imprint of Michigan Publishing.

Lule, J. (2015). Globalization and media: global village of babel. Rowman \& Littlefield Publishers.

Manovich, L. (2002). The Language of new media. MIT Press.

Martin, W. (2017, October 23). These will be the 32 most powerful economies in the world by 2050. The Independent. http://www.independent.co.uk/news/business/these-will-be-the-32most-powerful-economies-in-the-world-by-2050-a7587401.html.

Mastro, D., \& Tukachinsky, R. (2011). The Influence of Exemplar Versus Prototype-Based Media Primes on Racial/Ethnic Evaluations. Journal of Communication, 61(5), 916-937. https://doi.org/10.1111/j.1460-2466.2011.01587.x

McCourt, T., \& Burkart, P. (2003). When Creators, Corporations and Consumers Collide: Napster and the Development of On-line Music Distribution. Media, Culture \& Society, 25(3), 333-350. https://doi.org/10.1177/0163443703025003003

McDonald, K., \& Smith-Rowsey, D. (2018). The Netflix effect: Technology and entertainment in the 21st century. Bloomsbury Academic; Reprint Edition.

McLuhan, M. (1962). The Gutenberg galaxy: the making of typographic man. Routledge and Kegan Paul.

McLuhan, M. (2003). Understanding media: the extensions of man. (W. T. Gordon, Ed.). Gingko Press. 
Moody, R. (2020, July 20). Netflix Subscribers and Revenue by Country [2020 version]. Comparitech. https://www.comparitech.com/tv-streaming/netflix-subscribers/.

Moore, C. (2019, September 30). Hulu and the 5 things that set it apart from other streaming giants. Fox Business. https://www.foxbusiness.com/technology/5-things-to-know-abouthulu.

Morozov, E. (2011). The Net Delusion: the Dark Side of internet Freedom. PublicAffairs.

Mumford, L. (1974). The myth of the machine; The pentagon of power. Harcourt.

MuZhao, S. (2019). Superhero Coproductions and Technological Anxiety. In L. Burke, I. Gordon, \& A. Ndalianis (Eds.), The superhero symbol: media, culture, and politics. essay, Rutgers University Press.

Nash, N. (1996, January 15). How Bavarian Prosecutors Forced Compuserve's Hand on Censorship. http://www.mtholyoke.edu/ cagora/technology/nyt/bavaria.htm.

Navizon. (2015). Who we are. Navizon. Retrieved March 2018 from https://navizon.com/navizon-company.

Neilsen. (2019, January 14). Nielsen Local Watch Report: The Evolving OTA Home. https://www.nielsen.com/us/en/insights/report/2019/nielsen-local-watch-report-theevolving-ota-home.

Nelson, E. (2014). Windows into the World: Distributor Strategies and Consumer Choice in an Era of Connected Viewing. In Holt, J. \& Sanson, K. (Eds) Connected viewing: selling, streaming, \& sharing media in the digital era (pp. 62-78). essay, Routledge.

Netflix. (2003). (rep.). Netflix Reports Pro-Forma Net Income On Record 4th Quarter 2002 Revenue. Retrieved from https://s22.q4cdn.com/959853165/files/doc_financials/quarterly_reports/2002/q4/netflix01 15.pdf

Netflix. (2008). (rep.). Netflix Announces Q4 2007 Financial Results . Retrieved from https://s22.q4cdn.com/959853165/files/doc_financials/quarterly_reports/2007/q4/160228.p df

Netflix. (2010). (rep.). Netflix Announces Q4 2009 Financial Results . Retrieved from https://s22.q4cdn.com/959853165/files/doc_financials/quarterly_reports/2009/q4/NFLX_4 Q09_Earnings_Release_012710.pdf

Netflix. (2012). (rep.). Investor Letter Q4 2011. Retrieved from https://s22.q4cdn.com/959853165/files/doc_financials/quarterly_reports/2011/q4/InvestorLetter-Q4-2011.pdf 
Netflix. (2020). About. About Netflix. https://media.netflix.com/en/about-netflix.

Netflix Help. (2020). Interactive TV shows and movies on Netflix. Help Center. https://help.netflix.com/en/node/62526.

Netflix Press. (2016, January 6)). Netflix Is Now Available Around the World. Netflix. Retrieved from https://media.netflix.com/en/press-releases/netflix-is-now-available-around-theworld.

Newman, D. (2018, May 8). Preparing For The Future By Embracing Radical Innovation. Forbes. https://www.forbes.com/sites/danielnewman/2018/05/08/preparing-for-the-futureby-embracing-radical-innovation/?sh=2cc3c5ff718e.

Nissim, M. (2016, September 14). BBC Worldwide still has the global Bake Off rights. Digital Spy. https:/www.digitalspy.com/tv/reality-tv/a807901/bbc-worldwide-still-has-theinternational-rights-to-great-british-bake-off-so-there/.

Nye, D. (2001, June 21). Time Warner to Add HBO Video-On-Demand to Digital Cable in Columbia, S.C. Knight Ridder/Tribune Business News | HighBeam Research. https://web.archive.org/web/20130507135455/http://www.highbeam.com/doc/1G175710982.html.

O'Connor, S., \& Armstrong, N. (2015, October 28). Directed by Hollywood, Edited by China: How China's Censorship and Influence Affect Films Worldwide. Directed by Hollywood, Edited by China: How China's Censorship and Influence Affect Films Worldwide | U.S.CHINA | ECONOMIC and SECURITY REVIEW COMMISSION. https://www.uscc.gov/research/directed-hollywood-edited-china-how-chinas-censorshipand-influence-affect-films-worldwide.

Pew Research Center. (2020, June 5). Demographics of Social Media Users and Adoption in the United States. Pew Research Center: Internet, Science \& Tech. https://www.pewresearch.org/internet/fact-sheet/social-media/.

Plecher, H. (2020, November 26). Australia - Total population 2015-2025. Statista. https://www.statista.com/statistics/263740/total-population-of-australia/.

Plunkett, J. (2015, July 28). Great British Bake Off: new contestants poised to serve up sixth series. The Guardian. https://www.theguardian.com/tv-and-radio/2015/jul/28/great-britishbake-off-contestants-series-six.

Productivity Commission 2016, Intellectual Property Arrangements, Inquiry Report No. 78, Canberra.

Reda J. (2020) Geoblocking: At Odds with the EU Single Market and Consumer Expectations. In: Szczepanik P., Zahrádka P., Macek J., Stepan P. (eds) Digital Peripheries. Springer Series in Media Industries. Springer, Cham. https://doi.org/10.1007/978-3-030-44850-9_5 
Reilly, C. (2015, April 20). HBO Now locks out Australian VPN users over unauthorised use. CNET. https://www.cnet.com/news/hbo-now-locks-out-international-australian-vpn-usersover-unauthorised-use/.

Rheingold, H. (2000). The Virtual community: homesteading on the electronic frontier. The MIT Press.

Rugg, A., \& Burroughs, B. (2016). Periscope, Live-Streaming and Mobile Video Culture. In R. Lobato \& J. Meese (Eds.), Geoblocking and global video culture (pp. 64-73). essay, Institute of Network Cultures.

Rychter, T. (2016, January 12). Netflix Triples Its Expansion, Forecasts End to Geoblocking. Broadsheet. https://www.broadsheet.com.au/melbourne/entertainment/article/netflixtriples-its-expansion-forecasts-end-geoblocking.

San Filippo, M. (2017). Doing Time: Queer Temporalities and Orange is the New Black. In C. Barker \& M. Wiatrowski (Eds.), The age of Netflix: critical essays on streaming media, digital delivery and instant access (pp. 75-97). essay, McFarland \& Company, Inc., Publishers.

Sassen, S. (2006). Territory, Authority, Rights From Medieval to Global Assemblages. Princeton University Press.

Schiller, D. (1999). Digital capitalism networking the global market system. MIT Press.

Schulman, A. (2018, May 28). Studios are now looking for actors who are Insta-famous. New York Post. https://nypost.com/2018/05/27/studios-are-now-looking-for-actors-who-areinsta-famous/.

Scott, S. (2018, November 12). The Importance Of Media Chronology For French Cinema. Forbes. https://www.forbes.com/sites/sheenascott/2018/11/12/the-importance-of-mediachronology-for-french-cinema/?sh=70097cd872c2.

Shirky, C. (2009). Here comes everybody: the power of organizing without organizations. Penguin Press.

Silva, R. (2020, September 11). What You Need to Know About DVD Region Codes. Lifewire. https://www.lifewire.com/dvd-region-codes-1845720.

Singh, M. (2019, March 31). Global video streaming market is largely controlled by the usual suspects. VentureBeat. https://venturebeat.com/2019/03/30/global-video-streamingmarket-is-largely-controlled-by-the-usual-suspects/.

Smith, N. (2017, October 18). Who Has the World's No. 1 Economy? Not the U.S. By most measures, China has passed the U.S. and is pulling away. Bloomberg.com. 
https://www.bloomberg.com/opinion/articles/2017-10-18/who-has-the-world-s-no-1economy-not-the-u-s.

Solsman, J. E. (2016, February 29). Netflix's 'Crouching Tiger' Sequel Made It Onto AMC Screens After All. TheWrap. https://www.thewrap.com/netflix-crouching-tiger-hiddendragon-sequel-amc-screens-after-all-imax/.

Solsman, J. E. (2020, October 30). Peacock: Everything to know. CNET. https://www.cnet.com/news/peacock-tv-app-free-streaming-movies-harry-potter-premium/.

Solsman, J. E., \& Sorrentino, M. (2020, October 30). Disney Plus: Everything you need to know as The Mandalorian returns. CNET. https://www.cnet.com/news/disney-plus-movies-hulufree-mandalorian-halloween-bundle-netflix/.

Spence, A. (2015, September 18). In Europe, debate over streaming video and geo-blocking. POLITICO Media. https://www.politico.com/media/story/2015/09/in-europe-debate-overstreaming-video-and-geo-blocking-004149/.

Spangler, T. (2020, September 16). 'Cuties' Backlash Led Netflix U.S. Cancellations to Spike Nearly Eightfold, Analytics Firm Says. Variety.

https://variety.com/2020/digital/news/cuties-backlash-netflix-cancellations-record-levels$1234769354 /$.

Stamatoudi, I. A. (2016). New developments in Eu and international copyright law. Kluwer Law International.

Stankiewicz, K. (2020, September 9). Netflix's Reed Hastings: 'We have not been spending any time' trying to get into China. CNBC. https://www.cnbc.com/2020/09/09/reed-hastings-onwhy-netflix-has-not-focused-lately-on-entering-china.html.

Star, S. L. (1999). The Ethnography of Infrastructure. American Behavioral Scientist, 43(3), 377-391. https://doi.org/10.1177/00027649921955326

Statista Research Department. (2020, June 19). Netflix subscribers by country in Europe 2018. Statista. https://www.statista.com/statistics/448394/number-of-netflix-subscribers-europeby-country/.

Stevenson, A. (2015, September 21). Netflix CEO: All TV will be internet in 10-20 yrs. https://www.cnbc.com/2015/09/18/netflix-ceo-all-tv-will-be-internet-in-10-20-yrs.html.

Strover, S., \& Moner, W. (2014). The Contours of On-Demand Viewing. In J. Holt \& K. Sanson (Eds.), Connected viewing: selling, streaming, \& sharing media in the digital era (pp. 234 254). essay, Routledge.

Szalai, G. (2010, October 14). HBO Go heads to FiOS. The Hollywood Reporter. https://www.hollywoodreporter.com/news/hbo-go-heads-fios-20758. 
Tan, H. (2017, October 18). Communist Party Congress: What investors are watching during China's big meeting. CNBC. https://www.cnbc.com/2017/10/17/chinese-communist-partycongress-what-investors-are-watching.html.

Thompson, D. (2014, October 15). HBO Go-It-Alone: There Goes the Cable Bundle? The Atlantic. https://www.theatlantic.com/business/archive/2014/10/hbo-go-it-alone-theregoes-the-cable-bundle/381489/.

Trenholm, R. (2020, September 15). Disney Plus spreads to 8 more countries. CNET. https://www.cnet.com/news/disney-plus-streaming-service-spreads-to-8-more-countries/.

Trimble, M. (2014) “The Territoriality Referendum”. Scholarly Works. Paper 905.

Trimble, M. (2016). “Geoblocking, Technical Standards and the Law”. Scholarly Works. Paper 947.

United Nations. (2020). Breaking Media Stereotypes with Indigenous Storytelling. United Nations. https://www.un.org/en/academic-impact/we-are-indigenous-breaking-mediastereotypes-indigenous-storytelling.

Unofficial Netflix Global Search. (2020). Welcome to uNoGS! Netflix Global Search on uNoGS. http://unogs.com/countrydetail/.

Vivarelli, N. (2018, September 3). Local Product Quotas for Netflix, Amazon to Become Law, EU Official Says (EXCLUSIVE). Variety. https://variety.com/2018/film/news/netflixamazon-local-product-quotas-european-union-law-1202924740/.

Vlessing, E. (2019, September 26). Netflix Accelerates Canadian Investment as Streaming Competition Heats Up. The Hollywood Reporter.

https://www.hollywoodreporter.com/news/netflix-accelerates-canadian-investmentstreaming-competition-1243592.

Warzel, C. (2019, January 9). It's 2019 And Twitter's Moderation Team Is Still Struggling With Swastika Photoshops. BuzzFeed News. https://www.buzzfeednews.com/article/charliewarzel/twitter-swastika-baby-moderationteam-struggling.

Watson, A. (2020a, November 16). Global number of Disney+ subscribers 2020. Statista. https://www.statista.com/statistics/1095372/disney-plus-number-of-subscribers-us/.

Watson, A. (2020b, November 10). Netflix: number of subscribers worldwide 2020. Statista. https://www.statista.com/statistics/250934/quarterly-number-of-netflix-streamingsubscribers-worldwide/.

Wood, E. R. (2020, September 20). Evan Rachel Wood Instagram: Netflix "Cuties" Post. Instagram. https://www.instagram.com/p/CFY2vn_FtfU/?hl=en. 
World Economic Forum. (2020). Netflix. World Economic Forum. https://www.weforum.org/organizations/netflix.

World Intellectual Property Organization. (2018). What is Intellectual Property (IP)? WIPO. https://www.wipo.int/about-ip/en/.

Wu, T. (2011). The Master Switch: The Rise and Fall of Information Empires. Vintage.

Yelp. (2018). Local Analytics \& Sentiment. Yelp Knowledge Local Analytics \& Insights. https://www.yelp.com/knowledge.

Yu, P. K. (2016). A Seamless Global Digital Marketplace of Entertainment Content. In M. Richardson \& S. Ricketson (Eds.), Research handbook on intellectual property in media and entertainment (Ser. Research Handbooks in Intellectual Property, pp. 265-289). essay, Edward Elgar Publishing.

Yu, P. K. (March 28, 2019). “A Hater's Guide to Geoblocking”. Boston University Journal of Science and Technology Law, Vol. 25, pp. 503-29, 2019, Texas A\&M University School of Law Legal Studies Research Paper No. 19-12.

Zarocostas, J. (2018, August). The role of IP rights in the fashion business: a US perspective. https://www.wipo.int/wipo_magazine/en/2018/04/article_0006.html. 